\title{
Hyperkalemic cardioplegia for adult and pediatric surgery: end of an era?
}

\author{
Geoffrey P. Dobson ${ }^{*}$, Giuseppe Faggian'2, Francesco Onorati ${ }^{2}$ and Jakob Vinten-Johansen ${ }^{3}$ \\ Department of Physiology and Pharmacology, Heart and Trauma Research Laboratory, James Cook University, Townsville, QLD, Australia \\ 2 Division of Cardiac Surgery, University of Verona Medical School, Verona, Italy \\ ${ }^{3}$ Cardiothoracic Research Laboratory of Emory University Hospital Midtown, Carlyle Fraser Heart Center, Atlanta, GA, USA
}

\section{Edited by:}

Robert Boushel, University of

Copenhagen, Denmark

\section{Reviewed by:}

Robert Boushel, University of

Copenhagen, Denmark

Andreas Bergdahl, Concordia

University, Canada

${ }^{*}$ Correspondence:

Geoffrey P. Dobson, Department of

Physiology and Pharmacology, Heart

and Trauma Research Laboratory,

James Cook University, Townsville,

QLD4811, Australia

e-mail: geoffrey.dobson@jcu.edu.au
Despite surgical proficiency and innovation driving low mortality rates in cardiac surgery, the disease severity, comorbidity rate, and operative procedural difficulty have increased. Today's cardiac surgery patient is older, has a "sicker" heart and often presents with multiple comorbidities; a scenario that was relatively rare 20 years ago. The global challenge has been to find new ways to make surgery safer for the patient and more predictable for the surgeon. A confounding factor that may influence clinical outcome is high $\mathrm{K}^{+}$cardioplegia. For over 40 years, potassium depolarization has been linked to transmembrane ionic imbalances, arrhythmias and conduction disturbances, vasoconstriction, coronary spasm, contractile stunning, and low output syndrome. Other than inducing rapid electrochemical arrest, high $\mathrm{K}^{+}$cardioplegia offers little or no inherent protection to adult or pediatric patients. This review provides a brief history of high $\mathrm{K}^{+}$ cardioplegia, five areas of increasing concern with prolonged membrane $\mathrm{K}^{+}$depolarization, and the basic science and clinical data underpinning a new normokalemic, "polarizing" cardioplegia comprising adenosine and lidocaine ( $A L)$ with magnesium $\left(\mathrm{Mg}^{2+}\right)$ ( $\left(\mathrm{LLM}^{\mathrm{TM}}\right)$. We argue that improved cardioprotection, better outcomes, faster recoveries and lower healthcare costs are achievable and, despite the early predictions from the stent industry and cardiology, the "cath lab" may not be the place where the new wave of high-risk morbid patients are best served.

Keywords: cardioplegia, ischemia, cardiac surgery, heart, potassium, hyperkalemia, endothelium, history

\section{INTRODUCTION}

\section{IN-HOSPITAL MORTALITY RATES: ONLY THE TIP OF THE ICEBERG}

"Declare the past, diagnose the present, foretell the future; practice these acts. As to diseases, make a habit of two things - to help, or at least to do no harm."

Attributed to Hippocrates (Epidemics, Bk.1, Sect. XI) (Markel, 2004)

Coronary artery disease is responsible for approximately onethird of the world's population deaths over 35 years of age (Mangiacapra et al., 2011). Globally there are over 800,000 coronary artery bypass graft (CABG) surgery or valvular operations each year, with around 1000 operations each day in the US (Goldman et al., 2004; Thom et al., 2006; Dobson, 2010). Inhospital/30-day mortality rates are around 1\% for CABG, 5-6\% for valve, and $7 \%$ for combined CABG and valve surgery (Nesher et al., 2008; Hannan et al., 2013) (Figure 1). These mortality rates are not equivalent across hospitals (Goodney et al., 2003), age (Vicchio et al., 2012), gender (Edwards et al., 2005), ethnicity (Becker and Rahimi, 2006; Song et al., 2008) or countries (Menasché, 2000). Octogenarians have a 3-fold increased risk of death $(\sim 7.5 \%)$ compared with younger adults (Speziale et al., 2011), and 90 year old, non-elective, patients have a mortality ranging between 7 and $18 \%$ with a five year survival of $51 \%$
(Speziale et al., 2010) (Milano et al., 1993). Adult females have up to 1.6 times higher in-hospital mortality rates and higher morbidity than their male counterparts (Edwards et al., 1998, 2005; Vaccarino et al., 2002; Koch et al., 2003; Azakie and Russell, 2004). The increased risks in woman are believed to involve greater perioperative susceptibility to ischemia-reperfusion (IR) injury, different myocyte-endothelial physiology, different hormonal status, higher incidence of diabetes, hypertension and renal disease, and the effect of age and ethnicity, with worse outcomes among Afro-Americans (Edwards et al., 2005; Seifert et al., 2007; Martin et al., 2012).

Pediatric patients also have a unique set of surgical and postoperative challenges. Complex congenital corrective operations have an in-hospital mortality rate of $\sim 5.0 \%$ and, as in adults, the female gender appears to be an independent risk factor for higher mortality and adverse events (1.3 times higher in-hospital mortality) (Welke et al., 2006; Seifert et al., 2007). In high-risk, low weight, pediatric patients (weighing $<2-2.5 \mathrm{~kg}$ ) hypoplastic left heart syndrome has an in-hospital mortality of 20-45\% (Curzon et al., 2008) (Figure 1).

\section{POST-OPERATIVE MORBIDITY: THE VAST AREA BENEATH THE SURFACE}

Despite surgical proficiency and medical innovation driving low mortality rates, the disease severity, operative procedural 


\section{Early Postoperative Morbidity: An Unmet Need in Cardiac Surgery}

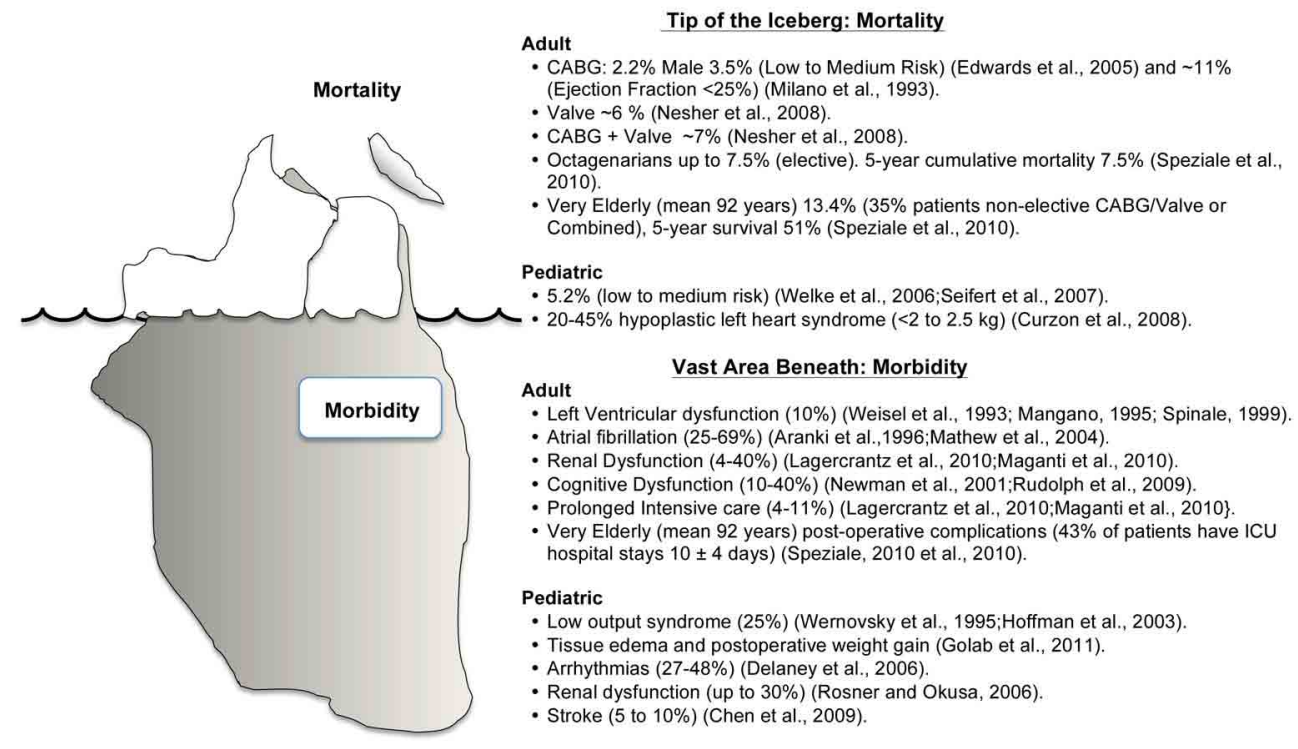

FIGURE 1|Schematic representation of mortality and morbidity in cardiac surgery. Mortality and morbidity have many interacting and confounding factors with ischemia-reperfusion injury playing a significant role in the underlying etiologies. Improving early post-operative morbidity is an unmet need in cardiac surgery (see text for Discussion). difficulty, and comorbidity rate have all increased in recent years (Figure 1). About $10 \%$ of CABG surgery patients will have significant left ventricular dysfunction lasting several hours, days, or weeks (Weisel, 1993; Mangano, 1995; Spinale, 1999). Twenty five to $40 \%$ of patients will have post-operative atrial fibrillation (Aranki et al., 1996; Mathew et al., 2004), and in those patients undergoing combined $\mathrm{CABG}$ and valvular surgery the incidence may increase to $69 \%$ (Scherr et al., 2006). In the USA alone, atrial fibrillation costs healthcare providers over 1.5 billion dollars per year (Steinberg, 2004), and this cost likely doubles on a global scale. In addition, depending upon the type of surgery, $4-40 \%$ of patients will have some form of renal dysfunction (Lagercrantz et al., 2010; Maganti et al., 2010; Shaw, 2012), and $10-40 \%$ of adult patients will experience transient cognitive dysfunction or delirium, which can last for up to 5 years (Newman et al., 2001; Rudolph et al., 2009), and 2-13\% patients will have a stroke (Kellermann and Jungwirth, 2010). Perioperative bleeding is another major complication of cardiac surgery and excessive bleeding occurs around $20 \%$ of patients, and 5-7\% will lose in excess of $2 \mathrm{~L}$ within the first $24 \mathrm{~h}$ postoperatively (Raja, 2005; Yavari and Becker, 2009). It has been estimated that about 50\% of blood loss is due to identifiable surgical bleeding, and the other $50 \%$ is due to a complex hypocoagulopathy associated with surgical trauma and cardiopulmonary bypass (Raja, 2005; Yavari and Becker, 2009).

Among the very elderly, over $40 \%$ will experience significant post-operative complications requiring extended ICU stays often involving many weeks (Speziale et al., 2010). Similarly, in pediatric patients undergoing complex congenital corrective operations, many will have acute post-operative complications such as tissue edema with postoperative weight gain (Golab et al., 2011), systemic coagulation disorders (Hayash et al., 2011), surgical complications and low output syndrome (up to 25\%) (Wernovsky et al., 1995; Hoffman et al., 2003), arrhythmias (27-48\%) (Delaney et al., 2006), renal dysfunction (up to 30\%) (Rosner and Okusa, 2006), and cerebral dysfunction and stroke (5-10\%) (Chen et al., 2009).

\section{ROLE OF ISCHEMIA-REPERFUSION (IR) INJURY}

Prior to the 1990s, there was considerable skepticism among cardiologists and some cardiac surgeons regarding the clinical authenticity of myocardial ischemia-reperfusion injury. However, over the last two decades, IR injury has been recognized as a significant contributor to mortality and morbidity in cardiac surgery patients (Vaage and Valen, 1993; Vinten-Johansen and Nakanishi, 1993; Anselmi et al., 2004; Beyersdorf, 2009), with females being more susceptible than males (Abramov et al., 2000; Butterworth et al., 2000; McCully et al., 2006; Doughtie et al., 2010). Consequences of IR injury are exacerbated by physiological responses to cardiopulmonary bypass and surgical trauma caused by release of pro-inflammatory mediators. Hence, as opposed to IR injury found in percutaneous coronary interventions, cardiac surgery represents a "three-hit" model of potential injury to the heart: ischemia-reperfusion, cardiopulmonary bypass and surgical trauma (Weman et al., 2000). It may be more accurate to redefine reperfusion injury as "postcardioplegic" injury (Vinten-Johansen and Nakanishi, 1993). Postcardioplegic injury is particularly prevalent during and following the surgical trauma associated with adult and pediatric cardiac surgery (Anselmi et al., 2004; Madhok et al., 2006; Welke 
et al., 2006; Seifert et al., 2007; Butler et al., 2009; Gessler et al., 2009).

Post-cardioplegic injury is dependent on pre-operative and/or intra-operative myocardial ischemia; without ischemia there is no reperfusion injury. Injury is classified as reversible or irreversible. Reversible injury includes arrhythmias, edema, vascular dysfunction, and contractile stunning expressed as low output syndrome requiring inotropic or mechanical support to maintain acceptable hemodynamics (Vinten-Johansen and Nakanishi, 1993; Rudd and Dobson, 2011a). Irreversible reperfusion injury includes necrosis and apoptosis (Anselmi et al., 2004, 2009). Tissue edema and microvascular dysfunction can transition from reversible to irreversible (i.e., no-reflow) in response to severe or prolonged ischemia, and can contribute to ultimate necrosis of myocardium. Necrosis involves disruption or disintegration of the cell membrane, and the release of cell contents and large proteins that are used as biomarkers indicative of morphological injury, e.g., creatine kinase $(\mathrm{CK}, \mathrm{CK}-\mathrm{MB})$ or cardiac troponins ( $\mathrm{T}$ or I subunits). Peri-operative cell death is substantiated by the release of these biomarkers into the plasma (Costa et al., 2001; Lehrke et al., 2004). Numerous studies have shown that these elevations in perioperative CK-MB or cTn (within 24-48 h) are correlated with both short-term and longterm risk of mortality (Klatte et al., 2001; Lehrke et al., 2004; Domanski et al., 2011). This increase in biomarkers after surgery has been ascribed in part to suboptimal intra-operative myocardial protection. In contrast to necrosis, apoptosis, or programmed cell death, is non-explosive, non-inflammatory cell death initiated over a longer period of time than the more rapid onset of necrosis.

\section{Mechanisms of IR injury}

Reperfusion injury is a process, and not an endpoint. The process of Ischemia-reperfusion is associated with cell $\mathrm{K}^{+}$efflux, membrane depolarization, anaerobic lactate production and ATP decline, intracellular $\mathrm{H}^{+}, \mathrm{Na}^{+}$, and $\mathrm{Ca}^{2+}$ loading, ionic imbalances, cell swelling, free radical and oxidant production, mitochondrial pore opening and dysfunction, apoptosis and necrosis (Piper et al., 2003, 2004; Cannon, 2005; Vinten-Johansen et al., 2007b). Ischemia-reperfusion is also responsible for endothelial activation leading to microvascular dysfunction and deterioration of coronary flow reserve (Ferguson et al., 1996; Feng et al., 2008), vasoconstriction and spasm (Ruel et al., 2004), myocardial contractile dysfunction (Weisel, 1993; Allen, 2004), reperfusion arrhythmias (Anselmi et al., 2004, 2009), activation of the inflammation cascade (cytokines, chemokines, complement activation, neutrophil activation) (Levy and Tanaka, 2003; Merchant et al., 2008; Suleiman et al., 2008; Anselmi et al., 2009) and coagulation imbalances (Raivio et al., 2009; Yavari and Becker, 2009). Reperfusion following cardiac surgery has shown to be associated with a significant thrombin generation followed by activation of protein C (Raivio et al., 2009).

\section{Potassium in cardioplegia and IR injury}

Another factor that may exacerbate IR injury is high potassium in cardioplegia. Each year, over four metric tons of depolarizing potassium $\left(\mathrm{K}^{+}\right)$are perfused through the coronary arteries of cardiac patients worldwide, and about two metric tons in USA patients (Dobson, 2010). After presenting a brief history of $\mathrm{K}^{+}$ cardioplegia, we will discuss how prolonged $\mathrm{K}^{+}$-dependent cellular depolarization can create a hostile, unnatural pro-ischemic environment for the heart, which may contribute to damage and post-operative morbidity in the cardiac surgery patient. Next, we will discuss alternatives to high $\mathrm{K}^{+}$cardioplegia including a new polarizing cardioplegia and reanimation solution comprising adenosine and lidocaine with $\mathrm{Mg}^{2+}\left(\mathrm{ALM}^{\mathrm{TM}}\right)$ (Dobson, 2004) that may address the unmet needs of the new high-risk morbid patient.

\section{BRIEF HISTORY OF CARDIOPLEGIA: FROM RINGER TO CARDIAC SURGERY}

If too little potassium is present, the contractions become broader, and there results in fusion of the beats. If too much potassium is present ...then the contraction of the ventricle is imperfect, and by increasing the quantity of potassium salt the beat becomes weaker and weaker till it stops.

Sidney Ringer (1883) From Moore (Moore, 1911) pvii

The term cardioplegia (cardio, heart and plegia, paralysis) was first introduced by Lam in 1957 (Lam et al., 1957), yet the method of arrest has its roots in the early experiments of British physiologist Sidney Ringer using the frog heart (Figure 2). In 1883 Ringer reported that potassium chloride was a powerful arresting agent (Ringer, 1883), a serendipitous discovery like many in science and medicine (Dobson, 2005). Curiously, Ringer's laboratory had a malfunctioning water distiller, and his technician prepared the heart solutions using tap water supplied by London's New River Water Company (Moore, 1911). The technician found that hearts perfused with this tap water-based solution contracted rhythmically and forcefully for a number of hours. After identifying the anomalies between tap water that was high in calcium and magnesium salts, and distilled water, Ringer had the experiments repeated using distilled water, and the hearts quickly failed. To maintain contraction it was necessary to add $\mathrm{Ca}^{2+}$ and other salts to the crystalloid medium (Moore, 1911). By accident Ringer and his team next discovered the importance of potassium in "stilling" the heart in diastole and calcium in "stimulating" the heart in systole (see quote above).

A few decades later, Hering (1907) reported the association between high serum potassium and emergent "fibrillary" contractions, which led to cardiac arrest (Hering, 1953). In 1929, Hooker extended these observations and showed in a fibrillating dog heart that injecting $1 \mathrm{ml}$ of $2.5 \% \mathrm{KCl}(336 \mathrm{mM})$ into the coronary arteries rapidly stopped the heart, and after washout the heart returned to sinus rhythm (Hooker, 1929). Wiggers showed that an intravenous administration of calcium after $\mathrm{KCl}$ "cardioversion," led to a more stable recovery (Wiggers, 1950). In 1954, Montgomery used a similar $\mathrm{KCl}$ approach in hypothermic human patients to defibrillate hearts (Montgomery et al., 1954). However, it was not until 1955 that Lam and colleagues in the US administered an intraventricular injection of $\mathrm{KCl}(667 \mathrm{mEq} / \mathrm{L})$ to induce cardiac 


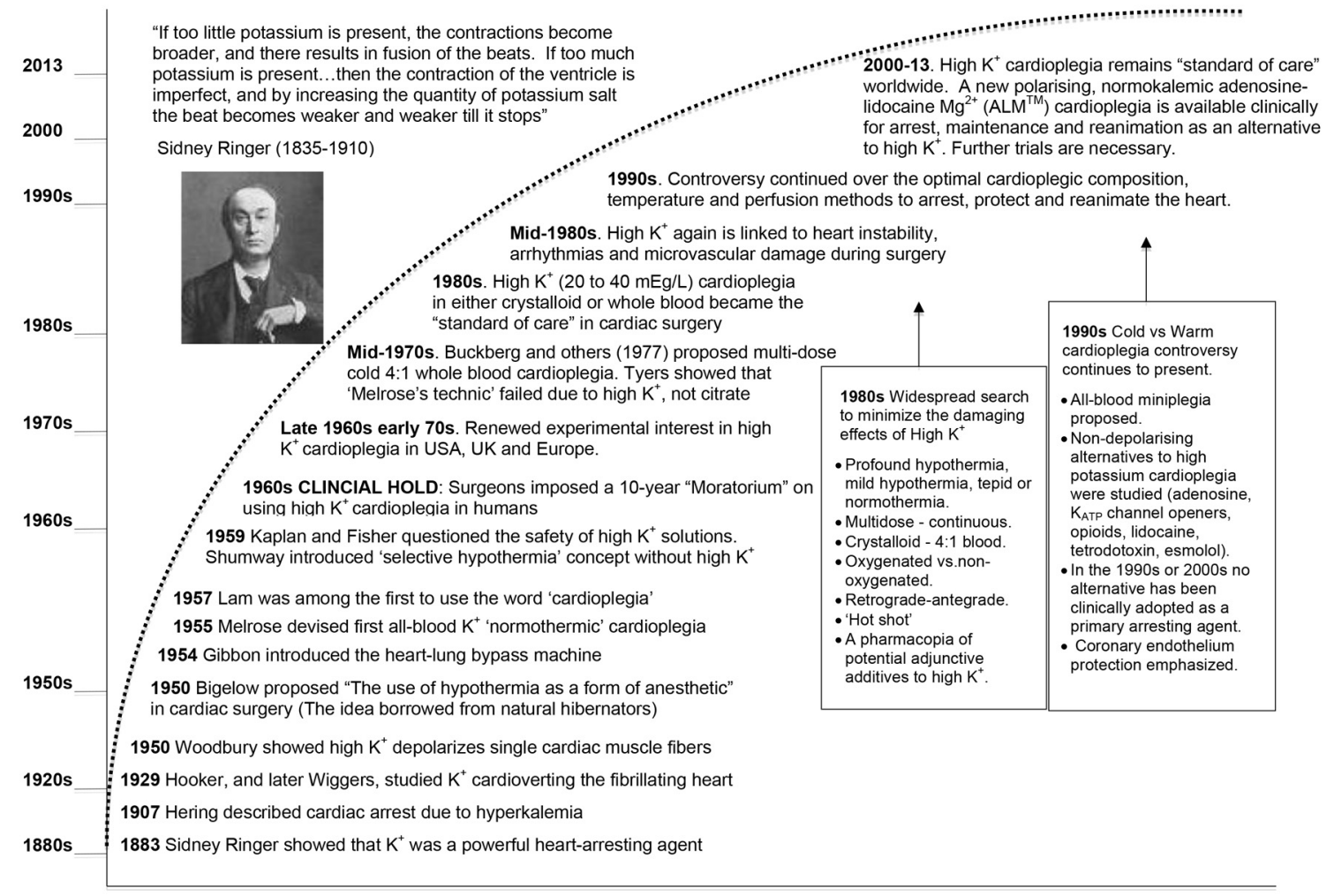

FIGURE 2 | A brief history of the development of potassium cardioplegia from basic science to cardiac surgery (See text for details).

arrest in hypothermic dogs (without bypass) (Lam et al., 1955). Lam's group subsequently abandoned the $\mathrm{KCl}$ method because of refractory ventricular fibrillation (VF) and myocardial damage during reperfusion and reanimation (Effler et al., 1956; Lam et al., 1957; Schaff et al., 1978; Shiroishi, 1999) (Figure 2). Lam also tried acetylcholine $(10 \mathrm{mg} / \mathrm{kg}$ body $\mathrm{wt})$ to induce arrest and while the heart would beat more forcefully during reanimation than when $\mathrm{KCl}$ was used, the incidence of VF was higher (Weirich, 1962). Lam also noted that $\mathrm{O}_{2}$ consumption of the potassiumarrested heart was lower than acetylcholine, implying it provided a more complete arrest (Lam et al., 1955).

In 1955 Melrose and colleagues, after corresponding with Lam's group, conjectured that the likely source of arrhythmias in Lam's $\mathrm{KCl}$ model was from the chloride. The London team performed the first cardioplegic arrest using a citrated form of potassium in a canine model of cardiopulmonary bypass. The "Melrose technic," as it became known, used $2.0 \mathrm{ml}$ of $25 \%$ solution of tri-potassium citrate added to $18 \mathrm{ml}$ warm oxygenated whole blood in a syringe (9:1 blood: potassium ratio), and injecting directly into the aortic root of hypothermic dogs $\left(25^{\circ} \mathrm{C}\right)$ (Melrose et al., 1955; Gerbode and Melrose, 1958). The heart arrested in seconds and remained electrically quiescent for $30 \mathrm{~min}$ and returned good function in the healthy dog. Melrose's group were the first to propose that high potassium-citrate may afford "elective reversible cardiac arrest" in human open-heart surgery
(Melrose et al., 1955). Three years later, Gerbode and Melrose increasingly used potassium citrate to induce cardiac arrest in humans (Gerbode and Melrose, 1958).

Despite the early clinical excitement (Effler et al., 1956), the "Melrose technic" was abandoned in the late 1950s because it predisposed the heart to what Lam and colleagues had always suspected; refractory ventricular fibrillation, contractile dysfunction and cell death (Allen and Lillehei, 1957; Helmsworth et al., 1959; Nunn et al., 1959; Urschel et al., 1959; Wasserman et al., 1959; Willman et al., 1959; Bjork and Fors, 1961; Tyers et al., 1975). In 1962, Weirich wrote: "The use of the Melrose method of elective cardiac arrest induced by the single injection of a 2.5 percent potassium citrate-oxygenated blood solution has been abandoned by virtually all physicians who perform intracardiac operations." (Weirich, 1962). It is curious why little or no mention was made by Melrose, Lam or early adopters about the possible mechanism of potassium citrate or potassium chloride arrest, given that $\mathrm{K}^{+}$-induced membrane depolarization was demonstrated by Woodbury in 1950 using microelectrodes in single cardiac fibers (Woodbury et al., 1950; Draper and Weidmann, 1951), by Burgen in isolated atria (Burgen and Terroux, 1953) and by Weidmann and colleagues in whole hearts (Niedergerke, 1956; Weidmann, 1956; Hoffman, 2002) (Figure 2). It appears that there were few collaborations between those studying surgical cardioplegia and researchers in the basic electrophysiological sciences. Importantly, 
while the "Melrose Technique" failed to reach efficacy, Melrose, Lam and their colleagues contributed enormously to the early history of cardiac surgery because they showed that surgical cardioplegia, as a strategy of buying biological time, was feasible.

Over the next 15 years, high potassium cardioplegia was placed on "clinical hold" by cardiac surgeons themselves as a result of poor clinical outcomes (Nunn et al., 1959) (Figure 1). Potassium-based solutions were eventually replaced by either: (1) hypothermic or normothermic ischemic arrest induced by aortic occlusion, (2) by intermittent aortic occlusion, or (3) by direct coronary artery perfusion (Kirklin et al., 1979; Mentzer et al., 2003). Shumway and associates proposed another modification using topical hypothermia as a "safeguard" to offset ischemic injury (Shumway et al., 1959). Unfortunately, these alternatives were no better than the "Melrose Technique," which was highlighted by Cooley's irreversibly damaged "stone heart" (Cooley et al., 1975).

The field of cardioprotection in the 1960s was in desperate need of fresh ideas, innovation and improved outcomes. As a result, scientists and surgeons began to collaborate and, in the late 1960 s and early 1970s, a second wave of clinical interest in potassium cardioplegia began to surface in Germany (Hoelscher, 1967; Kirsch et al., 1972; Bretschneider et al., 1975), the UK (Hearse and Stewart, 1974; Hearse et al., 1981) and the USA (Gay and Ebert, 1973; Kirklin et al., 1979; Buckberg, 1993) (see Figure 2). The collective body of experimental work was impressive and formed the basis of today's cardioplegia and organ preservation solutions (Cordell, 1995; Vinten-Johansen et al., 2000; Chambers and Hearse, 2001). Currently over 99\% of cardioplegic and most preservation solutions contain $\mathrm{K}^{+}$concentrations over $15 \mathrm{mEq} / \mathrm{L}$ (or $\mathrm{mM}$ ), which depolarizes the myocardial cell membrane from a resting voltage of about $-85 \mathrm{mV}\left(\sim 5 \mathrm{mM} \mathrm{K}^{+}\right)$to $-50 \mathrm{mV}$ (Dobson, 2010). The relationship between increasing extracellular potassium concentrations and membrane potential in the ventricle during cardioplegic diastolic arrest from isolated rat, rabbit, and guinea-pig hearts is shown in Figure 3. As we shall discuss below, for over four decades depolarizing potassium cardioplegia has been a double-edged sword, particularly after Tyers and colleagues demonstrated unequivocally that potassium, not citrate, was responsible for the clinical failure of "Melrose's method" (Tyers et al., 1975). Depolarizing potassium solutions remain the standard-of-care for cardioplegic arrest in cardiac surgery today.

\section{FIVE AREAS OF CONCERN WITH HYPERKALEMIC CARDIOPLEGIA}

\footnotetext{
"Thus, although the use of elevated concentrations of potassium to induce the rapid depolarized arrest of the heart in diastole is by far the most widely used technique ... it cannot be used haphazardly, has a number of disadvantages, and is not necessarily the best and most optimally protective."
}

Chambers and Hearse (2001) p. 894

From a scientific standpoint, there are at least five (5) areas of concern with potassium concentrations of $10 \mathrm{mM}$ and above (Dobson, 2010): (1) unnatural membrane voltages and cellular ionic imbalances during global ischemic arrest and regional

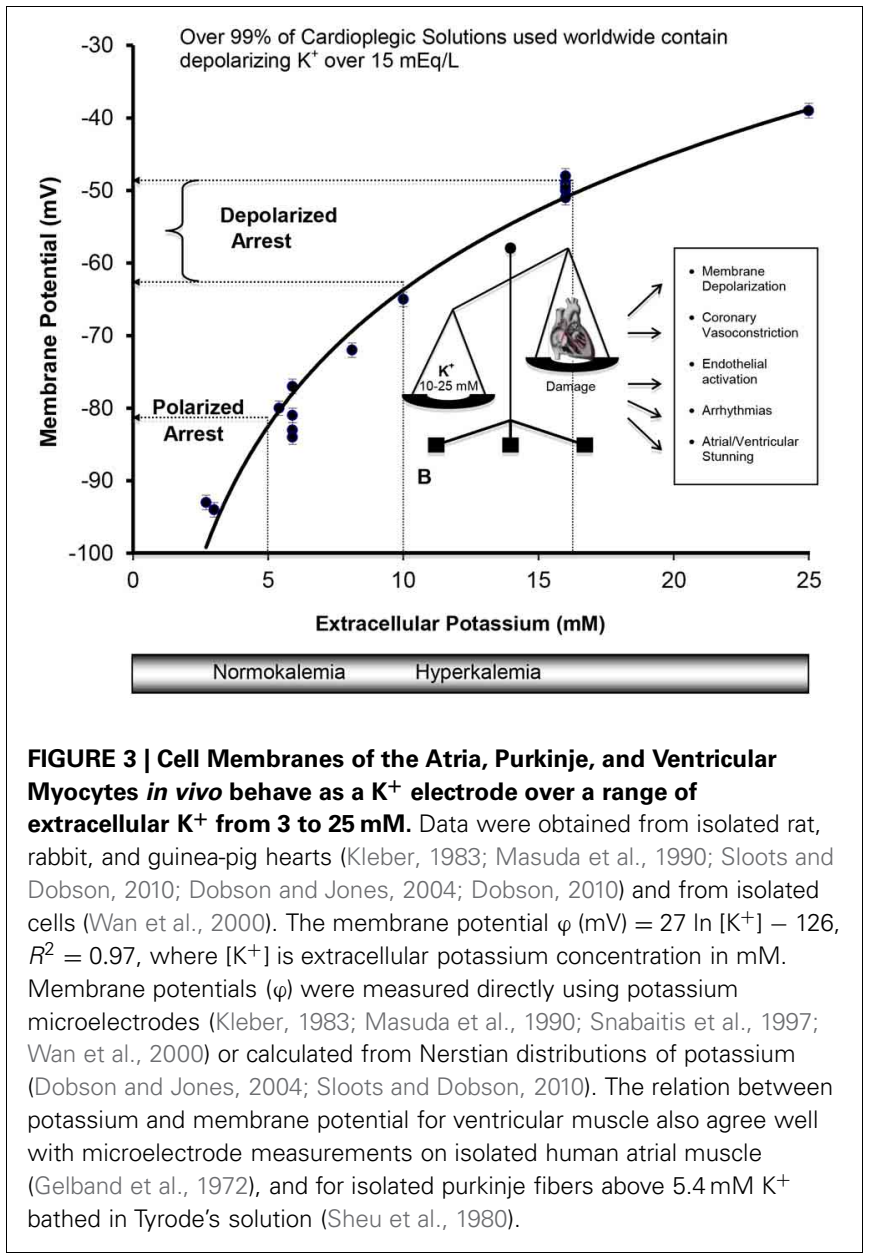

ischemia during reperfusion; (2) coronary vasoconstriction of varying degrees leading to maldistribution of cardioplegia, loss of myocardial protection and possible vascular spasm; (3) activation the coronary vascular endothelium to become leaky, pro-inflammatory and promotes platelet aggregation; (4) postoperative arrhythmias and conduction disturbances; and (5) a higher incidence of low cardiac output from ventricular stunning.

\section{ADVERSE EFFECTS OF HYPERKALEMIA ON MEMBRANE POTENTIAL AND $\mathrm{Ca}^{2+}$ LOADING}

"In (heart) fibers which do not have pacemaker characteristics, the diastolic potential behaves as a $\mathrm{K}^{+}$electrode and varies as expected by the Nernst relationship when the extracellular $\mathrm{K}^{\div}$ concentration is above $3 \mathrm{mM}$."

\section{Leonard S. Gettes (Gettes, 1976) p. 792}

Hyperkalemia arrests the heart in diastole due to potassium's ability to reduce the availability of "open" $\mathrm{Na}^{+}$fast channels, which are responsible for the rapid Phase $\mathrm{O}$ upstroke (depolarization) of the cardiac action potential (Kleber, 1983; Chambers and Hearse, 2001; Dobson and Jones, 2004). Cell membranes of the atria, Purkinje fibers, and ventricles behave 
like what Leonard S. Gettes termed "a potassium electrode," meaning that the membrane potential during diastole is close to a Nernstian potassium potential (Gettes, 1976) where the sum of the net electrical and chemical concentration forces on the potassium ion is zero $[\Delta \mathrm{G} \text { (Al-Mehdi et al. })_{\text {out } / \text { in }}=0$ ] (Masuda et al., 1990; Veech et al., 1995). The Nernstian potential for the isolated rat heart over a range of 3-25 mM extracellular $\mathrm{K}^{+}$can be calculated from the following relation where (Figure 3).

Membrane potential $(\varphi \mathrm{mV})=26 \ln \left[\mathrm{K}^{+}, \mathrm{mmol} / \mathrm{L}\right]+123$ (Sloots and Dobson, 2010).

The close agreement between these Nernstian estimates calculated from intra- and extracellular $\mathrm{K}^{+}$distribution (Sloots and Dobson, 2010), and direct $\mathrm{K}^{+}$electrode measurements implies that the resting membrane potential in heart muscle is predominately a potassium equilibrium potential within the errors of measurement (i.e., behaves as a $\mathrm{K}^{+}$electrode) (Gettes, 1976).

The clinical problems associated with prolonged membrane depolarization include $\mathrm{Ca}^{2+}$ loading of the myocyte and IR injury (arrhythmias, stunning, inflammation, necrosis, and apoptosis) (Suleiman et al., 2001). Depolarization-induced $\mathrm{Ca}^{2+}$ loading occurs first from $\mathrm{Na}^{+}$entry through the voltage-dependent $\mathrm{Na}^{+}$ fast channels. At $-50 \mathrm{mV}\left(16 \mathrm{mM} \mathrm{K}^{+}\right)$, despite $\sim 3.5 \%$ availability of $\mathrm{Na}^{+}$channels and only $0.1 \%$ of maximal $\mathrm{Na}^{+}$conductance compared to $-80 \mathrm{mV}$, the high sodium driving force $\left(\Delta \mathrm{G}_{\mathrm{Na}+\text { out } / \text { in }}=-15 \mathrm{KJmol}^{-1}\right)$ leads to $\mathrm{Na}^{+}$entry via the small $\mathrm{Na}^{+}$"window" current that remains open at these depolarized states (Bers et al., 2003). A rise in cell $\mathrm{Na}^{+}$leads to a reversal of the voltage-dependent $\mathrm{Na}^{+} / \mathrm{Ca}^{2+}$ exchanger $\left(3 \mathrm{Na}^{+}\right.$out: $1 \mathrm{Ca}^{2+}$ in), with a resulting rise in intracellular $\mathrm{Ca}^{2+}$ (see Figure 4).

Further $\mathrm{Ca}^{2+}$ entry can occur during Ischemia, acidosis and hypothermia. Global ischemia may lead to further

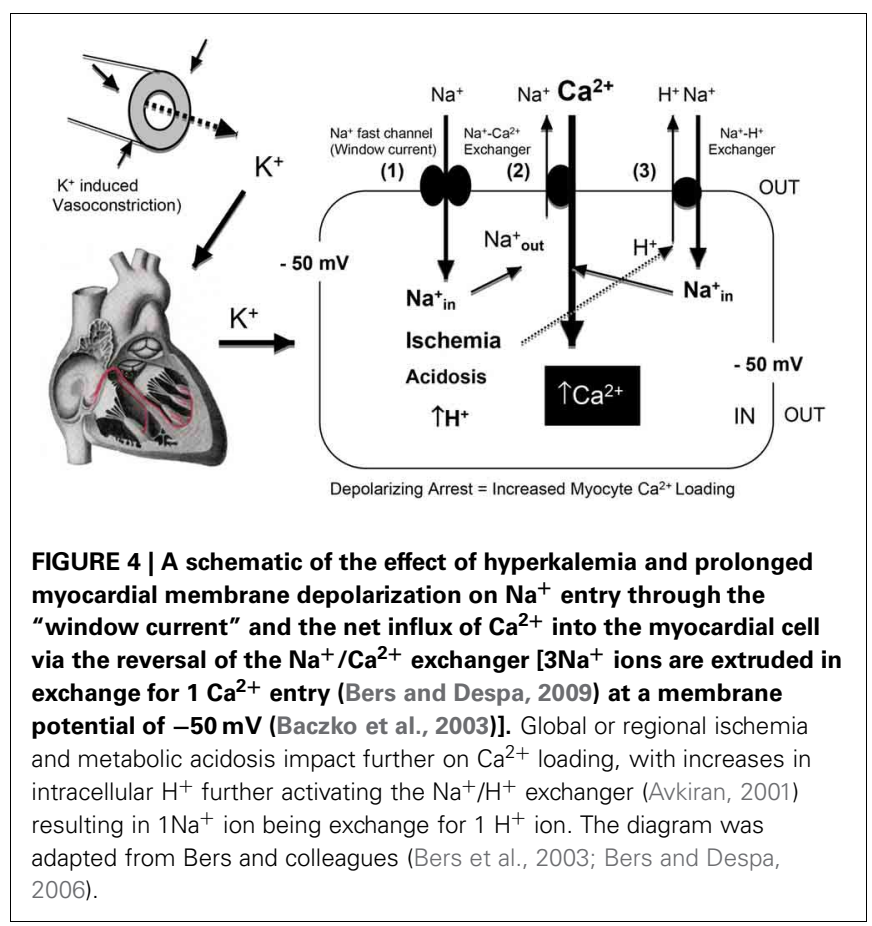

membrane depolarization from localized increases in extracellular $\mathrm{K}^{+}$(11 mM or higher) (Harris et al., 1954; Gettes et al., 1982; Kleber et al., 1987) and intracellular acidosis can activate the $\mathrm{Na}^{+} / \mathrm{H}^{+}$exchanger $\left(\mathrm{H}_{\text {out }}^{+} \mathrm{Na}_{\text {in }}^{+}\right)$and $\mathrm{Ca}^{2+}$ enters via the $\mathrm{Na}^{+} / \mathrm{Ca}^{2+}$ exchanger $\left(\mathrm{Na}_{\text {out }}^{+}\right.$and $\mathrm{Ca}_{\text {in }}^{2+}$ ) (Figure 4). These processes may be of reduced importance during surgical cardioplegia because metabolism (aerobic and anaerobic) has already been slowed by: (1) electrochemical arrest, and (2) hypothermia. However, if subendocardial regions of the left ventricular wall are not adequately perfused and protected during cardioplegic arrest (Brazier et al., 1977), regional differences in $\mathrm{Ca}^{2+}$ loading and ischemia-reperfusion damage may occur. Hypothermia is also known to exacerbate the effect of ischemia and $\mathrm{Ca}^{2+}$ loading (Sprung et al., 1995; Lathrop et al., 1998; Gaillard et al., 2000) and alter the properties of the ventricular action potential (Figure 5). The vasoconstrictive effects of hyperkalemia may further contribute to sub-optimal subendocardial protection (see next Section). In contrast, in pediatric cardiac surgery a very different "ischemic" scenario may exist where the baby heart is normally arrested with a "one shot" delivery (Allen, 2004). In this case, the heart cells are bathed in a cold, static ischemic and depolarized state, with myocardial protection becoming more compromised with time, particularly during complex corrective operations requiring longer cross-clamp times.

Following cold ischemic arrest, as mentioned earlier, $\mathrm{Ca}^{2+}$ loading also occurs during reperfusion. There are four timesensitive periods of reperfusion; rewarming, reperfusing, reanimating and returning the heart to the general circulation. Protecting the heart during the " $4 R$ " periods is paramount to satisfactory clinical outcome (Vinten-Johansen and Nakanishi, 1993; Aoki et al., 1994; Liu et al., 1994; Cascio et al., 1995; Wilde and Aksnes, 1995; Stowe et al., 2000). As the heart moves from a cold depolarized state to a warm polarized state, it is electrically and metabolically challenged because of transmural and regional voltage heterogeneities which have to rapidly return to their "normal" operating limits to ensure a coordinated wave of depolarization from the SA node, atria, AV node to the ventricles (see Figure 5). The effects of hyperkalemia cardioplegia, combined with the effects of ischemia, acidosis and hypothermia, predisposes the heart to electrical instability during reperfusion which can lead to arrhythmias (Section Adverse Effects of High $\mathrm{K}^{+}$on Post-operative Arrhythmias and Conduction Disturbances) and post-operative left ventricular pump dysfunction (Section Adverse Effects of High $\mathrm{K}^{+}$on Cardiac Output and Stunning) (Tsutsumi et al., 1983; Flack et al., 1992). These effects of IR injury will be further exacerbated in older, sicker patients undergoing longer cardiopulmonary bypass times, or in complex pediatric congenital corrective operations, which pose a serious challenge to current hyperkalemia myocardial protection strategies.

\section{ADVERSE EFFECTS OF HYPERKALEMIA ON CORONARY VASOCONSTRICTION}

"Cardioplegia, whether blood or crystalloid, is also intrinsically associated with functional changes in the coronary vasculature 


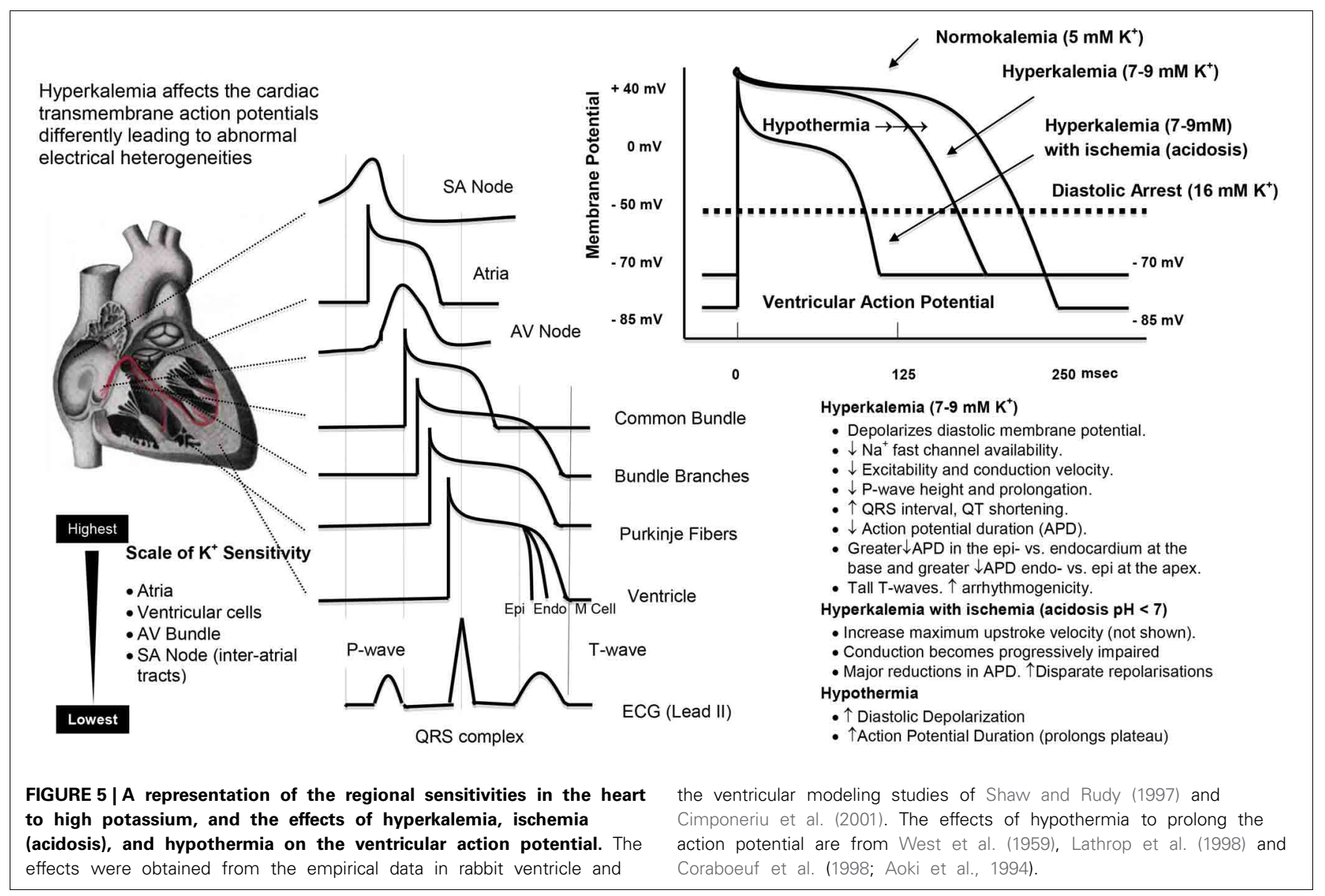

that add to the effects of cardiopulmonary bypass. This may be observed after even routine cardiac cases, with up to $8 \%$ of patients having coronary artery spasm manifested by temporary ST segment elevations on ECG after surgery, and an even greater proportion exhibiting myocardial contractile dysfunction that usually peaks $4-6 \mathrm{~h}$ postoperatively. These phenomena may be seen in virtually any patient regardless of age, and irrespective of the presence of atherosclerotic coronary artery disease or other risk factors for endothelial dysfunction.”

(Ruel et al., 2004) p. 1002

Potassium-induced coronary vasoconstriction may result in loss of cardioprotection by limiting cardioplegia flow and distribution to the diseased myocardium (Leicher et al., 1983; Sellke et al., 1996; Aronson, 1999). High potassium is also linked to coronary spasm in adults, with or without hypertension (Ruel et al., 2004) and in pediatric patients (Nomura et al., 1997). Experimentally, high potassium solutions have been used for over 40 years as a tool to induce maximal vasoconstriction in aortic ring or coronary artery conduit preparations (Norton and Detar, 1972; Kuo and Chancellor, 1995; Sellke et al., 1996; Chong et al., 2001; Kerendi et al., 2004).

Vasoconstriction can result from direct depolarization of vascular smooth muscle or the underlying endothelium (Figure 6).
Quignard and coworkers showed that cardioplegic potassium concentrations $(15 \mathrm{mM})$ depolarized vascular smooth muscle membranes from -53 to $-45 \mathrm{mV}$ in guinea-pig carotid and porcine coronary arteries, which led to contraction (Quignard et al., 1999). Casteels and colleagues further showed that the minimal depolarization to evoke contraction of smooth muscle cells isolated from the pulmonary artery was at $9.0 \mathrm{mM} \mathrm{KCl}$ (Casteels et al., 1977). Vasoconstriction can also occur from the underlying vascular endothelium, which is electrically connected to smooth muscle (Seiden et al., 2000; Han et al., 2009) (Figure 5). Coronary vascular tone (relaxation/constriction) is regulated by a delicate balance between endothelial vasconstrictive and vasorelaxive factors, which in turn modulate "endeffector" potassium channels $\left(\mathrm{K}_{\mathrm{Ca}}, \mathrm{Kv}\right.$, and $\mathrm{K}_{\mathrm{ATP}}$ channels) and other channels located in underlying vascular smooth muscle of the vessel wall (Figure 6) (Brayden, 1996; Han et al., 2009; Dick and Tune, 2010). Furchgott and Zawadzki were the first to show a link between hyperkalemia-induced vasoconstriction and impairment of endothelium-derived nitric oxide $(\mathrm{NO})$ release, and other relaxation factors (Furchgott and Zawadski, 1980). Other relaxation factors include prostacyclin $\left(\mathrm{PGI}_{2}\right)$, endothelium-derived hyperpolarization factor (EDHF) and adenosine and/or conducted hyperpolarization processes which link the endothelium to vascular smooth muscle function (He, 2005; Wu et al., 2005; Yang and He, 2005). He and colleagues in 2005 showed, 


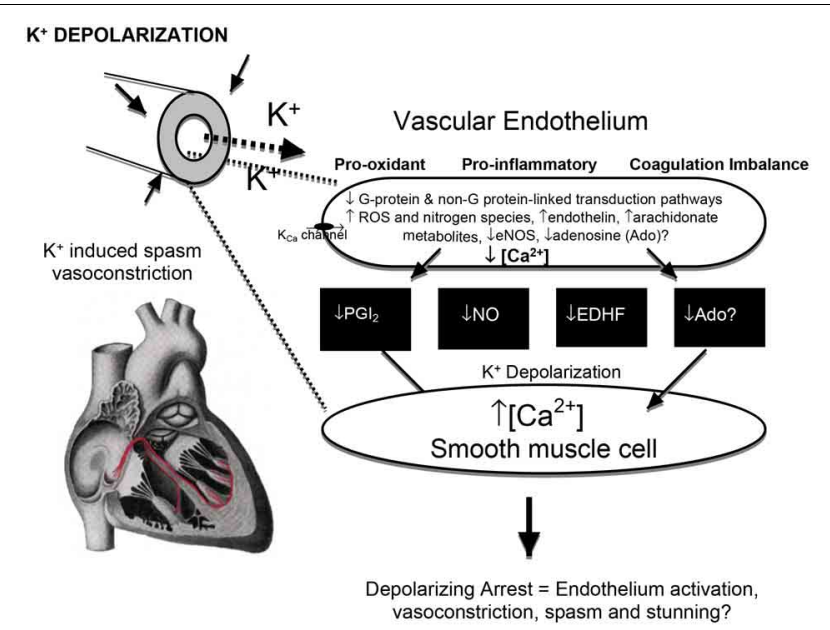

FIGURE 6 | The effect of high potassium on the endothelium and smooth muscle interactions, vasoconstriction, and possible injury. Membrane $\mathrm{K}^{+}$depolarization decreases the driving force for $\mathrm{Ca}^{2+}$ entry into endothelial cells through $\mathrm{Ca}^{2+}$-activated $\mathrm{K}^{+}$channels (Coleman et al., 2004), increases voltage sensitive endothelial NADPH oxidases (and other oxidants) (Sellke et al., 1993; Li and Shah, 2004) which can lead to vascular smooth muscle contraction and vasoconstriction (van Breemen et al., 1997) from a reduced availability of endothelial-derived vasodilators [prostacyclin $\left(\mathrm{PGI}_{2}\right)$, nitric oxide (NO), non-NO/PGI 2 relaxation factors (EDHF's) and adenosine] (He, 2005; Wu et al., 2005; Yang and He, 2005). Hyperkalemia in cardioplegia has been linked to loss of ACh-dependent relaxation, which may be exacerbated by ischemia and hypothermia (Tyers, 1997; Parolari et al., 2002; Yang and $\mathrm{He}, 2005)$.

for example, that incubating porcine small resistance coronary arteries in either St. Thomas's solution or Celsior preservation solutions resulted in a significant potassium-induced depolarization and loss of endothelial-derived hyperpolarizing factor (EDHF)-mediated function (Wu et al., 2005; Yang and He, 2005). The endothelium-derived vasoconstrictor Endothelin-1 may contribute to vasoconstriction (Feng et al., 2010), as it is involved in ischemia-reperfusion injury, spasm and transient left ventricular dysfunction following hyperkalemic arrest (Knothe et al., 1992; Dorman et al., 2000).

Magnesium is often added to cardioplegia to reduce intracellular $\mathrm{Ca}^{2+}$ loading during ischemia (Nakaigawa et al., 1997; Ichiba et al., 1998; Murphy, 2000; Mubagwa et al., 2007) and to counter $\mathrm{K}^{+}$-induced vasoconstriction (Matsuda et al., 1999; Yang and $\mathrm{He}$, 2005). Colder temperatures also offset the vasoconstriction effects of high potassium (Chiavarelli et al., 1982), however, it can lead to local and systemic inflammation, coagulation disturbances and tissue edema (Mezzetti et al., 1995; Torracca et al., 1996; Gaillard et al., 2000; Torchiana et al., 2000; Ravishankar et al., 2003). Thus, while hypothermia partially mitigates the potassium constrictor property, it may not provide optimal myocardial protection in cardiac surgery.

\section{ADVERSE EFFECTS HYPERKALEMIA ON MYOCARDIAL ENDOTHELIAL FUNCTION}

"Modern cardiopulmonary bypass and cardioplegic arrest techniques remain associated with an acute transcriptional response of hundreds of genes that primarily effect the largest organ of the body, the endothelium, as well as other constituents of blood vessels."

(Ruel et al., 2004) p. 1002

The endothelium sits at the geographical nexus between the blood and myocardium and has an exceptionally high surface area of $\sim 35 \mathrm{~m}^{2}$ in the adult heart for only $\sim 3 \%$ of the total myocardial volume (Hearse and Stewart, 1974; Verma and Anderson, 2002). Along with high potassium's vasoconstrictive and spasmodic effects (discussed above), $\mathrm{K}^{+}$levels as low as $10 \mathrm{mM} \mathrm{K}^{+}$ have been linked to endothelial injury including vascular depolarization, inflammation, neutrophil adherence, leaky junctions, platelet activation, pro-oxidant production, and impaired coagulation status (Jellinek et al., 1981; Mankad et al., 1991, 1997; Nilsson et al., 1993; Sellke et al., 1993; Parolari et al., 2002; Verma and Anderson, 2002; Perrault and Carrier, 2005; Higashi et al., 2009) (Figure 6).

As early as 1981 Jellinek and colleagues showed that high potassium $(>30 \mathrm{mM})$ led to structural changes in endothelial cells such as intracellular vacuolization and blebbing with vacuole formation, and that these deleterious effects were reduced with hypothermia (Jellinek et al., 1981). In the same year, Carpentier et al. (1981) reported that depolarizing potassium cardioplegia markedly reduced the viability of human endothelial cells and fibroblasts after several hours of incubation. Hoover and colleagues further demonstrated in vein grafts exposed to potassium solution that there was an aggressive adventitial fibrotic reaction compared to a control normokalemic Ringer's solution (Hoover et al., 1981). In 1983, Olinger and others showed in their primate model of graft atherogenesis that prolonged exposure of the cephalic vein grafts to hyperkalemic crystalloid cardioplegic solutions $(27 \mathrm{mM} \mathrm{KCl})$ resulted in increased lipid uptake and cholesterol deposition in the subintimal space 12 weeks after surgery (Olinger et al., 1983). It is possible that high potassium lead to intimal damage and loss of patency in the 16-25\% of saphenous vein conduits that occur in the first post-surgical year, and $10 \%$ of occlusions in radial artery grafts (Goldman et al., 2004; Magee et al., 2008; Buxton et al., 2009). This association between depolarizing hyperkalemia and graft failure requires further investigation.

While the mechanisms of high $\mathrm{K}^{+}$-induced endothelial damage are controversial, it appears that membrane depolarization is a first step of injury and activation and oxidant production (Figure 6). Membrane depolarization increases voltage sensitive endothelial NADPH oxidases (and other oxidants) and contributes to oxidative injury and endothelial activation (Sellke et al., 1993; van Breemen et al., 1997; Li and Shah, 2004). Many years ago, Yacoub and colleagues reported that increasing the concentration in St. Thomas's solution (Plegisol ${ }^{\circledR}$ ) or Bretschneider's (HTK, Custodiol ${ }^{\circledR}$ ) solution from 20 to $30 \mathrm{mM}$ played a critical role in causing endothelial damage, which was assessed as a loss of endothelium-dependent vasodilation (Mankad et al., 1991). In 2008, Radovits and colleagues stored isolated rat aortic rings for 24-hour in cold traditional Bretschneider's solution [HTK, Custodiol ${ }^{\circledR}$, and reported endothelial dysfunction (Radovits 
et al., 2008). In 1993, Sellke and others showed that coronary endothelial dysfunction after ischemic cardioplegic arrest and cardiopulmonary bypass, and it was also involved with the production of oxygen-derived free radicals (Sellke et al., 1993).

Endothelial membrane depolarization is known to promote platelet adhesion and neutrophil activation and inflammation (Niu et al., 1996; Halkos et al., 2004; Li and Shah, 2004). Interestingly, as early as 1987 Ishikawa and Sasakawa showed that increasing $\mathrm{K}^{+}$led to increasing depolarization of platelets, and that aggregation induced by ADP or collagen was enhanced by depolarization with increasing extracellular $\left[\mathrm{K}^{+}\right]$(Ishikawa and Sasakawa, 1987). In 2003, Krotz and colleagues similarly showed that endothelial membrane depolarization promoted platelet aggregation through increased superoxide production $\left(\mathrm{O}_{2}^{-}\right)$and inactivation of endothelial ectonucleotidases, and this effect was abolished by membrane hyperpolarization (Krötz et al., 2003). In 2005, Matsuzaki et al., further reported membrane depolarization-induced ROS generation when rat and mouse endothelial cells were switched from a normokalemic $(5.9 \mathrm{mEq}$ $\left.\mathrm{K}^{+}\right)$to a hyperkalemic bathing solution $\left(24 \mathrm{mEq} \mathrm{K} \mathrm{K}^{+}\right.$) (Matsuzaki et al., 2005). Platelet aggregation and neutrophil adhesion are thought to be key events in inflammation and acute vascular thrombosis, particularly when activated platelets come into contact with the subendothelial matrix, like collagen (Siess, 1989).

High $\mathrm{K}^{+}$also promotes tissue oxidative stress, which may lead to myocardial ischemia-reperfusion injury and exacerbate inflammation (Figure 6). Al-Mehdi and colleagues have employed high potassium to convert lung cells from a normal to pro-oxidant state (Al-Mehdi et al., 1997, 1998). These workers showed in the intact lung or reconstituted cell systems that high potassium triggered a depolarization-linked activation of endothelial NADPH oxidase and extracellular generation of $\mathrm{O}_{2}^{-}$(Al-Mehdi et al., 1997, 1998). In 2000, Sohn and others also used high potassium $(90 \mathrm{mM})$ to depolarize human endothelial cells, and found that the extent of depolarization of the membrane was directly responsible for the production of superoxide $\left(\mathrm{O}_{2}^{-}\right)$, and that the effect was inhibited in the presence of a hyperpolarizing $\mathrm{K}_{\mathrm{ATP}}$ channel opener (HOE 234) (Sohn et al., 2000). Furthermore, pretreatment with the tyrosine kinase inhibitor genestein completely abolished the $\mathrm{K}^{+}$depolarization-induced production of $\mathrm{O}_{2}^{-}$, indicating an involvement of tyrosine phosphorylation (Sohn et al., 2000) (Figure 5). Thus, there is a strong association between high potassium cardioplegia, endothelial activation, and oxidant stress which may lead to post-operative cardiac and vascular dysfunction.

\section{ADVERSE EFFECTS OF HYPERKALEMIA ON POST-OPERATIVE ARRHYTHMIAS AND CONDUCTION DISTURBANCES}

\begin{abstract}
"Potassium, calcium, sodium, and magnesium play a role in the genesis of experimental arrhythmias. In the clinical setting, however, altered $\mathrm{K}^{+}$concentration is responsible for the vast majority of such arrhythmias. This is true because within the range of levels of various electrolytes encountered in clinical disorders, $\mathrm{K}^{+}$is the electrolyte most likely to alter the electrophysiologic properties of the heart."
\end{abstract}

Fisch C (1973) (Fisch, 1973)
Early postoperative arrhythmias are a frequent complication of adult and pediatric cardiac surgery (Harris et al., 1954; Ebert et al., 1962; Flack et al., 1992; Cohen et al., 1993; Yau et al., 1993; Gaillard et al., 2000; Valsangiacomo et al., 2002). In 1980, Ellis showed that higher potassium concentrations in cardioplegia in humans resulted in a higher number of ventricular arrhythmias following cross-clamp removal, and this was worse at lower temperatures (Ellis et al., 1980). Post-operative arrhythmias can lead to left ventricular dysfunction, hemodynamic deterioration and costly treatment regimens amounting to billions of dollars per annum in the USA alone (Aranki et al., 1996; Mathew et al., 2004; Steinberg, 2004; Echahidi et al., 2008; Anselmi et al., 2009). Arrhythmias are also a major cause of morbidity and mortality in pediatric patients (Lan et al., 2003), where the overall incidence of arrhythmias can be as high as $48 \%$ (Pfammatter et al., 2002; Valsangiacomo et al., 2002). We are unaware of any studies having investigated the role of hyperkalemic cardioplegia on the incidence of early post-operative arrhythmias in the pediatric patient.

High potassium-linked arrythmogenicity is related to the creation of abnormal regional and transmural electrical heterogeneities required for the normal conduction of the heart (Figure 5). It has been known for over 40 years that the atria are the most sensitive to high $\mathrm{K}^{+}$(de Mello and Hoffman, 1960), followed by ventricular cells, His cells, SA nodal cells, and interatrial tracts (Ettinger et al., 1974) see (Figure 5). That the SA node is more resistant to increasing $\mathrm{K}^{+}$explains why nodal activity persists after early cardioplegic arrest of the atria and ventricles. Thus, differences in regional and wall potassium sensitivities, combined with localized $\mathrm{K}^{+}$changes from cold ischemia and diastolic membrane voltage changes, may give rise to new onset arrhythmias following cardiac surgery. Tsutsumi and colleagues further showed differences in $\mathrm{K}^{+}$sensitivity across the wall of the ventricle at the base and near the apex of the heart (Tsutsumi et al., 1983). Higher $\mathrm{K}^{+}$resulted in greater decreases in repolarization times in the basal epicardium compared with the endocardium, and a greater decrease at the endo vs. epicardium near the apex (Tsutsumi et al., 1983). Abnormal times for ventricular repolarization (Figure 5), along with local conduction slowing, may be key factors in predisposing the heart to arrhythmias during reanimation (Ettinger et al., 1974; Tsutsumi et al., 1983).

Depolarizing potassium can also lead to conduction (SA, AV, and Bundle of His) disturbances (Taggart et al., 2000). From the early 1980s, there were many groups investigating the failure of standard high potassium cardioplegia and hypothermic techniques to protect the heart's conduction system during cardiac surgery (Ellis et al., 1980). Ferguson and colleagues using multiple bipolar intracardiac and unipolar intramural electrodes reported the presence of electrical activity in the lower atrial septum, the atrioventricular node-His bundle complex, and in ventricular myocardium during hyperkalemic cardioplegic arrest that interestingly could not be detected visually or on the limb-lead electrocardiogram (Ferguson et al., 1986). Magilligan and colleagues suggested additional local cooling was needed at specific sites to reduce the incidence of conduction disturbances, block and junctional rhythm and low ventricular 
output following reperfusion (Magilligan et al., 1985; Ferguson et al., 1986). In summary, regional hyperkalemia and sensitivities (Figure 5), may induce regional refractroriness and local conduction slowing, which predispose the heart to post-operative arrhythmias.

Could the effect of hyperkalemia, hypothermia, and electrical disturbances contribute to post-operative atrial fibrillation (AF)? As mentioned in the introduction, AF is an early comorbid event with an incidence of around 30\% after CABG and as high as 69\% after more complex procedures (Almassi et al., 1997; Steinberg, 2004; Scherr et al., 2006). At present it is unclear whether high $\mathrm{K}^{+}$ in cardioplegia is directly linked to post-operative AF (Mathew et al., 2004; Steinberg, 2004; Echahidi et al., 2008; Anselmi et al., 2009), as similar incidences occur following "on-pump" and "offpump" where no hyperkalemic cardiopelgia is used (Hosokawa et al., 2007). However, it is possible that the underlying causes of $\mathrm{AF}$ in both types of surgery have direct and indirect roles for depolarizing $\mathrm{K}^{+}$in a setting of ischemia-reperfusion, endothelial dysfunction and inflammation (Vinten-Johansen et al., 2007a). In "on-pump surgery," AF could be exacerbated from high $\mathrm{K}^{+}$ in the surgical cardioplegia, and in "off-pump" surgery from rises in local extracellular $\mathrm{K}^{+}$from multiple bouts of regional ischemia during occlusion of the target vessel, and from the compounding effect of acidosis which can activate endothelial cells to produce damaging oxidants and amplify the inflammatory process (Kitagawa and Johnston, 1985; Al-Mehdi et al., 1997). Regional ischemia can lead to increases in extracellular $\mathrm{K}^{+}$of over $20 \mathrm{mM}$, and Miura's group showed that these changes are linked to non-uniform rises in intracellular $\mathrm{Ca}^{2+}$ and sustained arrhythmias (Miura et al., 2012). In 2008, Kon and colleagues also reported a strong correlation during "off-pump" cardiac between myocardial ischemia and gradients of transcardiac inflammation markers (TNF-alpha, IL-8) and thrombosis (thrombin generation-F1.2, contact activation pathway-FXII-a, platelet derived microparticles) (Kon et al., 2008). This data suggests that even brief episodes of ischemia-reperfusion during off-pump surgery may cause local injury currents in the atria, which may be significant because the atria are the most sensitive to high $\mathrm{K}^{+}$(Figure 5). In 2009, Tran and colleagues also reported a link between plasma $\mathrm{K}^{+}$during cardiac surgery and post-operative atrial fibrillation (Tran et al., 2009). Thus, hyperkalemia, whether imposed on the heart from depolarizing $\mathrm{K}^{+}$in surgical cardioplegia or from bouts of regional ischemia during beating heart surgery, may be linked functionally to membrane depolarization and an activated endothelium and inflammatory response, which collectively promote the generation of atrial (and ventricular) arrhythmias. Further studies are required to test this hypothesis.

\section{ADVERSE EFFECTS OF HYPERKALEMIA ON CARDIAC OUTPUT AND STUNNING}

\footnotetext{
"There is clinical evidence that myocardial stunning is a frequent sequela of surgical global ischemia, despite our modern techniques of myocardial protection. The ubiquitous usage of hyperkalemic depolarizing solutions in all forms of cardioplegia may be partly responsible for this phenomenon because of the known
}

ongoing metabolic requirements and damaging transmembrane ionic fluxes that occur at depolarized membrane potentials."

Damiano RJ Jr, Cohen NM. (Damiano and Cohen, 1994)

Left Ventricular dysfunction is a key determinant of patient outcome following cardiac surgery (Algarni et al., 2011). One form of post-operative LV dysfunction is myocardial stunning or the loss of post-operative contractility from IR injury without cell death (Braunwald and Kloner, 1982; Kloner et al., 1994). The phenomenon was first described experimentally in 1975 by Heyndrickx and colleagues, who reported an abnormal, depressed ventricular function after regional ischemia in dogs despite normal return of coronary blood flow and ECG waveform (Heyndrickx et al., 1975). It is manifest as a decrease in cardiac output typically lasting $2-4 \mathrm{~h}$ post-operatively (Gillies et al., 2005), and can persist for longer periods without apparent signs of infarction or other serum injury markers (Troponins or CKMB) (Kloner and Jennings, 2001). Stunning occurs in about $10 \%$ of adults following cardiac surgery (Weisel, 1993; Vaage and Valen, 1993; Mangano, 1995; Spinale, 1999; Flack et al., 2000; Chang et al., 2002; Anselmi et al., 2004) and in 10-15\% of pediatric patients (Parr et al., 1975; Booker, 1998; Ravishankar et al., 2003). Stunning may contribute to low cardiac output syndrome (LCOS) in adults (Algarni et al., 2011) and pediatric patients (Weisel, 1993; Booker, 1998; Spinale, 1999; Wessel, 2001; Allen, 2004; Jones et al., 2005). The incidence of LCOS occurs int 3-14\% of adult CABG patients and is associated with a 10 -fold to 17 fold increase in mortality (Algarni et al., 2011), and in around $25 \%$ of pediatric cardiac surgery patients (Jones et al., 2005). The classic features of LCOS include tachycardia, oliguria, poor peripheral perfusion, and low blood pressures (Jones et al., 2005). Importantly, a low ejection fraction (EF) is a poor predicator of overall cardiac reserves and does not predict LCOS (Zaroff et al., 1994), however, a low EF plus inadequate cardioprotection is associated with LCOS and possible stunning (Zaroff et al., 1994; Aronson, 1999).

Hyperkalemic cardioplegia may contribute to myocardial stunning and LCOS from the effect of high potassium and IR injury on $\mathrm{Ca}^{2+}$ loading, vasoconstriction, reanimation arrhythmias, and endothelial dysfunction (Figures 3-6) (Booker, 1998; Allen, 2004; Amark et al., 2005). In animal models cold hyperkalemic cardioplegia, and the transition from hypothermia to normothermia, before cross-clamp removal is also a factor linked to stunning (Przyklenk et al., 1994; Spinale, 1999; Eberhardt et al., 2000; Ambrosio and Tritto, 2001). An area of particular interest in stunning is the release of catecholamines from adrenergic nerve terminals leading to further transient $\mathrm{Ca}^{2+}$ loading (Lubbe et al., 1992; Paterson et al., 1993; Vatner and Vatner, 1998; Lameris et al., 2000; Vittone et al., 2006), and the production of oxidants and oxygen-derived free radicals from injured myocytes and activated endothelial cells exacerbating inflammation and coagulation imbalances (Bolli et al., 1988; Carden and Granger, 2000; Kloner and Jennings, 2001; Zweier and Talukder, 2006). The direct and indirect roles of high potassium as part of the underlying pathophysiology of myocardial stunning warrant further investigation (Algarni et al., 2011). 


\section{FIVE DECADES OF SEARCHING FOR ALTERNATIVES TO DEPOLARIZING POTASSIUM}

"Nothing is new except arrangement."

Will Durant (1885-1981).

For over five decades, surgeons and scientists have acknowledged the adverse effects of high potassium cardioplegia (Chambers and Fallouh, 2010) (Figure 2). After a 10 year "moratorium" beginning in the late 1950s, Bretschneider and colleagues began to test alternatives, and in 1967 they hypothesized that dramatically reducing sodium (from $\sim 130 \mathrm{mM}$ to $12 \mathrm{mM}$ ) and keeping $\mathrm{Ca}^{2+}$ low (near zero), and reducing potassium in the presence of the Class 1 antiarrhythmic agent procaine $(0.2 \%)$ may offer a safer and effective way to inhibit the action potential and arresting the heart (Reidemeister et al., 1967). In the same year, Hoelscher tested procaine as a non-depolarizing arresting agent in rabbit hearts, and confirmed that the "Melrose technic" using potassium citrate was pro-arrhythmic and caused severe myocardial damage (Hoelscher, 1967). In 1972, Kirsch proposed another cardioplegia formulation containing procaine, magnesium aspartate, and sorbital with apparently good clinical results (Kirsch et al., 1972). However, in 1977 Jynge et al. evaluated the components of the Kirsch and Bretschneider solutions using dose response curves, and compared the efficacy with their own home-grown St. Thomas' Hospital solution with $15 \mathrm{mM} \mathrm{KCl}$ and $16 \mathrm{mM} \mathrm{MgCl}_{2}$ (Jynge et al., 1977). Using the isolated Langendorff rat heart model, they concluded that the St Thomas Hospital solution had superior in functional recovery (Jynge et al., 1977). Jynge and colleagues further cautioned the field that until the mechanisms underlying ischemic damage were better understood, it would be unwise to recommend "the use of solutions containing extremes of concentration or solutions devoid of ions normally found in the extracellular fluid" (Jynge et al., 1977). St Thomas' Solution was introduced clinically in 1975.

In the 1970s the science of cardioplegia began to expand and diversify. In 1975 Tyers and associates introduced tetrodotoxin as another cardioplegia agent in the isolated rat heart (Tyers et al., 1975). Tetrodotoxin was first shown in 1960 by Narahashi to polarize the cell membrane, presumed by blocking sodium channels (Narahashi et al., 1960; Narahashi, 2008), and in 1997 Chambers and colleagues extended Tyers studies (Snabaitis et al., 1997). In 1983, Leicher and colleagues also tested blood cardioplegia using (1) $1.5 \mathrm{mM}$ lidocaine alone, (2) $1.5 \mathrm{mM}$ lidocaine with $30 \mathrm{mM}$ potassium, and (3) $30 \mathrm{mM}$ potassium alone, and they concluded that high $\mathrm{K}^{+}$cardioplegia causes marked vasoconstriction, and impairs cardioplegic delivery and distribution (Leicher et al., 1983) (Figure 2). As a primary cardioplegic agent, lidocaine alone has not translated into surgical practice (Yamaguchi et al., 2007), however, the drug is commonly used at lower concentrations with or without magnesium during reperfusion to reduce ventricular arrhythmias (Baraka et al., 1993; Kanchi et al., 2004; Yamaguchi et al., 2007).

Another non-depolarizing cardioplegic agent was adenosine. In 1989, Opie and colleagues tested $10 \mathrm{mM}$ adenosine in the isolated rat heart (Schubert et al., 1989). Belardinelli had previously shown that $50 \mu \mathrm{M}$ adenosine inhibited isolated rabbit SA node pacemaker cells by hyperpolarizing the membrane by $\sim 12 \mathrm{mV}$ (Belardinelli and Giles, 1988). Opie and colleagues reported that high doses of adenosine induced rapid arrest but delayed post-ischemic recovery, and after assessing all the data they advocated switching back to depolarizing potassium cardioplegia with adenosine as an adjunct (De Jong et al., 1990). This work formed the basis for Phase I and II clinical trials in the late 1990s (Mentzer et al., 1999). Unfortunately, the trials showed no significant cardioprotective advantage of having adenosine present in hyperkalemic blood cardioplegia (Mentzer et al., 1997, 1999; Cohen et al., 1998; Vinten-Johansen et al., 2003). In 2007, Jacobsen and colleagues have shown that $1.2 \mathrm{mM}$ adenosine instead of supranormal potassium in cold-crystalloid cardioplegic solution improved cardioprotection in the porcine model of cardiopulmonary bypass (Jakobsen et al., 2007). More recently, the same group showed in humans that the adenosine cardioplegia resulted in shorter times to arrest (11 vs. $44 \mathrm{~s}, P<0.001)$ and lower postoperative atrial fibrillation ( 19 vs. $54 \% p=0.01)$ compared with high potassium cardioplegia $(20 \mathrm{mM}$ ) (Jakobsen et al., 2013). The discrepancy between Jacobsen's and previous adenosine cardioplegia studies (Schubert et al., 1989; Mentzer et al., 1999; Vinten-Johansen et al., 2003; Ahlsson et al., 2012) may be explained by their addition of local anesthetic (procaine) (VintenJohansen and Dobson, 2013). Dobson and colleagues have shown that adenosine plus a local anesthetic confers superior protection than adenosine alone (Dobson and Jones, 2004) (see Section Adenosine and Lidocaine (AL): A More Natural Way to Arrest, Protect, and Preserve the Heart). Dobson chose lidocaine because as a Class $1 \mathrm{~B}$ anti-arrhythmic it shortens repolarization time, whereas procaine (Class 1A) prolongs repolarization time (Opie and Gersh, 2008), which may cause post-operative reanimation irritability (Vinten-Johansen and Dobson, 2013).

In the 1990s, ATP-sensitive potassium $\left(\mathrm{K}_{\mathrm{ATP}}\right)$ channel openers were another class of drugs that raised the interest of surgeons as alternatives to hyperkalemia (Figure 1). Following Noma's discovery of the $\mathrm{K}_{\text {ATP }}$ channel in heart in 1983 (Noma, 1983), a number of $K_{A T P}$ openers were subsequently developed (e.g., pinacidil, aprikalim, nicorandil, and cromakalim), and they shared the property of hyperpolarizing the cell membrane of a number of tissues, including myocardium (Nichols and Lederer, 1991). At high concentrations, $\mathrm{K}_{\mathrm{ATP}}$ channel openers prevented the $\mathrm{Na}^{+}$fast channels from reaching their threshold to open and thereby arrested the heart in asystole (Chambers and Hearse, 2001). Initially there was great excitement about the possibility of $\mathrm{K}_{\mathrm{ATP}}$ openers as primary non-depolarizing cardioplegic agents (Cohen et al., 1993, 1995; Lopez et al., 1996; Jayawant et al., 1997; Jayawant and Damiano, 1998). Unfortunately, like many new drugs, their application did not translate to clinical safety and efficacy because they failed to protect the myocardium, and many were pro-arrhythmic during reperfusion (Chi et al., 1990; Chambers and Hearse, 1999). The field had come full circle; non-depolarizing agents such as procaine and lidocaine, hyperpolarizing agents such as adenosine and $\mathrm{K}_{\mathrm{ATP}}$ openers, once again became servants to high potassium concentrations. They were principally experimentally and in some cases clinically used as 
adjuncts in hyperkalemic cardioplegic solutions and longer-term preservation solutions, rather than the primary arresting agents (McCully and Levitsky, 2003; Diodato et al., 2005; Mizutani et al., 2006).

Other arresting agents have been experimentally examined and reexamined over the past 50 years, including acetylcholine (Lam et al., 1958), calcium antagonists (verapamil, nifedipine, and diltiazem) (Robb-Nicholson et al., 1978), high concentrations of magnesium (Kirsch et al., 1972), other sodium channel blockers (Snabaitis et al., 1997), 2,3-Butanedione monoxime (Chambers, 2003) and opioids (Bolling et al., 1997). More recently, non-depolarizing esmolol- $\mathrm{HCl}$ cardioplegia has been suggested as a possible alternative to high potassium (Warters et al., 1998; Chambers, 2003). Esmolol-HCl is an ultra-shortacting beta-blocker with a half-life of about $10 \mathrm{~min}$, and at high concentrations can both arrest the heart and attenuate myocardial ischemia-reperfusion injury (Geissler, 2002; Chambers, 2003). Although Chambers showed that multidose infusions $(2 \mathrm{~min}$ given every $15 \mathrm{~min}$ ) of a $1.0 \mathrm{mmol} / \mathrm{L}$ esmolol solution arrested and protected isolated crystalloid-perfused rat hearts for up to $90 \mathrm{~min}$ at normothermic temperatures (Chambers, 2003), earlier work by Deslauriers and colleagues (Ede et al., 1997) reported esmolol-related increases in left ventricular diastolic pressure and pulmonary arterial pressures during arrest, and a difficulty in weaning the pigs off bypass (Ede et al., 1997). Further work is required to test the surgical applications of esmolol in the clinical setting.

\section{ADENOSINE, LIDOCAINE, AND Mg $^{2+}\left(\right.$ ALM $\left.^{\text {TM }}\right)$ : A MORE NATURAL WAY TO ARREST, PROTECT AND PRESERVE THE HEART}

"For any question in science, there is one animal best suited to study it"

August Krogh [quoted from Krebs (1975)].

\section{LESSONS FROM NATURAL HIBERNATORS}

In the late 1990s, one of us (GPD) asked the question: "Could the human heart be pharmacologically modified to operate more like the heart of a natural hibernator during cardiac surgery?" (Dobson, 2004). The question taps into hundreds of millions of years of animal adaptations from Nature's own laboratory with the goal of developing new strategies and therapeutics to treat human disease. Wilfred Bigelow used the "August Krogh" principle in 1950 when he first introduced therapeutic hypothermia into cardiac surgery by recalling his experience as a boy in Canada and natural hibernators dropping their core temperatures to a few degrees above ambient (Bigelow, 1984). Bigelow wrote: "I became aware that surgeons would never be able to correct or cure heart conditions unless they were able to stop the circulation of the blood through the heart, open it, and operate in a bloodless field under direct vision" ... "One night I awoke with a simple solution ...cool the whole body, reduce oxygen requirements, and interrupt the circulation and open the heart" (Bigelow, 1984; Sealy, 1989).

With respect to slowing the heart, natural hibernating animals (or summer estivators) do not flood their heart cells with high $\mathrm{K}^{+}$and depolarize their cell membranes as they enter torpor, hibernation or estivation (Willis et al., 1971; Al-Badry and Taha, 1983; Wang et al., 2002; Dobson, 2004). As temperature drops from 35 to $10^{\circ} \mathrm{C}$, myocytes from the rat depolarize from about -80 to $-45 \mathrm{mV}$ see (Wang et al., 2002), whereas myocytes from the hibernating ground squirrel can be supercooled to $-5^{\circ} \mathrm{C}$ and defend their membrane potential at around $-60 \mathrm{mV}$ (Wang and Zhou, 1999). Furthermore, natural hibernators do not vasoconstrict their coronary arteries with depolarizing $\mathrm{K}^{+}$, and potentially compromise blood flow distribution and myocardical protection during hibernation (Sjöquist et al., 1986; Burlington et al., 1989; Kudej and Vatner, 2003; Dobson, 2004). Studies on woodchucks (Marmota monax) have shown that coronary blood flow was maintained despite an $84 \%$ fall in cardiac output during hibernation relative to the awake state (Kudej and Vatner, 2003). Thus, from the lessons of natural hibernators, the way surgeons have imposed depolarized, low energy states on the human heart and coronary vasculature using high $\mathrm{K}^{+}$is unphysiological on at least two accounts: (1) hibernators reduce their metabolism without imposing a depolarizing insult on their cells, and (2) the coronary arteries of hibernators are left wide open despite a low-energy torpid state of the heart.

\section{THE AL(M) POLARIZING CONCEPT}

Down-regulating the heart during hibernation may involve multi-modulation of $\mathrm{Na}^{+}$channel activity and associated innate central nervous system-linked-cell preconditioning mechanisms with the production of $\mathrm{K}_{\mathrm{ATP}}$ channel openers or $\mathrm{O}_{2}$ demandlowering agents by endogenous agents that are released during low oxygen transition states such as naturally occurring adenosine. Adenosine has been shown to be important in priming the brain for entrance into hibernation in the arctic ground squirrel (Jinka et al., 2011). The two drugs chosen to mimic the hibernating heart and examined 10 years ago from a long list of energy lowering compounds, $\mathrm{K}_{\text {ATP }}^{+}$openers, and $\mathrm{Na}^{+}$blockers were adenosine and lidocaine (see Figure 7).

The AL polarizing hypothesis was formulated in 1998 and based on the following reasoning. If the voltage-amplitude (Phase O upstroke) of the cardiac action potential was reduced to its diastolic baseline by blocking the inward $\mathrm{Na}^{+}$fast current (y-axis), and if the action potential duration of the atria, Purkinje fibers, and ventricles were reduced by opening $\mathrm{K}_{\mathrm{ATP}}$ channels ( $\mathrm{x}$-axis) (see Figure 5), the heart should arrest at its "resting" diastolic membrane potential of -80 to $-85 \mathrm{mV}$ (Dobson, 2004). There would be no need for depolarizing potassium to induce electrochemical arrest. Along with adenosine opening $\mathrm{K}_{\text {ATP }}$ channels (Terzic et al., 1995) and lidocaine blocking $\mathrm{Na}^{+}$fast channels (Josephson, 1988; Moller and Covino, 1988; Zamponi et al., 1993; Opie and Gersh, 2008), the additional benefit of arresting (and non-arresting) concentrations of $\mathrm{A}$ and $\mathrm{L}$ is that they both rapidly and reversibly slow heart rate (negative chronotropism) (Drury and Szent-Gyorgyi, 1929) (Wilson et al., 1993; Belardinelli et al., 1995), slow atrioventricular conduction (negative dromotropism) (Smith, 1989; Pitkanen et al., 1992; Wagner et al., 1998; Davies, 1999; Canyon and Dobson, 2004; David et al., 2007), and they each possess coronary vasodilatory (Berne, 1963; Schrader, 1990; Ely and Berne, 1992; Travis et al., 1999), 


\section{Adenosine}

\section{$+\quad$ Lidocaine}

- Naturally occurring

- Adenosine $A_{1}, A_{2 a}, A_{2 b}$ and $A_{3}$ receptors

- Negative chrono-, inotropic, dromotropic effects

- Coronary vasodilator

- KatP channel opener

- Antiarrhythmic (supraventricular)

- Anti-adrenergic properties

- $\downarrow$ neutrophil selectin/integrin expression/activation

- Inhibits expression of adhesion molecules

- $\downarrow$ lymphocyte activation and tissue entry

- $\quad \downarrow$ inflammation without excessive immunosuppression

- $\quad \downarrow$ platelet plugging

- $\quad \downarrow$ cytokine TnF alpha

- $\quad \downarrow$ tissue factor expression

- Natural 'trigger' in pre- and post-conditioning

- Suppresses neuropathic-nociceptive pain

- Involved in induction of natural hibernation \& heart stabilization at low temperatures

- $\mathrm{Na}^{+}$fast channel blocker

- Negative chrono-, inotropic, and dromotropic effects

- Coronary vasodilator

- Antiarrhythmic (ventricular and atrial)

- Free radical scavenger $\left(\mathrm{OH}^{-}\right)$

- $\downarrow$ neutrophil priming/activation

- $\quad \downarrow$ platelet plugging

- $\quad \downarrow$ TnF alpha

- $\quad \downarrow$ T-cell proliferation partly by inhibition of NFkappaB signaling

- Inhibits release of high mobility group box 1 (HMGB-1) via NF-kappaB signaling

- $\quad \downarrow$ tissue factor expression of monocytes

- $\downarrow$ thrombin's action to depolarize cardiomyocytes

- Suppresses neuropathic-nociceptive pain

- Possible cross-talk with Gai-coupled signaling through the adenosine $A_{1}$ receptor

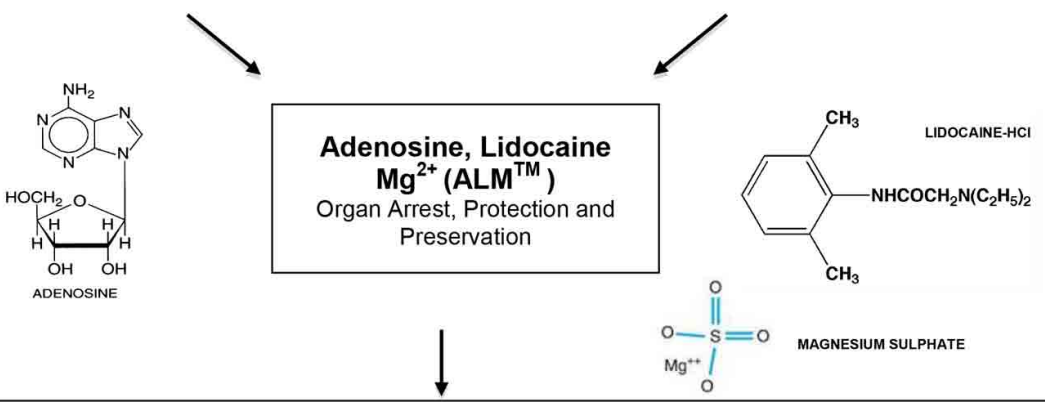

Properties and Applications

- At high doses, $A L(M)$ 'clamps' and 'stabilizes' the resting membrane potential to arrest the heart in cardiac surgery.

- Decreases coronary vascular resistance and anti-spasmodic.

- At lower, non-arrest doses, it reanimates the heart

- Exerts pro-survival, preconditioning, and anti-arrhythmic properties.

- Attenuates ischemia-reperfusion injury and exerts potent anti-inflammatory properties

- Corrects coagulation imbalances following hemorrhagic shock and cardiac arrest

- At lower, non-arrest doses, $7.5 \% \mathrm{NaCl}^{\mathrm{ALM}^{\mathrm{TM}}}$ rescues and stabilizes the heart and vascular system with renal protection following blood loss and shock.

- Lowers whole body $\mathrm{O}_{2}$ consumption, and multiple organ protection following sepsis

- Possibly provides neuroprotection after traumatic brain injury

FIGURE 7 | Summary of the major properties and structures of adenosine and lidocaine (with $\mathrm{Mg}^{2+}$ ), and their potential mechanisms of action for heart arrest, protection and preservation (see text for details).

anti-ischemic (Tosaki et al., 1988; Lasley et al., 1990; Downey et al., 1993; Kamiyama et al., 1995; Jovanovic et al., 1997, 1998; McCully et al., 1998; Vinten-Johansen et al., 1999, 2005; Kanchi et al., 2004; Hove et al., 2007; Wang et al., 2007), anti-arrhythmic (Camm and Garratt, 1991; Alexander et al., 1999; Kucera et al., 2002; Wyman et al., 2004; Jacobson and Gao, 2006) and antiinflammatory properties (Goldstein et al., 1977; McGregor et al., 1980; Tomoda et al., 1990; Sasagawa, 1991; Cronstein et al., 1992;
Das and Misra, 1992a,b; Mikawa et al., 1997; Vitola et al., 1997; Hollmann and Durieux, 2000; Hollmann et al., 2001; Huang et al., 2002; De Kalver et al., 2003; Vinten-Johansen et al., 2003; Halkos et al., 2004; Hasko and Cronstein, 2004; Hollmann et al., 2004; Lenfant et al., 2004; Lappas et al., 2005; Amir et al., 2006; Cassuto et al., 2006; Takahashi et al., 2007; Hasko et al., 2008) and possible coagulation correcting effects (Cooke et al., 1977; Borg and Modig, 1985; Stewart, 1993; Deguchi et al., 1998; Tobias 
et al., 1999; Hollmann and Durieux, 2000; Broussas et al., 2002; Pinet et al., 2002; Evans et al., 2003; Lappas et al., 2005; Sands and Palmer, 2005; Kreckler et al., 2006) (see Figure 7). Possible cross-talk between A and L may also occur as was recently shown by Benkwitz et al. (2003). Since the adenosine receptors and $\mathrm{Na}^{+}$ fast channels are common among most tissues of the body, the clinical applicability of the AL (and $\mathrm{Mg}^{2+}$ ) concept may confer multi-organ protection such as brain, spinal cord, kidney, liver, GI tract, muscle, and lung (Figure 7).

\section{ADVANTAGES OF POLARIZED vs. DEPOLARIZED ARREST AND REANIMATION}

\begin{abstract}
"Thus maneuvers that precluded activation of the $\mathrm{Na}^{+}$channels, for example, holding the resting membrane potential at $-80 \mathrm{mV}$ significantly increased time to cell death or prevented contracture entirely."
\end{abstract}

Ward et al. (2006)

The advantage of the polarized arrest and reanimation concept arises from fewer membrane channels, pores and exchangers being open or activated compared with the depolarized state (Chambers and Hearse, 2001; Dobson and Jones, 2004). Depolarised cells are electrically more unstable because many voltage-dependent membrane channels $\left(\mathrm{Ca}^{2+}, \mathrm{Na}^{+}\right.$window current, $\left.\mathrm{K}^{+}\right)$, pores and exchangers $\left(\mathrm{Na}^{+} / \mathrm{H}^{+}\right.$and $\left.\mathrm{Na}^{+} / \mathrm{Ca}^{2+}\right)$ are activated (Kondo, 1987; Carmeliet, 1999; Baczko et al., 2003), which can lead to $\mathrm{Na}^{+}$and $\mathrm{Ca}^{2+}$ loading, endothelial activation, coronary artery constriction, arrhythmias and stunning. As mentioned earlier, high $\mathrm{K}^{+}$-induced membrane depolarization can lead to the superoxide production in endothelial and vascular smooth muscle cells, platelet aggregation, macrophage and neutrophil activation (Sohn et al., 2000), and underlying tissue damage (Al-Mehdi et al., 1997). In 2006, Ward and colleagues (Ward et al., 2006) reported that emigrated neutrophils, after adhering to ventricular myocytes, caused an immediate membrane depolarization, which contributed to an inflammatorylinked generation of arrhythmias, tissue injury and contractile dysfunction (Ward et al., 2006). Ward et al., further showed that holding the cell membrane potential around the natural "resting" polarized state reduced damage from inflammatory attack (Ward et al., 2006). Thus maintaining a "polarized" membrane potential, or at least stabilizing the voltage during times of stress like global and regional ischemia, appears to be a key factor in preventing the endothelium from activating and triggering a local inflammatory response with increased levels of pro-inflammatory cytokines (IL1 , IL-6, and TNF- $\alpha$ ) and other immunologic and coagulopathic derangements.

\section{PLACING THE HEART IN A “NATURAL" STATE OF THERAPEUTIC SUSPENDED ANIMATION \\ AL cardioplegia: pre-clinical data}

Our early preclinical data using the isolated rat heart (Dobson and Jones, 2004) and in the canine model of cardiopulmonary bypass (Corvera et al., 2005) supported the AL concept as a new cardioplegic formulation in warm and cold crystalloid and blood environments. In 2004, Dobson and Jones showed that AL cardioplegia, "clamped" the membrane potential close to its resting voltage of $-83 \mathrm{mV}$, as was predicted on theoretical grounds. They also showed that AL cardioplegia arrested the heart for up to $4 \mathrm{~h}$ at $29^{\circ} \mathrm{C}$ with small $30 \%$ increases in coronary vascular resistance (CVR), 85-100\% recovery of heart rate and systolic pressure, and $70-80 \%$ recovery of cardiac output, while only $17 \%$ of hearts arrested with St. Thomas' Hospital solution No 2 (Plegisol ${ }^{\circledR}$ ) survived (Dobson and Jones, 2004). Proof-of-concept was further demonstrated using all-blood AL cardioplegia in the canine model of cardiopulmonary bypass (Corvera et al., 2005), and in 2007, we reported that AL cardioplegia can be delivered continuously or intermittently at $33^{\circ} \mathrm{C}$ with no significant loss in functional parameters (Sloots et al., 2007).

In 2010 Sloots and Dobson (Sloots and Dobson, 2010) examined the effect of varying levels of extracellular potassium in $\mathrm{AL}$ cardioplegia $\left(0.1,3.0,5.9,10,16 \mathrm{mM} \mathrm{K}^{+}\right)$on the membrane potential $(\varphi)$, CVR, incidence of arrhythmias, heart rate, systolic pressures, aortic and coronary flows, cardiac output, time to first beat, and stroke volume after 1 and $2 \mathrm{~h}$ of arrest at $32-33^{\circ} \mathrm{C}$ (Figures 8A-C). Sloots and Dobson showed that warm AL cardioplegia is most efficient under normokalemic conditions when the myocardial cell membrane potential is close to its resting state. Hearts arrested using higher $\mathrm{K}^{+}$levels (depolarizing cardioplegia) or interestingly, using lower $\mathrm{K}^{+}$levels (hyperpolarizing cardioplegia), had significantly higher CVR's, experienced reanimation arrhythmias and were "slow-to-recover" with significant losses in left ventricular (LV) function, SV and contractility (Sloots and Dobson, 2010). LV functional loss was highly correlated with high or very low potassium levels in the cardioplegia (Figures $\mathbf{8 A - C}$ ). Nearly $40 \%$ of AL $\left(0.1 \mathrm{mM} \mathrm{K}^{+}\right)$and $25 \mathrm{mM} \mathrm{K}^{+}$alone hearts failed to return $\mathrm{HR}$, developed pressures or $\mathrm{CO}$ after $1 \mathrm{~h}$ arrest at 32$33^{\circ} \mathrm{C}$. In 2009, Rudd and Dobson advanced the AL cardioplegic concept as a new paradigm for orthotopic heart transplantation, and showed that arrest and reanimation was versatile at both cold $\left(4^{\circ} \mathrm{C}\right)$ and warmer $\left(28-30^{\circ} \mathrm{C}\right)$ temperatures compared with Celsior solution (Rudd and Dobson, 2009). In 2011, Rudd and Dobson further showed that the rat heart could be placed in suspended animation with $\mathrm{AL}$, insulin and melatonin for $8 \mathrm{~h}$ in cold static storage $\left(4^{\circ} \mathrm{C}\right)$ and returned $80 \%$ of left ventricular function compared to two FDA approved preservation solutions, Custodiol-HTK and Celsior, that could barely return 10\% left ventricular function (Rudd and Dobson, 2011b). Further studies are underway to further improve $\mathrm{ALM}^{\mathrm{TM}}$ cardioplegia and preservation solutions.

\section{Reanimation with ALM: key to restoring a broken heart}

The AL concept of voltage control and defending ionic and metabolic balance may also be applicable for reperfusion following heart surgery or organ storage. Canyon and Dobson showed that pre-treatment (i.e., preconditioning) with intravenous low dose AL infusion $5 \mathrm{~min}$ prior and during $30 \mathrm{~min}$ of regional ischemia led to superior protection from acute ischemic damage resulting in no death, no severe arrhythmias and a significant 38\% decrease in infarct size (Canyon and Dobson, 2004). In contrast, fifty-eight percent (58\%) of saline controls died from ventricular fibrillation (Canyon and Dobson, 2004). In another study, the adenosine $\mathrm{A}_{1}$ agonist 2-chloro-N6-cyclopentyladenosine 


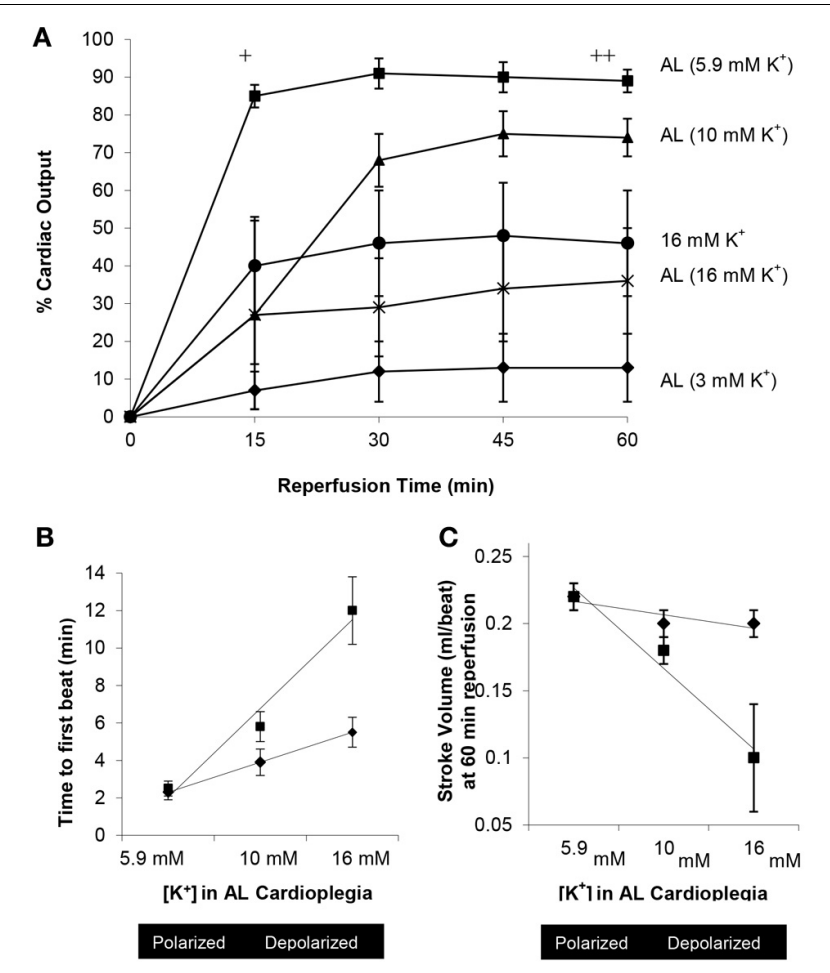

FIGURE 8 | Effect of increasing extracellular potassium in AL cardioplegia on return of cardiac output, time to first beat and stroke volume after 1 and $2 \mathrm{~h}$ arrest at $32-33^{\circ} \mathrm{C}$ in the isolated working rat heart [Adapted from Sloots and Dobson (2010)]. (A) Percentage recovery of cardiac output in following $2 \mathrm{~h}$ arrest at $32-33^{\circ} \mathrm{C} .{ }^{+} \mathrm{AL}(5.9 \mathrm{mM}$ $\left.\mathrm{K}^{+}\right) p<0.01$ (One-Way analysis of variance) compared with $\mathrm{AL}(3,10$, $16 \mathrm{mM} \mathrm{K}^{+}$) and $16 \mathrm{mM} \mathrm{K}^{+}$alone. ${ }^{++} \mathrm{AL}\left(5.9 \mathrm{mM} \mathrm{K}^{+}\right) p<0.01$ (One-Way analysis of variance) compared with $\mathrm{AL}\left(3 \mathrm{mM} \mathrm{K}^{+}\right)$; $p<0.05$ (repeated measures) compared with $\mathrm{AL}\left(3,16 \mathrm{mM} \mathrm{K}^{+}\right)$and $16 \mathrm{mM} \mathrm{K}^{+}$alone. *AL $\left(10 \mathrm{mM} \mathrm{K}^{+}\right) p<0.01$ (repeated measures) compared with $\mathrm{AL}\left(3 \mathrm{mM} \mathrm{K}^{+}\right.$). (B) Relationship between the time to first beat at reanimation after 1 or $2 \mathrm{~h}$ arrest and the concentration of potassium in $\mathrm{AL}$ cardioplegia solution (5.9, 10 , and $16 \mathrm{mM} \mathrm{K}^{+}$). (C) Relationship between stroke volume and increasing concentrations of potassium in $\mathrm{AL}$ cardioplegia solution $(5.9,10$, and $16 \mathrm{mM}$ $\mathrm{K}^{+}$) at $60 \mathrm{~min}$ reperfusion after 1 and $2 \mathrm{~h}$ arrest.

(CCPA) was substituted for adenosine, and the CCPA-lidocaine combination showed remarkable infarct size reduction of over $80 \%$, which was equivalent to that of ischemic preconditioning itself (Canyon and Dobson, 2005). In 2006, Canyon and Dobson showed using ${ }^{31} \mathrm{P}$ nuclear magnetic resonance (NMR) that the protective effects of AL constant infusion therapy were expressed as preservation of high-energy phosphates (ATP, PCr) in the area-at-risk of the left ventricle, and this was explained by a down-regulation of the myocardium during ischemia (Canyon and Dobson, 2006). This in vivo study is consistent with the energy-sparing properties shown in the cardioplegia studies. That the ATP and PCr concentrations were maintained during ischemia supports our hypothesis that AL pretreatment/ischemia therapy may provide protection by ensuring better metabolic and electrical matching in different heterogeneous regions of the heart, and may be useful for off-pump surgery or angioplasty.

In 2011 Rudd and Dobson combined the polarizing AL arrest and reperfusion strategy to cold preservation of the heart.
Rewarming the donor rat heart after 6 or $8 \mathrm{~h}$ cold static storage for 5 min with a normokalemic, oxygenated, polarizing AL arrest solution resulted in significantly higher aortic flow, coronary flow, and cardiac output compared with controls and other FDA-approved solutions (Rudd and Dobson, 2011a,b). Interestingly, rewarming cold hyperkalemic Celsior hearts with polarizing AL solution reduced stunning compared with the hyperkalemic "hot shot" (Rudd and Dobson, 2011a). With this strategy Rudd and Dobson added a fifth new approach to minimize myocardial damage $d u r$ ing rewarming and implantation of donor hearts, and possibly other organs. These five strategies are (1) temperature control, (2) hemodynamic control (unloaded nonworking mode), (3) pressure control, (4) reperfusate control, and (5) membrane voltage control using normokalemic, polarizing strategies (Rudd and Dobson, 2011a).

\section{ALMTM CARDIOPLEGIA: FROM CONCEPT TO CLINICAL TRIALS THE VERONA TRIAL: FIRST PROSPECTIVE, RANDOMIZED TRIAL}

The Verona trial was an important trial as it was the first randomized prospective clinical trial using $\mathrm{ALM}^{\mathrm{TM}}$ (with insulin) in microplegia compared to 4:1 Buckberg solution (Onorati et al., 2012). Eighty adult patients were selected from a total of 878 and were emergency cases with unstable angina and required CABG surgery only (not valve). Patients were randomized to receive either standard 4:1 blood ("Buckberg") cardioplegia or all-blood cardioplegia (microplegia) enhanced with ALM and insulin (Onorati et al., 2012). The authors found that ALMinsulin significantly (1) reduced transmyocardial troponin-I and lactate release, (2) improved post-operative cardiac function, (3) increased the incidence of return of spontaneous rhythm at declamping, (4) reduced the use of higher doses of inotropic agents, (5) reduced blood transfusions and use of most blood products, and (6) decreased the length of both ICU and total hospital stay compared to the 4:1 Buckberg blood cardioplegia formulation (Table 1). There was no mortality in either group, and therefore mortality is not the only important end point with impact. The authors note that further multi-center trials are required, and it may be of interest to include a full cost saving analysis since in their study the one full day less in the ICU in the USA would represent a savings of \$4000-10,000 per patient (Rapoport et al., 2003), along with the 50\% reduction in use of blood products with direct and indirect costs ranging between $\$ 522$ and \$1183 per unit of red cells (Shander et al., 2010). From a safety perspective, blood transfusions are not "outcome neutral" and may negatively impact on patient recovery in the ICU (Gong et al., 2005).

\section{ALM $^{\text {TM }}$ PROTECTION IN A 4x REDO PATIENT REQUIRING $7 \mathrm{~h}$ CARDIOPLEGIC ARREST}

ALM cardioplegia was used in a high risk case at Intermountain Medical Center, Salt Lake City (O'Rullian et al., 2008). The patient was a 71 year-old four-time redo male who was diagnosed with prosthetic valve endocarditis of both aortic and mitral valves, and subsequently required a re-operative aortic and mitral valve replacement. The patient was placed CPB and the heart was arrested within $15 \mathrm{~s}$ using normothermic all-blood AL 
Table 1 | Prospective Randomized Human trial data comparing Microplegia ALM(I) with 4:1 Buckberg Solution.

\begin{tabular}{|c|c|c|c|c|}
\hline & ALM(I) Microplegia $(n=40)$ & Buckberg (4:1) $(n=40)$ & $P$-level & Significance \\
\hline $\begin{array}{l}\text { - Troponin (during operation, } 6 \text {, } \\
12 \text {, and } 48 \mathrm{~h}\end{array}$ & $0.5-2.5$ & $1.25-7.0$ & 0.001 & $\checkmark$ \\
\hline - Lactate (same as above) & $0.7-1.5$ & $1.5-2.5$ & 0.0001 & $\checkmark$ \\
\hline \multicolumn{5}{|l|}{ CARDIAC PERFORMANCE } \\
\hline $\begin{array}{l}\text { - Cardiac Index (cardiac } \\
\text { output } / \mathrm{m}^{2} \text { ) }\end{array}$ & 3.9 & 2.75 & 0.0001 & $\checkmark$ \\
\hline $\begin{array}{l}\text { - Diastolic Function (E-wave, } \\
\text { E/A, and Ea at TD) }\end{array}$ & $\downarrow E$-wave $\downarrow$ Ea velocity $\uparrow E ， \uparrow E / A a n d ~ \uparrow E a$ & Lower Diastolic Function & $<0.05$ & $\checkmark$ \\
\hline - Balloon support (IABP)(\%) & 5 & 10 & 0.675 & NS \\
\hline - Use of Inotropes (\%) & $57 \%$ & $85 \%$ & & $\checkmark$ \\
\hline - Length of time inotropes (h) & 31 & 51 & 0.041 & $\checkmark$ \\
\hline \multicolumn{5}{|l|}{ BLOOD TRANSFUSION } \\
\hline - \% patients needing blood (pts) & 25 & 58 & 0.001 & $\checkmark$ \\
\hline - Red Packed cells (U/pt) & 0.3 & 1.3 & 0.001 & $\checkmark$ \\
\hline - Fresh Frozen plasma & 0.2 & 1.3 & 0.001 & $\checkmark$ \\
\hline - Platelets (Units/pt) & 0.02 & 1.3 & 0.149 & NS \\
\hline \multicolumn{5}{|l|}{ ICU AND HOSPITAL STAY } \\
\hline - ICU (H) & 48 & 73 & 0.015 & $\checkmark$ \\
\hline - Total hospital (days) & 7.4 & 9.4 & 0.002 & $\checkmark$ \\
\hline
\end{tabular}

Data are post-operative with significance level on RHS column (Onorati et al., 2012). The Italian authors confusingly refer to trend when talking about significant differences $(P<0.05)$. Actual $p$-values are included above. ALM(I) is adenosine, lidocaine and $\mathrm{Mg}^{2+}$, and Insulin.

microplegia (AL with $25 \mathrm{mEq} / \mathrm{L} \mathrm{KCl,} 16 \mathrm{mM}$ MgSO4). Arrest was maintained with $7^{\circ} \mathrm{C}$ near-continuous retrograde $\mathrm{AL}$ microplegia using $0-2 \mathrm{mEq} / \mathrm{L}$ added potassium. After four cross-clamp periods from bleeding and valve seating complications, the heart was reanimated with a normokalemic blood "hot-shot" comprised of two liters of $\mathrm{AL}$ with magnesium but without $\mathrm{KCl}$. Ultimately, hemostasis was achieved and the patient was weaned from $\mathrm{CPB}$ without requiring an intra-aortic balloon pump, on a standard regimen of inotropic agents, and was extubated after $12 \mathrm{~h}$. The patient was on CBP for $9 \mathrm{~h}$ and $50 \mathrm{~min}$, with a total cross-clamp time of $7 \mathrm{~h}$. The heart was perfused with a total of 72 liters all-blood AL microplegia. However, the total crystalloid volume used for the additives and potassium was $250 \mathrm{ml}$. Postoperatively, there was no systemic hyperkalemia $(5.1 \mathrm{mmol} / \mathrm{L})$ no hemodilution (hematocrit 24\%), and no remarkable edema. This single case report shows how using $\mathrm{AL}$ at physiological potassium levels may find utility in very high-risk patients with prolonged bypass and cardioplegia volumes. Curiously, adenosine is known to have a short-half life in blood in vitro (reported to range from 4 to 10 seconds), however, this does not appear to limits AL's ability to arrest or protect the heart in the pediatric or high-risk case study indicating protection in animal and human studies may come from continuous activation of the adenosine receptors together with voltage-dependent $\mathrm{Na}+$ fast channel modulation.

\section{SAFETY OF AL CRYSTALLOID CARDIOPLEGIA FOR PEDIATRIC CARDIAC SURGERY}

Cardioprotection during pediatric surgery represents a major unmet need. Jin and colleagues (Jin et al., 2008) conducted a prospective, single-center, randomized clinical trial involving 134 pediatric patients with low-risk congenital heart disease. On the day of surgery, surgeons and intensive care physicians were blinded to three crystalloid cardioplegic formulations; high potassium group $\left(\mathrm{K}^{+}, 20 \mathrm{mM}\right)$, high potassium $\mathrm{AL}$ group $(20 \mathrm{mM}$ $\mathrm{K}^{+}, 0.7 \mathrm{mM} \mathrm{A}, 0.7 \mathrm{mM} \mathrm{L}$ ) and moderate potassium AL group $\left(10 \mathrm{mM} \mathrm{K}^{+}, 0.7 \mathrm{mM} \mathrm{A}, 0.7 \mathrm{mM} \mathrm{L}\right)$. Around $80 \%$ of patients had ventricular septal defects (VSD) and $60 \%$ had concomitant pulmonary hypertension. There were no significant differences among the three groups in defect types, age, sex or body weight or hemodynamics before CPB. The arrest protocol comprised a single hypothermic (ice-cold) antegrade infusion of $20 \mathrm{ml} \mathrm{kg}-1$ crystalloid cardioplegia administered over a $2 \mathrm{~min}$ period $(100 \mathrm{ml}$ per min for a total volume of $\sim 200 \mathrm{ml}$ ). The cardioplegia was aspirated by means of vigorous suction at the coronary sinus to prevent distribution into the systemic circulation. 
There were no significant group differences in time to arrest, cross-clamp time, cardiopulmonary bypass (CPB) time, perioperative hematocrit, fluid output at the end of the operation, mechanical ventilation time, total mediastinal drainage, ICU time ( 2.5 days) and post-operative hospital time (11-13 days). However, there was a trend toward higher number days spent in hospital and high potassium in the cardioplegia. The total postoperative hospital time for the high $\mathrm{K}^{+}$group was $12.7 \pm 1.2$ days, followed by high $\mathrm{K}^{+}(\mathrm{AL})(11.8 \pm 0.6$ days $)$ and the lowest was in the moderate $10 \mathrm{mM} \mathrm{K}^{+}(\mathrm{AL})$ group ( $11.1 \pm 1.4$ days) (Jin et al., 2008). Furthermore, there were significantly higher systolic and pulse pressures following $\mathrm{CPB}$ in the $10 \mathrm{mM} \mathrm{K}^{+}(\mathrm{AL})$ group compared with the non-AL $20 \mathrm{mM} \mathrm{K}^{+}$group, and again after modified ultrafiltration. Similarly, serum Troponin I levels were significantly lower in the moderate $10 \mathrm{mM} \mathrm{K}^{+}(\mathrm{AL})$ group compared to both the non-AL $20 \mathrm{mM} \mathrm{K}^{+}$group and High $\mathrm{K}^{+}(\mathrm{AL})$ group in the first $12 \mathrm{~h}$ following cross-clamp removal. The $10 \mathrm{mM}$ $\mathrm{K}^{+}(\mathrm{AL})$ group had serum troponin levels that were 37, 48, 63, and 62 of the values measured in the non-AL $\mathrm{K}^{+}$group at 1, 3, 6, and $12 \mathrm{~h}$ respectively. Jin et al., also reported a $30 \%$ lower use of post-operative inotropes in the $10 \mathrm{mM} \mathrm{K}^{+}(\mathrm{AL})$ group compared to non-AL $20 \mathrm{mM} \mathrm{K}^{+}$group (Jin et al., 2008). Unfortunately, Jin et al. (2008) did not test AL with physiological potassium concentrations $\left(\sim 5 \mathrm{mM} \mathrm{K}^{+}\right)$. The authors concluded that $\mathrm{AL}$ in hyperkalemic and moderately hyperkalemic crystalloid cardioplegia was safe and effective, and that $10 \mathrm{mM} \mathrm{K}^{+}(\mathrm{AL})$ cardioplegia formulation was associated with improved protective effects in pediatric patients.

\section{BEYOND CARDIOPLEGIA: ALM TM AS A BIOLOGICAL RESPONSE MODIFIER IN TRAUMA, INFLAMMATION, COAGULOPATHY, AND SEPSIS}

Since the heart returns such vigorous activity with less need for cardioversion and inotropic support following heart surgery, at James Cook University we began to investigate the ability of non-arresting concentrations of ALM to rescue and stabilize the heart following severe blood loss and shock. The key point is that ALM at high concentrations "arrests" the heart, and at lower concentrations resuscitates the heart. In our first hemorrhagic shock study, we confirmed that colloids $6 \%$ and $10 \%$ hetastarch or $6 \%$ dextran were problematic on cardiac stability, hemodynamics and all led to increased mortality in the rat model (Letson and Dobson, 2011a,b). In a second study, we showed that $\sim 1 \mathrm{ml} / \mathrm{kg}$ bolus ( $\sim 8$ drops per $300 \mathrm{~g}$ rat) of $7.5 \%$ $\mathrm{NaCl} / \mathrm{ALM}$ (without colloids) solved this problem by rescuing the heart and resuscitating MAP into a hypotensive range (Letson and Dobson, 2011a,b), and further it fully corrected acute traumatic hypocoagulopathy (Letson et al., 2012b). In a third study, we reported an unexpected 100\% survival in the 7.5\% $\mathrm{NaCl}$ ALM group after $60 \%$ blood loss with higher MAP and few or no arrhythmias compared with $7.5 \% \mathrm{NaCl}$ alone, or any other treatment groups (Letson and Dobson, 2011c). ALM also has the advantage of displaying potent anti-inflammatory properties by reducing the priming and activation of neutrophils (Shi et al., 2012).

In 2012, Letson and colleagues successfully translated ALM TM resuscitation from rat into the pig model of $75 \%$ blood loss
(Letson et al., 2012a). Small volume $4 \mathrm{ml} / \mathrm{kg} 7.5 \% \mathrm{NaCl}$ ALM resuscitated MAP into the hypotensive region with a 2 -fold increase in stroke volume, a $34 \%$ fall in blood lactate and a $43 \%$ higher $\mathrm{O}_{2}$ delivery. After the shed blood $(\sim 2 \mathrm{~L})$ was returned whole body $\mathrm{O}_{2}$ consumption fell, systemic vascular resistance increased $30 \%$, and urine output in the ALM group increased threefold compared with $7.5 \% \mathrm{NaCl}$ treatment (Letson et al., 2012a). Importantly, small volume $7.5 \% \mathrm{NaCl}$ (vehicle control) was not optimal in rat or pig, which is consistent with the recent randomized, multi-center trial that reported no significant benefit of $250 \mathrm{ml} \mathrm{7.5 \%} \mathrm{NaCl}$, or 7.5\% NaCl 6\% Dextran-70 compared to normal saline for early resuscitation of hemorrhagic shock (Bulger, 2011). The cardiac rescue potential of small volume $7.5 \% \mathrm{NaCl}$ ALM was further demonstrated by Grandfeldt and colleagues who showed that a $20 \mathrm{ml}$ bolus of $7.5 \% \mathrm{NaCl}$ ALM $(0.5 \mathrm{ml} / \mathrm{kg})$ significantly reduced fluid requirement by $40 \%$ to reach a target MAP of $50 \mathrm{mmHg}$ in pig model following 75\% blood loss (Granfeldt et al., 2012), and a $10 \mathrm{ml}$ bolus injection of $0.9 \% \mathrm{NaCl} \mathrm{AL} \mathrm{(no} \mathrm{Mg}^{2+}$ ) with return of shed blood led to a significant $27 \%$ drop in whole body $\mathrm{O}_{2}$ consumption and improved cardiac and renal function (Granfeldt et al., 2012). Lastly, pilot rat and sepsis studies show that an IV infusion of ALM тм improves cardiac function, reduces neutrophil activation and TnF alpha, and reduces whole body $\mathrm{O}_{2}$ consumption. Further work is required to test if these strategies are safe and efficacious in the preshospital civilian environment or on the battlefield where few saline based or colloidbased resuscitation fluids drugs currently work (Blackbourne et al., 2010). However, since cardiac surgery involves trauma, inflammation, and coagulopathy, it is possible that the ALM тм polarized concept may be therapeutic and provide whole body protection for the patient as was indicated from aspects of the Verona trial. A future goal will be to examine the effect of ALM тм infusion to protect the brain during circulatory arrest for aortic reconstruction surgery in pediatrics and adults.

\section{CONCLUDING REMARKS}

Despite groundbreaking advances in global health care, cardiac surgeons, anesthetists and perfusionists are confronted with a new older and sicker patient with an increasing risk profile. The new patient may require complex redo surgery or other emergency procedures from failed angioplasties, cardiogenic shock, or congenital defects. Depolarizing potassium cardioplegia may not provide optimal perioperative protection for today's adult or pediatric patient. New innovations are required and the ALM ${ }^{\text {тм }}$ concept with other additions may offer a new normokalemic polarizing strategy for heart and whole body protection. While the outcomes from early human trials appear promising, further prospective, randomized multi-center clinical trials are required.

\section{ACKNOWLEDGMENTS}

The authors would like to thank the National Health and Medical Research grant 540409 (Geoffrey P. Dobson) for financial support for part of this study. The authors take full responsibility for all aspects of the reliability and freedom from bias of the data presented and their discussed interpretations. 


\section{REFERENCES}

Abramov, D., Tamariz, M. G., Fremes, S. E., Guru, V., Borger, M. A., Christakis, G. T., et al. (2000). Trends in coronary artery bypass surgery results: a recent, 9-year study. Ann. Thorac. Surg. 70, 84-90. doi: $10.1016 /$ S0003-4975(00) 01249-2

Ahlsson, A., Sobrosa, C., Kaijser, L., Jansson, E., and Bomfim, V. (2012). Adenosine in cold blood cardioplegia - a placebo-controlled study. Interact. Cardiovasc. Thorac. Surg. 14, 48-55. doi: 10.1093/icvts/ivr027

Al-Badry, K. S., and Taha, H. M. (1983). Hibernation-hypothermia and metabolism in hedgehogs. Changes in water and electrolytes. Comp. Biochem. Physiol. A Comp. Physiol. 74, 435-441. doi: 10.1016/0300-9629(83)90627-8

Alexander, J. H., Granger, C. B., Sadowski, Z., Aylward, P. E., White, H. D., Thompson, T. D., et al. (1999). Prophylactic lidocaine use in acute myocardial infarction: incidence and outcomes from two international trials. The GUSTO-I and GUSTO-IIb investigators. Am. Heart J. 137, 799-805. doi: 10.1016/S0002-8703(99)70402-3

Algarni, K. D., Maganti, M., and Yau, T. M. (2011). Predictors of low cardiac output syndrome after isolated coronary artery bypass surgery: trends over 20 years. Ann. Thorac. Surg. 92, 1678-1684. doi: 10.1016/j.athoracsur.2011.06.017

Allen, B. S. (2004). Pediatric myocardial protection: where do we stand? J. Thorac. Cardiovasc. Surg. 128, 11-13. doi: 10.1016/j.jtcvs.2004. 03.017

Allen, P., and Lillehei, C. W. (1957). Use of induced cardiac arrest in open heart surgery; results in seventy patients. Minn. Med. 40, 672-676.

Almassi, G. H., Schowalter, T., Nicolosi, A. C., Aggarwal, A., Moritz, T. E., Henderson, W. G., et al. (1997). Atrial fibrillation after cardiac surgery: a major morbid event? Ann. Surg. 226, 501-511. doi: 10.1097/00000658-19971000000011

Al-Mehdi, A. B., Shuman, H., and Fisher, A. B. (1997). Oxidant generation with $\mathrm{K}+$ induced depolarisation in the isolated perfused lung. Free Radic. Biol. Med. 23, 47-56. doi: $\quad$ 10.1016/S0891-5849(96) 00574-6

Al-Mehdi, A. B., Zhao, G., Dodia, C., Tozawa, K., Costa, K., Muzykantov, V., et al. (1998). Endothelial NADPH oxidase as the source of oxidants in lungs exposed to ischemia or high K+. Circ. Res. 83, 730-737. doi: 10.1161/01.RES.83.7.730

Amark, K., Berggren, H., Bjork, K. Ekroth, A., Ekroth, R., Nilsson, K., et al. (2005). Blood cardioplegia provides superior protection in infant cardiac surgery. Ann Thorac. Surg. 80, 989-994. doi: 10.1016/j.athoracsur.2005.03.095

Ambrosio, G., and Tritto, I. (2001). Clinical manifestations of myocar dial stunning. Coron. Artery Dis. 12, 357-361. doi: 10.1097/00019501200108000-00004

Amir, R., Argoff, C. E., Bennett, G. J., Cummins, T. R., Durieux, M. E., Gerner, P., et al. (2006). The role of sodium channels in chronic inflammatory and neuropathic pain. J. Pain 7, S1-S29. doi: 10.1016/j.jpain.2006.01.444

Anselmi, A., Abbate, A., Girola, F., Nasso, G., Biondi-Zoccai, G. G. Possati, G., et al. (2004). Myocardial ischemia, stunning, inflammation, and apoptosis during cardiac surgery: a review of evidence. Eur. J. Cardiothorac. Surg. 25, 304-311. doi: 10.1016/j.ejcts.2003.12.003

Anselmi, A., Possati, G., and Gaudino, M. (2009). Postoperative inflammatory reaction and atrial fibrillation: simple correlation or causation? Ann. Thorac. Surg. 88, 326-333. doi: 10.1016/j.athoracsur.2009.01.031

Aoki, M., Nomura, F., and Mayer, J. E. J. (1994). Interactions between preischemic hypothermia and cardioplegic solutions in the neonatal lamb heart. J. Thorac. Cardiovasc. Surg. 107, 822-828.

Aranki, S. F., Shaw, D. P., Adams, D. H., Rizzo, R. J., Couper, G. S., VanderVliet, M., et al. (1996). Predictors of atrial fibrillation after coronary artery surgery. Current trends and impact on hospital resources. Circulation 94, 390-397. doi: 10.1161/01.CIR.94.3.390

Aronson, S. (1999). Cardioplegia delivery: more (or less) than what you see. Ann. Thorac. Surg. 68, 797-798.

Avkiran, M. (2001). Protection of the ischaemic myocardium by $\mathrm{Na}+/ \mathrm{H}+$ exchange inhibitors: potential mechanisms of action. Basic Res. Cardiol. 96, 306-311. doi: 10.1007/s003950170037

Azakie, A., and Russell, I. A. (2004) Gender differences in pediatric cardiac surgery: the surgeon's perspective. J. Thorac. Cardiovasc. Surg. 128, 4-6. doi: 10.1016/j.jtcvs.2004.04.002

Baczko, I., Giles, W. R., and Light, P. E. (2003). Resting membrane potential regulates $\mathrm{Na}(+)-\mathrm{Ca} 2+$ exchange-mediated $\mathrm{Ca} 2+$ overload during hypoxia-reoxygenation in rat ventricular myocytes J. Physiol. 550(Pt 3), 889-898. doi: 10.1113/jphysiol.2003.043372

Baraka, A., Hirt, N., Dabbous, A., Taha, S., Rouhana, C., Khoury, N., et al (1993). Lidocaine cardioplegia for prevention of reperfusion ventricular fibrillation. Ann. Thorac. Surg. 55, 1529-1533. doi: 10.1016/00034975(93)91104-U

Becker, E. R., and Rahimi, A. (2006). Disparities in race/ethnicity and gender in in-hospital mortality rates for coronary artery bypass surgery patients. J. Natl. Med. Assoc. 98, 1729-1739.

Belardinelli, L., and Giles, W. R. (1988). Ionic mechanisms of adenosine action in pacemaker cells from rabbit heart. J. Physiol. (Lond.) 405, 615-633.

Belardinelli, L., Shryock, J. C., Song, Y., Wang, D., and Srinivas, M (1995). Ionic basis of the electrophysiological actions of adenosine on cardiomyocytes. FASEB J. 9 , 359-365.

Benkwitz, C., Garrison, J. C., Linden, J., Durieux, M. E., and Hollmann, M. W. (2003). Lidocaine enhances Galphai protein function. Anesthesiology. 99, 1093-1101. doi: 10.1097/00000542-20031100000015

Berne, R. M. (1963). Cardiac nucleotides in hypoxia:possible role in regulation of coronary blood flow. Am. J. Physiol. 204, 317-322.

Bers, D. M., Barry, W. H., and Despa, S. (2003). Intracellular $\mathrm{Na}+$ regulation in cardiac myocytes. Cardiovasc. Res. 57, 897-912. doi: 10.1016/S0008 6363(02)00656-9

Bers, D. M., and Despa, S. (2006) Cardiac myocytes $\mathrm{Ca} 2+$ and $\mathrm{Na}+$ regulation in normal and failing hearts. I. Pharmacol. Sci. 100, 315-322. doi: 10.1254/jphs. CPJ06001X

Bers, D. M., and Despa, S. (2009). $\mathrm{Na}(+)$ transport in cardiac myocytes; implications for excitation-contraction coupling IUBMB Life 61, 215-221. doi: 10.1002/iub.163

Beyersdorf, F. (2009). The use of controlled reperfusion strategies in cardiac surgery to minimize ischaemia/reperfusion damage. Cardiovasc. Res. 83, 262-268. doi: $10.1093 / \mathrm{cvr} / \mathrm{cvp} 110$

Bigelow, W. G. (1984). Cold Hearts: The Story of Hypothermia and the Pacemaker in Heart Surgery. Toronto, ON: McClelland and Steward.

Bjork, V. O., and Fors, B. (1961). Induced cardiac arrest. J. Thorac Cardiovasc. Surg. 41, 387-394.
Blackbourne, L., Czarnik, J., Mabry, R., Eastridge, B., Baer, D., Butler, F., et al. (2010). Decreasing killed in action and died of wounds rates in combat wounded. editorial. J. Trauma 69, S1-S4. doi: 10.1097/TA.0b013e3181e4206f

Bolli, R., Patel, B. S., Jeoudi, M. O., Lai, E. K., and McCay, P. B. (1988). Demonstration of free radical generation in "stunned" myocardium of intact dogs with the use of the spin trap alpha-phenyl N-tert-butyl nitrone. J. Clin. Invest. 82, 476-485 doi: 10.1172/JCI113621

Bolling, S. F., Tramontini, N. L., Kilgore, K. S., Su, T. P., Oeltgen, P. R., and Harlow, H. H. (1997). Use of "natural" hibernation induction triggers for myocardial protection. Ann. Thorac. Surg. 64, 623-627. doi: 10.1016/S0003-4975(97)00631-0

Booker, P. D. (1998). Myocardial stunning in the neonate. $\mathrm{Br}$. J. Anaesth. 80, 371-383. doi: 10.1093/bja/80.3.371

Borg, T., and Modig, J. (1985) Potential anti-thrombotic effects of local anaesthetics due to their inhibition of platelet aggregation. Acta Anaesthesiol. Scand. 29, 739-742. doi: 10.1111/j.13996576.1985.tb02292.x

Braunwald, E., and Kloner, R. A. (1982). The stunned myocardium: prolonged, postischemic ventricular dysfunction. Circulation 66, 1146-1149. doi: 10.1161/01.CIR.66.6.1146

Brayden, J. E. (1996). Potassium channels in vascular smooth muscle. Clin. Exp. Pharm. Physiol. 23, 1069-1076. doi: 10.1111/j.14401681.1996.tb01172.x

Brazier, J. R., Cooper, N., McConnell, D. H., and Buckberg, G. D. (1977). Studies of the effects of hypothermia on regional myocardial blood flow and metabolism during cardiopulmonary bypass. III. Effects of temperature, time, and perfusion pressure in fibrillating hearts. J. Thorac. Cardiovasc. Surg. 73, 102-109.

Bretschneider, H. J., Huubner, G., and Knoll, D. (1975). Myocardial resistance and tolerance to ischemia: physiological and biochemical basis. J. Cardiovasc. Surg. 16, 241-260.

Broussas, M., Cornillet-Lefebvre, P., Potron, G., and Nguyen, P. (2002). Adenosine inhibits tissue factor expression by LPS-stimulated human monocytes: involvement of A3 adenosine receptor. Thromb. Haemost. 88, 123-130.

Buckberg, G. D. (1993). Myocardial protection: an overview. Semin Thorac. Cardiovasc. Surg. 5, 98-106. 
Bulger, E. M. (2011). 7.5\% Saline and $7.5 \%$ Saline/6\% Dextran for Hypovolemic Shock. J. Trauma 70, S27-S29. doi: 10.1097/TA.0b013e31821a559a

Burgen, A. S. V., and Terroux, K. G. (1953). The membrane resting and action potentials of the cat auricle. J. Physiol. 119, 139-152.

Burlington, R. F., Dean, M. S., and Jones, S. B. (1989). Coronary autogregulation and metabolism in hypothermic rat and ground squirrel hearts. Am. J. Physiol. 256, R357-R365.

Butler, T. L., Egan, J. R., Graf, F. G., Au, C. G., McMahon, A. C., North, K. N., et al. (2009). Dysfunction induced by ischemia versus edema: does edema matter? J. Thorac. Cardiovasc. Surg. 138, 141-147. doi: 10.1016/j.jtcvs.2008.12.008

Butterworth, J., James, R., Prielipp, R., Cerese, J., Livingston, J., and Burnett, D. (2000). Female gender associates with increased duration of intubation and length of stay after coronary artery surgery. CABG Clinical Benchmarking Database Participants. Anesthesiology 92, 414-424. doi: 10.1097/00000542200002000-00023

Buxton, B. F., Hayward, P. A., Newcomb, A. E., Moten, S. Seevanayagam, S., and Gordon, I. (2009). Choice of conduits for coronary artery bypass grafting: craft or science? Eur. J. Cardiothorac. Surg. 35, 658-670. doi: 10.1016/j.ejcts.2008.10.058

Camm, A. J., and Garratt, C. J. (1991). Adenosine and supraventricular tachycardia. N. Engl. J. Med. 325, 1621-1629. doi: 10.1056/NEJM199112053252306

Cannon, R. O. (2005). Mechanisms, management and future directions for reperfusion injury after acute myocardial infarction. Nat. Clin. Pract. Cardiovasc. Med. 2, 88-94. doi: 10.1038/ncpcardio0096

Canyon, S. J., and Dobson, G. P. (2004). Protection against ventricular arrhythmias and cardiac death using adenosine and lidocaine during regional ischemia in the in vivo rat. Am. J. Physiol. Heart Circ. Physiol. 287, H1286-H1295. doi: 10.1152/ajpheart.00273.2004

Canyon, S. J., and Dobson, G. P. (2005). Pretreatment with an Adenosine A1 receptor agonist and Lidocaine: a possible alternative to myocardial preconditioning. J. Thorac. Cardiovasc. Surg. 130, 371-377. doi: 10.1016/j.jtcvs.2004.12.052

Canyon, S. J., and Dobson, G. P. (2006). The effect of adenosine and lidocaine infusion on myocardial high energy phosphates and $\mathrm{pH}$ during regional ischemia in the rat model in vivo. Can. J. Physiol. Pharmacol. 84, 903-912. doi: 10.1139/Y06-035

Carden, D. L., and Granger, D. N. (2000). Pathophysiology of ischaemia \pm reperfusion injury. J. Pathol. 190, 255-266.

Carmeliet, E. (1999). Cardiac ionic channels and acute ischemia: from channels to arrhythmias. Physiol. Rev. 79, 917-1017.

Carpentier, S., Murawsky, M., and Carpentier, A. (1981). Cytotoxicity of cardioplegic solutions: evaluation by tissue culture. Circulation 64, II90-II95.

Cascio, W. E., Johnson, T. A., and Gettes, L. S. (1995). Electrophysiologic changes in ischemic ventricular myocardium: I. Influence of ionic, metabolic, and energetic changes. J. Cardiovasc. Electrophysiol. 6, 1039-1062. doi: 10.1111/j.15408167.1995.tb00381.x

Cassuto, J., Sinclair, R., and Bonderovic, M. (2006). Anti-inflammatory properties of local anesthetics and their present and potential clinical implications. Acta Anaesthesiol. Scand. 50, 265-282. doi: 10.1111/j.1399-6576.2006.00936.x

Casteels, R., Kitamura, K., Kuriyama, H., and Suzuki, H. (1977). The membrane properties of the smooth muscle cells of the rabbit main pulmonary artery. J. Physiol. 27, 41-61.

Chambers, D. J. (2003). Mechanisms and alternative methods of achieving cardiac arrest. Ann. Thorac. Surg. 75, S661-S666. doi: 10.1016/S00034975(02)04688-X

Chambers, D. J., and Fallouh, H. B. (2010). Cardioplegia and cardiac surgery: pharmacological arrest and cardioprotection during global ischemia and reperfusion. Pharmacol. Ther. 127, 41-52. doi: 10.1016/j.pharmthera.2010.04.001

Chambers, D. J., and Hearse, D. J. (1999). Developments in cardioprotection: "polarised" arrest as an alternative to "depolarised" arrest. Ann. Thorac. Surg. 68, 1960-1966. doi: $\quad 10.1016 /$ S0003-4975(99) 01020-6

Chambers, D. J., and Hearse, D. J. (2001). "Cardioplegia and Surgical Ischaemia," in Heart Physiology and Pathophysiology, eds N. Sperelakis, Y. Kurachi, A. Terzic, and M. V. Cohen (San Diego, CA: Academic Press), 887-926. doi: 10.1016/B978012656975-9/50053-5

Chang, P. P., Sussman, M. S., Conte, J. V., Grega, M. A., Schulman, S. P., Gerstenblith, G., et al. (2002). Postoperative ventricular function and cardiac enzymes after on-pump versus off-pump CABG surgery. Am. J. Cardiol. 89, 1107-1110. doi: 10.1016/S0002-9149(02)02293-2

Chen, J., Zimmerman, R. A., Jarvik, G. P., Nord, A. S., Clancy, R. R., Wernovsky, G., et al. (2009) Perioperative stroke in infants undergoing open heart operations for congenital heart disease. Ann Thorac. Surg. 88, 823-829. doi: 10.1016/j.athoracsur.2009.03.030

Chi, L., Uprichard, A. C., and Lucchesi, B. R. (1990). Profibrillatory actions of pinacidil in a conscious canine model of sudden coronary death. J. Cardiovasc. Pharmacol. 15 452-464. doi: 10.1097/00005344199003000-00016

Chiavarelli, M., Toscano, M. Chiavarelli, R., Carpi, A., and Marino, B. (1982). Effects of cardioplegic solutions on conductive coronary arteries. J. Thorac Cardiovasc. Surg. 84, 23-27.

Chong, W. C., Ong, P. J., Hayward, C., Moat, N., and Collins, P. (2001). Effects of storage solutions on in vitro vasoreactivity of radial artery conduits. J. Thorac. Cardiovasc. Surg. 122, 470-475. doi: 10.1067/mtc.2001.115921

Cimponeriu, A., Starmer, C. F., and Bezerianos, A. (2001). A theoretical analysis of acute ischemia and infarction using ECG reconstruction on a 2-D model of Myocardium.I. IEEE Trans. Biomed. Eng. 48, 41-54. doi: 10.1109/10.900247

Cohen, G., Feder-Elituv, R., Lazetta, J., Bunting, P., Mallidi, H., Bozinovski, J., et al. (1998). Phase 2 studies of adenosine cardioplegia. Circulation 98, II225-II233.

Cohen, N. M., Damiano, R. J., and Wechsler, A. S. (1995). Is there an alternative to potassium arrest? Ann. Thorac. Surg. 60, 858-863. doi: 10.1016/0003-4975(95)00210-C

Cohen, N. M., Wise, R. M., Wechsler, A. S., and Damiano, R. J. (1993). Elective cardiac arrest with a hyperpolarising adenosine triphosphatesensitive potassium channel opener: a novel form of myocardial protection? J. Thorac. Cardiovasc. Surg. 106, 317-328.

Coleman, H. A., Tare, M., and Parkington, H. C. (2004) Endothelial potassium channels, endothelium-dependent hyperpolarization and the regulation of vascular tone in health and disease. Clin. Exp. Pharmacol. Physiol. 31, 641-649. doi: 10.1111/j.1440-1681.2004.04053.x

Cooke, E. D., Bowcock, S. A., Lloyd, M. J., and Pilcher, M
F. (1977). Intravenous lignocaine in prevention of deep vein thrombosis after elective hip surgery. Lancet 2, 797-799. doi: 10.1016/S0140-6736(77)90727-9

Cooley, D. A., Reul, G. J. J., and Wukasch, D. C. (1975). Ischemic myocardial contracture ("stone heart"). A complication of cardiac surgery. Isr. J. Med. Sci. 11, 203-210. Coraboeuf, E., Coulombe, A., Deroubaix, E., Hatem, S., and Mercadier, J. J. (1998). Transient outward potassium current and repolarization of cardiac cells. Bull. Acad. Natl. Med. 182, 325-333.

Cordell, A. R. (1995). Milestones in the development of cardioplegia. Ann. Thorac. Surg. 60, 793-796. doi: 10.1016/0003-4975(95)00570-B

Corvera, J. S., Kin, H., Dobson, G. P., Kerendi, F., Halkos, M. E., Katzmark, S., et al. (2005). Polarized arrest with warm or cold adenosine/lidocaine blood cardioplegia is equivalent to hypothermic potassium blood cardioplegia. J. Thorac. Cardiovasc. Surg. 129, 599-606. doi: 10.1016/j.jtcvs.2004.07.021

Costa, M. A., Carere, R. G., Lichtenstein, S. V., Foley, D. P., de Valk, V., Lindenboom, W., et al. (2001). Incidence, predictors, and significance of abnormal cardiac enzyme rise in patients treated with bypass surgery in the arterial revascularization therapies study (ARTS). Circulation 104, 2689-2693. doi: $10.1161 /$ hc4701.099789

Cronstein, B. N., Levin, R. I., Philips, M., Hirschhorn, R., Abramson, S. B., and Weissmann, G. (1992). Neutrophil adherence to endothelium is enhanced via adenosine Al receptors and inhibited via adenosine A2 receptors. J. Immunol. 148, 2201-2206

Curzon, C. L., Milford-Beland, S., Li, J. S., O'Brien, S. M., Jacobs, J. P., Jacobs, M. L., et al. (2008). Cardiac surgery in infants with low birth weight is associated with increased mortality: analysis of the society of thoracic surgeons congenital heart database. J. Thorac. Cardiovasc. Surg. 135, 546-551. doi: 10.1016/j.jtcvs.2007.09.068

Damiano, R. J. J., and Cohen, N. M. (1994). Hyperpolarized arrest attenuates myocardial stunning following global surgical ischemia: an alternative to traditional hyperkalemic cardioplegia? J. Card. Surg. 9, 517-525.

Das, K. C., and Misra, H. P. (1992a). Antiarrhythmic agents. Scavengers of hydroxyl radicals and inhibitors of NADPH-dependent lipid 
peroxidation in bovine lung microsomes. J. Biol. Chem. 267, 19172-19178.

Das, K. C., and Misra, H. P. (1992b). Lidocaine: a hydroxyl and singlet oxygen quencher. Mol. Cell. Biochem. 115, 179-185. doi: 10.1007/BF00230329

David, J. S., Amour, J., Duracher, C., Ferretti, C., Precloux, P., Petit, P., et al. (2007). Comparison of the effects of mepivacaine and lidocaine on rat myocardium. Eur. J. Anaesthesiol. 24, 190-197. doi: 10.1017/S0265021506001359

Davies, L. K. (1999). Cardiopulomonary bypass in infants and children: how is it different? J. Cardiothorac. Vasc. Anesth. 13, 330-345. doi: 10.1016/ S1053-0770(99)90274-4

Deguchi, H., Takeya, H., Urano, H., Gabazza, E. C., Zhou, H., and Suzuki, K. (1998). Adenosine regulates tissue factor expression on endothelial cells. Thromb. Res. 91, 57-64. doi: 10.1016/S0049-3848 (98)00045-0

De Jong, J. W., Van der Meer, P., Van Loon, H., Owen, P., and Opie, L. H. (1990). Adenosine as an adjunct to potassium cardioplegia: effect of function, energy metabolism, and electrophysiology. J. Thorac. Cardiovasc. Surg. 100, 445-454.

De Kalver, M. J. M., Buckingham, M.G., and Rich, G. F. (2003). Lidocaine attenuates cytokine-induced cell injury in endothelial and vascular smooth muscle cells. Anesth. Analg. 97, 465-470. doi: 10.1213/ 01.ANE.0000073162.27208.E9

Delaney, J. W., Moltedo, J. M., Dziura, J. D., Kopf, G. S., and Snyder, C. S. (2006). Early postoperative arrhythmias after pediatric cardiac surgery. J. Thorac. Cardiovasc. Surg. 131, 1296-1301. doi: 10.1016/j.jtcvs.2006.02.010

de Mello, W., and Hoffman, B. F. (1960). Potassium ions and electrical activity of specialized cardiac fibers. Am. J. Physiol. 199, 1125-1130.

Dick, G. M., and Tune, J. D. (2010). Role of potassium channels in coronary vasodilation. Exp. Biol. Med. 235, 10-22. doi: 10.1258/ebm.2009.009201

Diodato, M. D. J., Shah, N. R., Prasad, S. M., Racen, E. L., Mizutani, S., Lawton, J. S., et al. (2005). Progress towards a more physiologic approach to donor heart preservation: the advantages of hyperpolarized arrest. J. Heart Lung Transplant. 24, 1362-1368. doi: 10.1016/j.healun.2004.10.011
Dobson, G. P. (2004). Organ arrest, protection and preservation: natural hibernation to cardiac surgery: a review. Comp. Biochem. Physiol. B Biochem. Mol. Biol. 139, 469-485. doi: 10.1016/j.cbpc.2004.06.002

Dobson, G. P. (2005). A Chaos of Delight: Science, Religion and Myth and the Shaping of Western Thought. Oakville, CT: David Brown and Co

Dobson, G. P. (2010). Membrane polarity: a target for myocardial protection and reduced inflammation in adult and pediatric cardiothoracic surgery (editorial - free standing). J. Thorac. Cardiovasc. Surg. 140, 1213-1217. doi: 10.1016/j.jtcvs.2010.05.040

Dobson, G. P., and Jones, M. W. (2004). Adenosine and Lignocaine: a new concept in non-depolarising surgical arrest, protection and preservation. J. Thorac. Cardiovasc. Surg. 127, 794-805. doi: 10.1016/S00225223(03)01192-9

Domanski, M. J., Mahaffey, K., Hasselblad, V., Brener, S. J., Smith, P. K., Hillis, G., et al. (2011). Association of myocardial enzyme elevation and survival following coronary artery bypass graft surgery. JAMA 305, 585-591. doi: 10.1001/jama.2011.99

Dorman, B. H., New, R. B., Bond, B. R., Mukherjee, R., Mukhin, Y. V., McElmurray, J. H., et al. (2000). Myocyte endothelin exposure during cardioplegic arrest exacerbates contractile dysfunction after reperfusion. Anesth. Analg. 90, 1080-1085. doi: 10.1097/00000539200005000-00014

Doughtie, C., Williams, M., Trivedi, J., and Slaughter, M. (2010). Is female gender an independent risk factor for peri-operative RBC transfusion in coronary artery bypass graft surgery? J. Am. Coll. Surg. 211, S31. doi: 10.1016/j.jamcollsurg.2010.06.075

Downey, J. M., Liu, G. S., and Thornton, J. D. (1993). Adenosine and the anti-infarct effects of preconditioning. Cardiovasc. Res. 27, 3-8. doi: 10.1093/cvr/27.1.3

Draper, M. H., and Weidmann, S. (1951). Cardiac resting and action potentials recorded with an intracellular electrode. J. Physiol. 115, 74-94.

Drury, A. N., and Szent-Gyorgyi, A. (1929). The physiological activity oif adenine compounds with especial reference to their action upon the mammalian heart. J. Physiol. (Lond.) 68, 213-237.

Eberhardt, E., Mehlhorn, U., Larose, K., De Vivie, E. R., and Dhein, S. (2000). Structural myocardial changes after coronary aftery surgery. Eur. J. Clin. Invest. 30, 938-946.

Ebert, P. A., Greenfield, L. G., Austen, W. G., and Morrow, A. G. (1962) Experimental comparison of methods for protecting the heart during aortic occlusion. Ann. Surg. 155, 25-37. doi: 10.1097/00000658196201000-00003

Echahidi, N., Pibarot, P., O'Hara, G., and Mathieu, P. (2008) Mechanisms, prevention, and treatment of atrial fibrillation after cardiac surgery. J. Am. Coll. Cardiol. 51, 793-801. doi: 10.1016/j.jacc.2007.10.043

Ede, M., Ye, J., Gregorash, L., Summers, R., Pargaonkar, S., LeHouerou, D., et al. (1997). Beyond hyperkalemia:betablockers-induced cardiac arrest for normothermic cardiac operations. Ann. Thorac. Surg. 63, 721-727. doi: 10.1016/S0003-4975(96)01114-9

Edwards, F. H., Carey, J. S., Grover, F. L., Bero, J. W., and Hartz, R. S. (1998). Impact of gender on coronary bypass operative mortality. Ann. Thorac. Surg. 66, 125-131. doi: 10.1016/S0003-4975 (98)00358-0

Edwards, F. H., Ferraris, V. A., Shahian, D. M., Peterson, E., Furnary, A P., Haan, C. K., et al. (2005). Gender-specific practice guidelines for coronary artery bypass surgery: perioperative management. Ann Thorac. Surg. 79, 2189-2194. doi: 10.1016/j.athoracsur.2005.02.065

Effler, D. B., Groves, L. K., Sones, F. M. J., and Kolff, W. J. (1956). Elective cardiac arrest in openheart surgery; report of three cases. Cleve. Clin. Q. 23, 105-114. doi: 10.3949/ccjm.23.2.105

Ellis, R. J., Mavroudis, C., Gardner, C., Turley, K., Ullyot, D., and Ebert, P. A. (1980). Relationship between atrioventricular arrhythmias and the concentration of $\mathrm{K}+$ ion in cardioplegic solution. J. Thorac. Cardiovasc. Surg. 80, 517-526.

Ely, S. W., and Berne, R. M. (1992). Protective effects of adenosine in myocardial ischaemia. Circulation 85, 893-904. doi 10.1161/01.CIR.85.3.893

Ettinger, P. O., Regan, T. S., and Olderwurtel, H. A. (1974). Hyperkalemia, cardiac conduction, and the electrocardiogram: overview. Am. Heart J. 88, 360-371. doi: 10.1016/0002-8703(74)90473-6

Evans, P. A., Heptinstall, S., Crowhurst, E. C., Davies, T., Glenn, J. R., Madira, W., et al. (2003). Prospective double-blind randomnized study of the effects of four intravenous fluids on platelet function and hemostasis in elective hip surgery. J. Thromb. Haemost. 1, 2140-2148. doi: 10.1046/j.15387836.2003.00411.x

Feng, J., Liu, Y., Clements, R. T., Sodha, N. R., Khabbaz, K. R., Senthilnathan, V., et al. (2008). Calcium-activated potassium channels contribute to human coronary microvascular dysfunction after cardioplegic arrest. Circulation 118, S46-S51. doi: 10.1161/ CIRCULATIONAHA.107.755827

Feng, J., Liu, Y., Khabbaz, K. R., Hagberg, R., Sodha, N. R., Osipov, R. M., et al. (2010). Endothelin-1-induced contractile responses of human coronary arterioles via endothelin-A receptors and PKC-a signaling pathways. Surgery 147, 798-804. doi: 10.1016/j.surg.2009.11.016

Ferguson, E. R., Spruell, R. D., Vicente, W. V. A., Murrah, C. P., and Holman, W. L. (1996). Coronary vascular regulation during post-cardioplegia reperfusion. J. Thorac. Cardiovasc. Surg. 112, 1054-1063. doi: 10.1016/S00225223(96)70107-1

Ferguson, T. B. J., Smith, P. K., Lofland, G. K., Holman, W. L., Helms, M. A., and Cox, J. L. (1986). The effects of cardioplegic potassium concentration and myocardial temperature on electrical activity in the heart during elective cardioplegic arrest. J. Thorac. Cardiovasc. Surg. 92, 755-765.

Fisch, C. (1973). Relation of electrolyte disturbances to cardiac arrhythmias. Circulation 47, 408-419. doi: 10.1161/01.CIR.47.2.408

Flack, J. E. 3rd., Cook, J. R., May, S. J., Lemeshow, S., Engelman, R. M., Rousou, J. A., et al. (2000). Does cardioplegia type affect outcome and survival in patients with advanced left ventricular dysfunction.? Results from CABG Patch Trial. Circulation 102 84-89. doi: 10.1161/01.CIR.102. suppl_3.III-84

Flack, J. E. 3rd., Hafer, J., Engelman, R. M., Rousou, J. A., Deaton, D. W., and Pekow, P. (1992). Effect of normothermic blood cardioplegia on postoperative conduction abnormalities and supraventricular arrhythmias. Circulation 86, II385-II392.

Furchgott, R. F., and Zawadski, J. V. (1980). The obligatory role of endothelial cells in the relaxation of arterial smooth muscle by acetylcholine. Nature 228, 373-376. doi: $10.1038 / 288373 \mathrm{a} 0$ 
Gaillard, D., Bical, O., Paumier, D., and Trivin, F. (2000). A review of myocardial normothermia: its theoretical basis and the potential clinial benefits in cardiac surgery. Cardiovasc. Surg. 8, 198-203. doi: 10.1016/S0967-2109(00)00008-9

Gay, W. A., and Ebert, P. A. (1973). Functional, metabolic, and morphological effects of potassium induced cardioplegia. Surgery 74, 284-290.

Geissler, H. J. (2002). Reduction of myocardial reperfusion injury by high-dose betablockade with esmolol. Thorac. Cardiovasc. Surg. 50, 367-372. doi: 10.1055/s-2002-35730

Gelband, H., Bush, H. L., Rosen, M. R., Myerburg, R. J., and Hoffman, B. F. (1972). Electrophysiologic properties of isolated preparations of human atrial myocardium. Circ. Res. 30, 293-300. doi: 10.1161/01.RES.30.3.293

Gerbode, F., and Melrose, D. G. (1958). The use of potassium arrest in open cardiac surgery. Am. J. Surg. 96, 221-227. doi: 10.1016/00029610(58)90906-1

Gessler, P., Schmitt, B., Prètre, R., and Latal, B. (2009). Inflammatory response and neurodevelopmental outcome after open-heart surgery in children. Pediatr. Cardiol. 30, 301-305. doi: 10.1007/s00246-0089354-5

Gettes, L. S. (1976). Possible role of ionic changes in the appearance of arrhythmias. Pharm. Ther. $B$ 2, 787-810. doi: 10.1016/0306039X(76)90079-9

Gettes, L. S., Hill, J. L., Saito, T., and Kagiyama, Y. (1982). Factors related to vulnerability to arrhythmias in acute myocardial infarction. Am. Heart J. 103, 667-672. doi: 10.1016/0002-8703(82)90472-0

Gillies, M., Bellomo, R., Doolan, L., and Buxton, B. (2005). Benchto-bedside review: ionotropic drug therapy after adult cardiac surgery: a systematic literature review. Crit. Care 9, 266-279. doi: 10.1186/cc3024

Golab, H. D., Scohy, T. V., de Jong, P. L., Kissler, J., Takkenberg, J. J., and Bogers, A. J. (2011). Relevance of colloid oncotic pressure regulation during neonatal and infant cardiopulmonary bypass: a prospective randomized study. Eur. J. Cardiothorac. Surg. 39, 886-891. doi: 10.1016/j.ejcts.2010.09.040

Goldman, S., Zadina, K., Moritz, T., Ovitt, T., Sethi, G., Copeland, J. G., et al. (2004). Long-term patency of saphenous vein and left internal mammary artery grafts after coronary artery bypass surgery. J. Am. Coll. Cardiol. 44, 2149-2156. doi: 10.1016/j.jacc.2004.08.064

Goldstein, I. M., Lind, S., Hoffstein, S., and Weissman, G. (1977). Infuence of local anaesthetics upon human polymorphonuclear leucocyte function in vitro. J. Exp. Med. 146, 483-494. doi: 10.1084/jem.146.2.483

Gong, M. N., Thompson, B. T., Williams, P., Pothie, L., Boyce, P. D., and Christiani, D. C. (2005). Clinical predictors of and mortality in acute respiratory distress syndrome: potential role of red cell transfusion. Crit. Care Med. 33, 1191-1198. doi: 10.1097/ 01.CCM.0000165566.82925.14

Goodney, P. P., O'Connor, G. T., Wennberg, D. E., and Birkmeyer, J. D. (2003). Do hospitals with low mortality rates in coronary artery bypass also perform well in valve replacement? Ann. Thorac. Surg. 76, 1131-1136. doi: 10.1016/S00034975(03)00827-0

Granfeldt, A., Nielsen, T. K., Solling, C., Hyldebrandt, J. A., Frøkiær, J., Wogensen, L., et al. (2012). Adenocaine and $\mathrm{Mg}^{2+}$ reduces fluid requirement to maintain hypotensive resuscitation and improves cardiac and renal function in a porcine model of severe hemorrhagic shock. Crit. Care Med. 40, 3013-3025. doi: 10.1097/CCM.0b013e31825fd4ed

Halkos, M. E., Kerendi, F., Corvera, J. S., Wang, N. P., Kin, H., Payne, C. S., et al. (2004). Myocardial protection with postconditioning is not enhanced by ischemic preconditioning. Ann. Thorac. Surg. 78, 961-969. doi: 10.1016/j.athoracsur.2004.03.033

Han, J. G., Yang, Q., Yao, X. Q., Kwan, Y. W., Shen, B., and He, G. W. (2009). Role of large-conductance calcium-activated potassium channels of coronary arteries in heart preservation. J. Heart Lung Transplant. 28, 1094-1101. doi: 10.1016/j.healun.2009.06.011

Hannan, E. L., Racz, M., Culliford, A. T., Lahey, S. J., Wechsler, A., Jordan, D., et al. (2013). Risk Score for predicting in-hospital/30-day mortality for patients undergoing valve and valve/coronary artery bypass graft surgery. Ann. Thorac. Surg. 95, 1282-1290. doi: 10.1016/j.athoracsur.2012. 11.019

Harris, A. S., Bisteni, A., Russel, R. A., Brigham, J. C., and Firestone, J. E. (1954). Excitatory factors in ventricular tachycardia resulting from myocardial ischemia: potassium a major excitant. Science 199,
200-203. doi: 10.1126/science.119. 3085.200

Hasko, G., and Cronstein, B. N. (2004). Adenosine: an endogenous regulator of innate immunity. Trends Immunol. 25, 33-39. doi: 10.1016/j.it.2003.11.003

Hasko, G., Linden, J., Cronstein, B., and Pacher, P. (2008). Adenosine receptors: therapeutic aspect for inflammatory and immune diseases. Nat. Rev. Drug Discov. 7, 759-770. doi: 10.1038/nrd2638

Hayash, I. T., Sakurai, Y., Fukuda, K., Yada, K., Ogiwara, K., Matsumoto, T., et al. (2011). Correlations between global clotting function tests, duration of operation, and postoperative chest tube drainage in pediatric cardiac surgery. Paediatr. Anaesth. 21, 865-871. doi: 10.1111/j.1460-9592. 2011.03524.x

He, G. W. (2005). Endothelial function related to vascular tone in cardiac surgery. Heart Lung Circ. 14, 13-18. doi: 10.1016/j.hlc.2004.11.003

Hearse, D. J., Braimbridge, M. V., and Jynge, P. (1981). "Principles of Cardioplegia," in Protection of the Ischaemic Myocardium Cardioplegia, eds D. J. Hearse, M V. Braimbridge, and P. Jynge (New York, NY: Raven Press), 151-326.

Hearse, D. J., and Stewart, D. A. (1974). Functional recovery of the myocardium after elective cardiac arrest in the isolated rat heart. Lancet 9, 192-194. doi: 10.1016/S0140-6736(74)92495-7

Helmsworth, J. A., Kaplan, A., Clark, L. C. J., McAdams, A. J., Mathews, E. C., and Edwards, F. K. (1959) Myocardial injury associated with asystole induced with potassium citrate. Ann. Surg. 149, 200-206. doi: 10.1097/00000658-19590200000005

Hering, H. E. (1907). Demonstration der aufhebung des flimmerns durch injektion von $\mathrm{KC1}$ losungen. Dtsch. med. Wchnschr. 33, 1567.

Hering, H. E. (1953). Quoted by Wiggers, C. J. Defibrillation of the ventricles. Circ. Res. 1, 191-199.

Heyndrickx, G. R., Millard, R. W., McRitchie, R. J., Maroko, P. R., and Vatner, S. F. (1975). Regional myocardial functional and electrophysiological alterations after brief coronary artery occlusion in conscious dogs. J. Clin. Invest. 56, 978-985. doi: 10.1172/JCI108178

Higashi, Y., Noma, K., Yoshizumi, M., and Kihara, Y. (2009). Endothelial function and oxidative stress in cardiovascular disease. Circ. J. 73, 411-418. doi: 10.1253/circj.CJ-081102
Hoelscher, B. (1967). Studies by electron microscopy on the effects of magnesium chloride-procaine amide or potassium citrate on the myocardium in induced cardiac arrest. J. Cardiovasc. Surg. (Torino). 8, 163-166.

Hoffman, B. F. (2002). And then came the microelectrode. Cardiovasc. Res. 53, 1-5. doi: 10.1016/S0008-6363 (01)00502-8

Hoffman, T. M., Wernovsky, G., Atz, A. M., Kulik, T. J., Nelson, D. P., Chang, A. C., et al. (2003). Efficacy and safety of milrinone in preventing low cardiac output syndrome in infants and children after corrective surgery for congenital heart disease. Circulation 107, 996-1002. doi: 10.1161/ 01.CIR.0000051365.81920.28

Hollmann, M. W., and Durieux, M. E. (2000). Local anesthetics and the inflammatory response: a new therapeutic indication? Anesthesiology 93, 858-875. doi: 10. 1097/00000542-200009000-00038

Hollmann, M. W., Gross, A., Jelacin, N., and Durieux, M. E. (2001). Local anesthetic effects on priming and activation of human neutrophils. Anesthesiology 95, 113-122. doi: 10.1097/00000542-20010700000021

Hollmann, M. W., Strumper, D., and Durieux, M. E. (2004). The poor man's epidural: systemic local anesthetics for improving postoperative outcomes. Med. Hypotheses 63, 386-389. doi: 10.1016/j.mehy.2004.02.057

Hooker, D. R. (1929). On the recovery of the heart in electric shock. Am. J. Physiol. 91, 305-328.

Hoover, E. L., Pett, S. B., Eldor, A., Alonso, D., Subramanian, V. A., Weksler, B., et al. (1981). The effects of crystalloid potassium cardioplegic solution on arterialized canine vein grafts. Assessment of chronic prostacyclin production and histopathologic alterations. Circulation 64(2 Pt 2), II96-II100.

Hosokawa, K., Nakajima, Y., Umenai, T., Ueno, H., Taniguchi, S., Matsukawa, T., et al. (2007). Predictors of atrial fibrillation after off-pump coronary artery bypass graft surgery. Br. J. Anaesth. 98, 575-580. doi: 10.1093/bja/aem067

Hove, M. T., Jansen, M. A., Nederhoff, M. G., and Van Echteld, C. J. (2007). Combined blockade of the $\mathrm{Na}+$ channel and the $\mathrm{Na}+/ \mathrm{H}+$ exchanger virtually prevents ischemic $\mathrm{Na}+$ overload in rat hearts. Mol. Cell. Biochem. 297, 101-110. doi: 10.1007/s11010-006-9334-0 
Huang, G. S., Chang, J. H., Lee, M. S., Wu, C. C., Lin, S. P., Lin, S. L., et al. (2002). The effect of anesthetic techniques on hemostatic function in arthroscopic surgery: evaluation by thromboelastography. Acta Anaesthesiol. Sin. 40, 121-126.

Ichiba, T., Matsuda, N., Takemoto, N., Ishiguro, S., Kuroda, H., and Mori, T. (1998). Regulation of intracellular calcium concentrations by calcium and magnesium in cardioplegic solutions protects rat neonatal myocytes from simulated ischemia. J. Mol. Cell. Cardiol. 30, 1105-1114. doi: 10.1006/jmcc. 1998.0676

Ishikawa, Y., and Sasakawa, S. (1987). Membrane potential of stored platelets and its effect on platelet functions. Thromb. Res. 45, 265-273. doi: 10.1016/0049-3848(87)90194-0

Jacobson, I., and Gao, Z.-G. (2006). Adenosine receptors as therapeutic targets. Nat. Rev. Drug Discov. 5, 247-264. doi: 10.1038/nrd1983

Jakobsen, ø., Muller, S., Aarsaether, E., Steensrud, T., and Sørlie, D. G. (2007). Adenosine instead of supranormal potassium in cardioplegic solution improves cardioprotection. Eur. J. Cardiothorac. Surg. 32, 493-500. doi: 10.1016/j.ejcts.2007.05.020

Jakobsen, O., Næsheim, T., Aas, K. N., Sørlie, D., and Steensrud, T. (2013). Adenosine instead of supranormal potassium in cardioplegia: it is safe, efficient, and reduces the incidence of postoperative atrial fibrillation. A randomized clinical trial. J. Thorac. Cardiovasc. Surg. 145, 812-818. doi: 10.1016/j.jtcvs.2012.07.058

Jayawant, A. M., and Damiano, R. J. (1998). The superiority of pinacidil over adenosine cardioplegia in blood perfused isolated hearts. Ann. Thorac. Surg. 66, 1329-1336. doi: 10.1016/S0003-4975(98)00772-3

Jayawant, A. M., Lawton, J. S., Hsia, P. W., and Damiano, R. J. (1997). Hyperpolarised cardioplegic arrest with Nicorandil. Circulation $96(9$ Suppl. 2), II-240-II-246.

Jellinek, M., Standeven, J. W., Menz, L. J., Hahn, J. W., and Barner, H. B. (1981). Cold blood potassium cardioplegia: effects of increasing concentrations of potassium. J. Thorac. Cardiovasc. Surg. 82, 26-37.

Jin, Z. X., Zhang, S. L., Wang, X. M., Bi, S. H., Xin, M., Zhou, J. J., et al. (2008). The myocardial protective effects of a moderate potassium adenosine-lidocaine cardioplegia in pediatric cardiac surgery. J. Thorac. Cardiovasc. Surg. 136, 1450-1455. doi: 10.1016/j.jtcvs.2008.03.025
Jinka, T. R., Tøien, O., and Drew, K. L. (2011). Season primes the brain in an arctic hibernator to facilitate entrance into torpor mediated by adenosine $\mathrm{Al}$ receptors. J. Neurosci. 31, 10752-10758. doi: 10.1523/JNEUROSCI.1240-11.2011

Jones, B., Hayden, M., Fraser, J. F., and Janes, E. (2005). Low cardiac output syndrome in children. Curr. Anesth. Crit. Care 16, 347-358. doi: 10.1016/j.cacc.2006.02.011

Josephson, I. R. (1988). Lidocaine blocks $\mathrm{Na}, \mathrm{Ca}$, and $\mathrm{K}$ currents of chick ventricular myocytes. J. Mol. Cell. Cardiol. 20, 593-604. doi: 10.1016/S0022-2828(88)80117-2

Jovanovic, A., Alekseev, A. E., Lopez, J. R., Shen, W. K., and Terzic, A. (1997). Adenosine prevents hyperkalemia-induced calcium loading in cardiac cells: relevance to cardioplegia. Ann. Thorac. Surg. 63, 153-161. doi: 10.1016/S0003-4975(96)00769-2

Jovanovic, A., Lopez, J. R., Alekseev, A. E., Shen, W. K., and Terzic, A. (1998). Adenosine prevents $\mathrm{K}^{+}$-induced $\mathrm{Ca}^{2+}$ loading: Insight into cardioprotection during cardioplegia. Ann. Thorac. Surg. 65, 586-591. doi: 10.1016/S0003-4975 (97)01240-X

Jynge, P., Hearse, D. J., and Braimbridge, M. V. (1977). Myocardial protection during ischemic cardiac arrest. A possible hazard with calcium-free cardioplegic infusates. J. Thorac. Cardiovasc. Surg. 73, 848-855.

Kamiyama, T., Tanonaka, K., Harada, H., Nakai, K., and Takeo, S. (1995). Mexiletine and lidocaine reduce post-ischemic functional and biochemical dysfunction of perfused hearts. Eur. J. Pharmacol. 272, 151-158. doi: 10.1016/0014-2999(94)00640-S

Kanchi, M., Prasad, N., Garg, D., and Banakal, S. K. (2004). Prophylactic magnesium sulphate vs. lidocaine during off-pump coronary artery bypass grafting. Eur. J. Anaesthesiol. 21, 914-927.

Kellermann, K., and Jungwirth, B. (2010). Avoiding stroke during cardiac surgery. Semin. Cardiothorac. Vasc. Anesth. 14, 95-101. doi: 10.1177/1089253210370902

Kerendi, F., Halkos, M. E., Corvera, J. S., Kin, H., Zhao, Z. Q., Mosunjac, M., et al. (2004). Inhibition of myosin light chain kinase provides prolonged attenuation of radial artery vasospasm. Eur. J. Cardiothorac. Surg. 26, 1149-1155. doi: 10.1016/j.ejcts.2004.08.030

Kirklin, J. W., Conti, V. R., and Blackstone, E. H. (1979).
Prevention of myocardial damage during cardiac operations. $N$. Engl. J. Med. 301, 135-141. doi: 10.1056/NEJM197907193010305

Kirsch, U., Rodewald, G., and Kalmar, P. (1972). Induced ischemic arrest: clinical experience with cardioplegia in open-heart surgery. J. Thorac Cardiovasc. Surg. 63, 121-130.

Kitagawa, S., and Johnston, R. B. (1985). Relationship between membrane potential changes and superoxide releasing capacity in resident and activated mouse peritoneal macrophages. J. Immunol. $135,3417-3423$.

Klatte, K., Chaitman, B. R., Theroux, P., Gavard, J. A., Stocke, K., Boyce, S., et al. (2001). Increased mortality after coronary artery bypass graft surgery is associated with increased levels of postoperative creatine kinase-myocardial band isoenzyme release. J. Am. Coll. Cardiol. 38, 1070-1077. doi 10.1016/S0735-1097(01)01481-4

Kleber, A. G. (1983). Resting membrane potential, extracellular potassium activity, and intracellular sodium activity during acute global ischemia in isolated perfused guinea pig hearts. Circ. Res. 52, 442-450. doi: 10.1161/01.RES.52. 4.442

Kleber, A. G., Riegger, C. B., and Janse, M. J. (1987). Extracellular K+ and $\mathrm{H}+$ shift in early ischemia: mechanisms and relation to changes in impulse generation. J. Mol. Cell. Cardiol. 19, 35-44. doi 10.1016/S0022-2828(87)80608-9

Kloner, R. A., and Jennings, R. B. (2001). Consequences of brief ischemia: stunning, preconditioning, and their clinical implications: part 1. Circulation 104, 2981-2989. doi: $10.1161 /$ hc 4801.100038

Kloner, R. A., Przyklenk, K., and Kay, G. L. (1994). Clinical evidence for stunned myocardium after coronary artery bypass surgery. J. Card. Surg. 9, 397-402.

Knothe, C., Boldt, J., Zickmann, B., Ballesteros, M., Dapper, F., and Hempelmann, G. (1992). Endothelin plasma levels in old and young patients during open heart surgery: correlations to cardiopulmonary and endocrinology parameters. J. Cardiovasc. Pharmacol. 20, 664-670. doi 10.1097/00005344-19921000000022

Koch, C. G., Khandwala, F., Nussmeier, N., and Blackstone, E. H. (2003). Gender and outcomes after coronary artery bypass grafting: a propensity matched comparison. J. Thorac. Cardiovasc. Surg. 126,
2032-2043. doi: 10.1016/S00225223(03)00950-4

Kon, Z. N., Brown, E. N., Grant, M. C., Ozeki, T., Burris, N. S., Collins, M. J., et al. (2008). Warm ischemia provokes inflammation and regional hypercoagulability within the heart during off-pump coronary artery bypass: a possible target for serine protease inhibition. Eur. J. Cardiothorac. Surg. 33, 215-221. doi: 10.1016/j.ejcts.2007.11.008

Kondo, N. (1987). Electrophysiological effects of $\mathrm{Ca}$ antagonists, tetrodotoxin, $[\mathrm{Ca}]_{\mathrm{o}}$ and $[\mathrm{Na}]_{\mathrm{o}}$ on myocardium of hibernating chipmunks: possible involvement of $\mathrm{Na}: \mathrm{Ca}$ exchange mechanism. Br. J. Pharmacol. 91, 315-319. doi: $\quad 10.1111 / j .1476-5381.1987$. tb10286.x

Krebs, H. A. (1975). The august krogh principle: "For many problems there is an animal on which it can be most conveniently studied." J. Exp. Zool. 194, 221-226. doi: 10.1002/jez.1401940115

Kreckler, L. M., Wan, T. C., Ge, Z. D., and Auchampach, J. A (2006). Adenosine inhibits tumor necrosis factor-alpha release from mouse peritoneal macrophages via $\mathrm{A} 2 \mathrm{~A}$ and $\mathrm{A} 2 \mathrm{~B}$ but not the $\mathrm{A} 3$ adenosine receptor. J. Pharmacol. Exp. Ther. 317, 172-180. doi: 10.1124/jpet.105.096016

Krötz, F., Sohn, H. Y., Keller, M., Gloe, T., Bolz, S. S., Becker, B. F., et al. (2003). Depolarization of endothelial cells enhances platelet aggregation through oxidative inactivation of endothelial NTPDase. Arterioscler. Thromb. Vasc. Biol. 22, 2003-2009. doi: 10.1161/ 01.ATV.0000043454.08172.51

Kucera, J. P., Rohr, S., and Rudy, Y. (2002). Localization of sodium channels in intercalated disks modulates cardiac conduction. Circ. Res. 91, 1176-1182. doi: 10.1161/ 01.RES.0000046237.54156.0A

Kudej, R. K., and Vatner, S. F. (2003). Nitric oxide-dependent vasodilation maintains blood flow in true hibernating myocardium. J. Mol. Cell. Cardiol. 35, 931-935. doi 10.1016/S0022-2828(03)00174-3

Kuo, L., and Chancellor, J. D. (1995). Adenosine potentiates flowinduced dilation of coronary arterioles by activating K-ATP channels in endothelium. Am. J. Physiol. Heart Circ. Physiol. 269, H541-H549.

Lagercrantz, E., Lindblom, D., and Sartipy, U. (2010). Survival and quality of life in cardiac surgery patients with prolonged intensive care. Ann. Thorac. Surg. 89, 
490-495. doi: 10.1016/j.athoracsur. 2009.09.073

Lam, C. R., Gahagan, T., Mota, C., and Green, E. (1958). Induced cardiac arrest (cardioplegia) in open heart surgical procedures. Surgery 43, 7-13.

Lam, C. R., Gahagan, T., Sergant, C., and Green, E. (1957). Clinical experiences with Induced cardiac arrest during intracardiac surgical procedures. Ann. Surg. 146, 439-449.

Lam, C. R., Geoghegan, T., and Lepore, A. (1955). Induced cardiac arrest for intracardiac surgical procedures; an experimental study. J. Thorac. Surg. $30,620-625$.

Lameris, T. W., de Zeeuw, S., Alberts, G., Boomsma, F., Duncker, D. J., Verdouw, P. D., et al. (2000). Time course and mechanism of myocardial catecholamine release during transient ischemia in vivo. Circulation 101, 2645-2650. doi: 10.1161/01.CIR.101.22.2645

Lan, Y. T., Lee, J. C., and Wetzel, G. (2003). Postoperative arrhythmia. Curr. Opin. Cardiol. 18, 73-78. doi: 10.1097/00001573-20030300000001

Lappas, C. M., Sullivan, G. W., and Linden, J. (2005). Adenosine A2A agonists in development for the treatment of inflammation. Expert Opin. Investig. Drugs 14, 797-806. doi: 10.1517/13543784.14.7.797

Lasley, R. D., Rhee, J. W., Van Wylen, D. G., and Mentzer, R. M. (1990). Adenosine Al receptor mediated protection of the globally ischemic rat heart. J. Mol. Cell. Cardiol. 22, 39-47. doi: 10.1016/0022-2828(90)90970-D

Lathrop, D. A., Contney, S. J., Bosnjak, Z. J., and Stowe, D. F. (1998). Reversal of hypothermia-induced action potential lengthening by the KATP channel agonist bimakalim in isolated guinea pig ventricular muscle. Gen. Pharmacol. 31, 125-131. doi: 10.1016/S0306-3623 (97)00395-9

Lehrke, S., Steen, H., Sievers, H. H., Peters, H., Opitz, A., MullerBardorff, M., et al. (2004). Cardiac troponin $\mathrm{T}$ for prediction of short- and long-term morbidity and mortality after elective open heart surgery. Clin. Chem. 50, 1560-1567. doi: 10.1373/clinchem. 2004.031468

Leicher, F. G., Magrassi, P., LaRaia, P. J., Derkac, W. M., Buckley, M. J., and Austen, W. G. (1983). Blood cardioplegia delivery. Deleterious effects of potassium versus lidocaine. Ann. Surg. 198, 266-272. doi: 10.1097/00000658-19830900000003
Lenfant, F., Lahet, J. J., CourderotMasuyer, C., Freysz, M., and Rochette, L. (2004). Lidocaine has better antioxidant potential than ropivacaine and bupivacaine: in vitro comparison in a model of human erythrocytes submitted to an oxidative stress. Biomed. Pharmacother. 58, 248-254. doi: 10.1016/j.biopha. 2003.12.013

Letson, H. L., and Dobson, G. P. (2011a). Small-volume $\quad 7.5 \%$ $\mathrm{NaCl}$ with $6 \%$ dextran-70 or $6 \%$ and $10 \%$ hetastarch are associated with arrhythmias and death following $60 \mathrm{~min}$ of severe hemorrhagic shock in the rat in vivo. J. Trauma 70, 1444-1452. doi: 10.1097/TA.0b013e3181e99c63

Letson, H. L., and Dobson, G. P. (2011b). Ultra-small IV bolus of $7.5 \% \mathrm{NaCl} / \mathrm{Mg} 2+$ with adenosine and lidocaine (ALM) improves early resuscitation outcome in the rat following severe hemorrhagic shock in vivo. J. Trauma 71, 708-719. doi: 10.1097/TA.0b013e3181fa27c7

Letson, H. L., and Dobson, G. P. (2011c). Unexpected $100 \%$ survival following $60 \%$ blood loss using small-volume $7.5 \% \quad \mathrm{NaCl}$ with adenocaine and $\mathrm{Mg} 2+$ in the rat model of extreme hemorrhagic shock. Shock 36, 586-594. doi: 10.1097/SHK.0b013e318237eb0c

Letson, H. L., Granfeldt, A., Hyldebrandt, J. A., Wang, E. R., Salcedo, P. A., Nielson, T. K., et al. (2012a). Rat to pig translation: small-volume $7.5 \% \mathrm{NaCl}$ adenocaine/Mg2+ has multiple physiological benefits during hypotensive and blood resuscitation in the porcine model of severe hemorrhagic shock. Circulation 126, A177.

Letson, H. L., Pecheniuk, N. M., Mhango, L. P., and Dobson, G. P. (2012b). Reversal of acute coagulopathy during hypotensive resuscitation using small-volume $7.5 \% \mathrm{NaCl}$ with adenocaine and $\mathrm{Mg} 2+$ in the rat model of severe hemorrhagic shock. Crit. Care Med. 40, 2417-2422. doi: 10.1097/CCM.0b013e31825334c3

Levy, J. H., and Tanaka, K. A. (2003). Inflammatory response to cardiopulmonary bypass. Ann. Thorac. Surg.75, S715-S720. doi: 10.1016/S0003-4975(02)04701-X

Li, J. M., and Shah, A. M. (2004). Endothelial cell superoxide generation: regulation and relevance for cardiovascular pathophysiology. Am. J. Physiol. Regul. Integr. Comp. Physiol. 287, R1014-R1030. doi: 10.1152/ajpregu.00124.2004
Liu, X., Engelman, R. M., Rousou, J. A., Flack, J. E. 3rd., Deaton, D. W., and Das, D. K. (1994). Normothermic cardioplegia prevents intracellular calcium accumulation during cardioplegic arrest and reperfusion. Circulation 90, II316-II320.

Lopez, J. R., Jahangir, R., Jahangir, A., Shen, W. K., and Terzic, A. (1996). Potassium channel openers prevent potassium-induced calcium loading of cardiac cells: possible implications in cardioplegia J. Thorac. Cardiovasc. Surg. 112 820-831. doi: 10.1016/S0022-5223 (96)70070-3

Lubbe, W. F., Podzuweit, T., and Opie, L. H. (1992). Potential arrhythmogenic role of cyclic adenosine monophosphate (AMP) and cytosolic calcium overload: implications for prophylactic effects of beta-blockers in myocardial infarction and proarrhythmic effects of phosphodiesterase inhibitors. J. Am Coll. Cardiol. 19, 1622-1633. doi: 10.1016/0735-1097(92)90629-2

Madhok, A. B., Ojamaa, K., Haridas, V., Parnell, V. A., Pahwa, S., and Chowdhury, D. (2006). Cytokine response in children undergoing surgery for congenital heart disease. Pediatr. Cardiol. 27, 408-413. doi: 10.1007/s00246-006-0934-y

Maganti, M., Badiwala, M., Sheikh, A., Scully, H., Feindel, C., David, T. E., et al. (2010). Predictors of low cardiac output syndrome after isolated mitral valve surgery. J. Thorac. Cardiovasc. Surg. 140, 790-796. doi: 10.1016/j.jtcvs.2009.11.022

Magee, M. J., Alexander, J. H., Hafley, G., Ferguson, T. B. J., Gibson, C. M., Harrington, R. A., et al (2008). Coronary artery bypass graft failure after on-pump and off-pump coronary artery bypass: findings from PREVENT IV. Ann. Thorac. Surg. 85, 494-500. doi: 10.1016/j.athoracsur.2007.10.008

Magilligan, D. J. J., Vij, D., Peper, W., Allor, D., Frinak, S., and Tilley, B. (1985). Failure of standard cardioplegic techniques to protect the conducting system. Ann. Thorac. Surg. 39, 403-408. doi: 10.1016/S00034975(10)61944-3

Mangano, D. T. (1995). Cardiovascular morbidity and CABG surgery-a perspective: epidemiology, costs, and potential therapeutic solutions. J. Card. Surg. 10, 366-368. doi: $\quad 10.1111 / \mathrm{j} .1540-8191.1995$ tb00663.x

Mangiacapra, F., De Bruyne, B., Wijns, W., and Bartunek, J. (2011) Optimizing revascularization strategies in coronary artery disease for optimal benefit to patients. Clin.
Pharmacol. Ther. 90, 630-633. doi: 10.1038/clpt.2011.162

Mankad, P. S., Amrani, M., Rothery, S., Devers., N. J., and Yacoub, M. H. (1997). Relative susceptibility of endothelium and myocardial cells to ischemia-reperfusion injury. Acta Physiol. Scand. 161, 103-112. doi: 10.1046/j.1365-201X. 1997.00195.x

Mankad, P. S., Chester, A. H., and Yacoub, M. H. (1991). Role of potassium concentration in cardioplegic solutions in mediating endothelial damage. Ann. Thorac. Surg. 51, 89-93. doi: 10.1016/00034975(91)90457-2

Markel, H. (2004). "I swear by Apollo"on taking the Hippocratic oath. N. Engl. J. Med. 350, 2026-2029. doi: 10.1056/NEJMp048092

Martin, L. M., Holmes, S. D., Henry, L. L., Schlauch, K. A., Stone, L. E., Roots, A., et al. (2012). Health-related quality of life after coronary artery bypass grafting surgery and the role of gender. Cardiovasc. Revasc. Med. 13, 321-327. doi: 10.1016/j.carrev.2012. 09.002

Masuda, T., Dobson, G. P., and Veech, R. L. (1990). The Gibbs-Donnan near-equilbrium system of heart. J. Biol. Chem. 265, 20321-20334.

Mathew, J. P., Fontes, M. L., Tudor, I. C., Ramsay, J., Duke, P., Mazer, C. D., et al. (2004). A multicenter risk index for atrial fibrillation after cardiac surgery. JAMA 291, 1720-1729. doi: 10.1001/jama.291. 14.1720

Matsuda, N., Tofukuji, M., Morgan, K. G., and Sellke, F. W. (1999). Coronary microvascular protection with $\mathrm{Mg}^{2+}$ : effects on intracellular calcium regulation and vascular function. Am. J. Physiol. 276, H1124-H1130.

Matsuzaki, I., Chatterjee, S., Debolt, K., Manevich, Y., Zhang, Q., and Fisher, A. B. (2005). Membrane depolarization and NADPH oxidase activation in aortic endothelium during ischemia reflect altered mechanotransduction. Am. J. Physiol. Heart Circ. Physiol. 288, H336-H343. doi: 10.1152/ajpheart. 00025.2004

McCully, J. D., and Levitsky, S. (2003). Mitochondrial ATPsensitive potassium channels in surgical cardioprotection. Arch. Biochem. Biophys. 420, 237-245. doi: 10.1016/j.abb.2003. 06.003

McCully, J. D., Toyoda, Y., Wakiyama, H., Rousou, A. J., Parker, R. A., and Levisky, S. (2006). Age- and genderrelated differences in ischemia/ 
reperfusion injury and cardioprotection: effects of diazoxide. Ann. Thorac. Surg. 82, 117-123. doi: 10.1016/j.athoracsur.2006.03.002

McCully, J. D., Uematsu, M., Parker, R. A., and Levitsky, S. (1998). Adenosine-enhanced ischemic preconditioning provides enhanced postischemic recovery and limitation of infarct size in the rabbit heart. J. Thorac. Cardiovasc. Surg. 116, 154-162. doi: 10.1016/S0022-5223 (98)70254-5

McGregor, P. R., Thorner, R. E., and Wright, D. M. (1980). Lidocaine inhibits granulocyte adherence and prevents granulocyte delivery to infammatory sites. Blood 56, 203-209.

Melrose, D. G., Dreyer, B., Bentall, H. H., and Baker, J. B. E. (1955). Elective cardiac arrest. Lancet 2, 21-22. doi: $10.1016 /$ S0140-6736(55)93381-X

Menasché, P. (2000). Cardioplegic solution challenges. Ital. Heart J. 1, S40-S42.

Mentzer, R. M. J., Birjiniuk, V., Khuri, S. F., Lowe, J. E., Rahko, P. S., Weisel, R. D., et al. (1999). Adenosine myocardial protection: preliminary results of a phase II clinical trial. Ann. Surg. 229, 643-649. discussion: 649-650. doi: 10.1097/00000658-19990500000006

Mentzer, R. M. J., Jahania, M. S., and Lasley, R. D. (2003). "Myocardial protection," in Cardiac Surgery in the Adult, 2nd Edn., eds L. H. Cohn and L. H. J. Edmunds (New York, NY: McGraw-Hill), 413-438.

Mentzer, R. M. J., Rahko, P. S., Molina-Viamonte, V., Canver, C. C., Chopra, P. S., Love, R. B., et al. (1997). Safety, tolerance, and efficacy of adenosine as an additive to blood cardioplegia in humans during coronary artery bypass surgery. Am. J. Cardiol. 79, 38-43. doi: 10.1016/S0002-9149 (97)00262-2

Merchant, S., Nadaraj, S., Chowdhury, D., Parnell, V. A., Sison, C., Miller, E. J., et al. (2008). Macrophage migration inhibitory factor in pediatric patients undergoing surgery for congenital heart repair. Mol. Med. 14, 124-130. doi: 10.2119/200700086.Merchant

Mezzetti, A., Calafiore, A. M., Lapenna, D., Deslauriers, R., Ganghong, T., Salerno, T. A., et al. (1995). Intermittent antegrade warm cardioplegia reduces oxidative stress and improves metabolism of the ischaemic-reperfused human myocardium. J. Thorac
Cardiovasc. Surg. 109, 785-795. doi: 10.1016/S0022-5223(95)70362-4

Mikawa, K., Akamatsu, H., Nishina, K., Shiga, M., Maekawa, N., Obara, H., et al. (1997). Inhibitory effect of local anaesthetics on reactive oxygen species production by human neutrophils. Acta Anaesthesiol. Scand. 41, 524-528. doi: 10.1111/j.13996576.1997.tb04735.x

Milano, C. A., White, W. D., Smith, L. R., Jones, R. H., Lowe, J. E., Smith, P. K., et al. (1993). Coronary artery bypass in patients with severely depressed ventricular function. Ann. Thorac. Surg. 56, 487-493. doi: 10.1016/0003-4975 (93) $90884-\mathrm{K}$

Miura, M., Hattori, T., Murai, N., Nagano, T., Nishio, T., Boyden, P. A., et al. (2012). Regional increase in extracellular potassium can be arrhythmogenic due to nonuniform muscle contraction in rat ventricular muscle. Am. J. Physiol. Heart Circ. Physiol. 302, H2301-H2309. doi: 10.1152/ ajpheart.01161.2011

Mizutani, S., Al-Dadah, A. S., Bloch, J. B., Prasad, S. M., Diodato, M. D. J., Schuessler, R. B., et al. (2006). Hyperkalemic cardioplegiainduced myocyte swelling and contractile dysfunction: prevention by diazoxide. Ann Thorac. Surg. 81, 154-159. doi: 10.1016/j.athoracsur.2005.06.057

Moller, R. A., and Covino, B. G. (1988). Cardiac electrophysiologic effects of lidocaine and bupivacaine. Anesth. Analg. 67, 107-114. doi: 10.1213/00000539-19880200000002

Montgomery, A. V., Prevedel, A. E., and Swan, H. (1954). Prostigmine inhibition of ventricular fibrillation in the hypothermic dog. Circulation 10, 721-727. doi: 10.1161/01.CIR.10.5.721

Moore, B. (1911). In memory of Sidney Ringer [1835-1910]: some account of the fundamental discoveries of the great pioneer of the bio-chemistry of crystallo-colloids in living cells. Biochem. J. 5, i.b3-xix.

Mubagwa, K., Gwanyanya, A., Zakharov, S., and Macianskiene, R. (2007). Regulation of cation channels in cardiac and smooth muscle cells by intracellular magnesium. Arch. Biochem. Biophys. 458, 73-89. doi: 10.1016/j.abb.2006. 10.014

Murphy, E. (2000). Mysteries of magnesium homeostasis. Circ. Res. 86, 245-248. doi: 10.1161/01.RES.86. 3.245

Nakaigawa, Y., Akazawa, S., Shimizu, R., Ishii, R., Ikeno, S., Inoue, S., et al.
(1997). Effects of magnesium sulphate on the cardiovascular system, coronary circulation and myocardial metabolism in anaesthetized dogs. Br. J. Anaesth. 79, 363-368 doi: 10.1093/bja/79.3.363

Narahashi, T. (2008). Tetrodotoxin: a brief history. Proc. Jpn. Acad. Ser. B Phys. Biol. Sci. 84, 147-154. doi: 10.2183/pjab.84.147

Narahashi, T., Deguchi, T., Urakawa, N., and Ohkubo, Y. (1960) Stabilization and rectification of muscle fiber membrane by tetrodotoxin. Am. J. Physiol. 198, 934-938.

Nesher, N., Alghamdi, A. A., Singh, S. K., Sever, J. Y., Christakis, G. T., Goldman, B. S., et al. (2008) Troponin after cardiac surgery: a predictor or a phenomenon? Ann Thorac. Surg. 85, 1348-1354. doi 10.1016/j.athoracsur.2007.12.077

Newman, M. F., Kirchner, J. L. Phillips-Bute, B., Gaver, V., Grocott, H., Jones, R. H., et al (2001). Longitudinal assessment of neurocognitive function after coronary-artery bypass surgery. $N$. Engl. J. Med. 344, 395-402. doi 10.1056/NEJM200102083440601

Nichols, C. G., and Lederer, W. J. (1991). Adenosine triphosphatesensitive potassium channels in the cardiovascular system. Am. J. Physiol. 261, H1675-H1686.

Niedergerke, R. (1956). The potassium chloride contracture of the heart and its modification by calcium. J. Physiol. 134, 584-599.

Nilsson, F. N., Miller, V. M., Johnson, C. M., Tazelaar, H., and McGregor, C. G. (1993). Cardioplegia alters porcine coronary endothelial cell growth and responses to aggregating platelets. J. Vasc. Res. 30, 43-52.

Niu, X. F., Ibbotson, G., and Kubes, P. (1996). A balance between nitric oxide and oxidants regulates mast cell-dependent neutrophilendothelial cell interactions. Circ. Res. 79, 992-999. doi: 10.1161/01. RES.79.5.992

Noma, A. (1983). ATP-regulated $\mathrm{K}^{+}$channels in cardiac tissue Nature 305, 147-148. doi: 10.1038/ $305147 \mathrm{a} 0$

Nomura, F., Forbess, J. M., Hiramatsu, T., and Mayer, J. E. (1997) Relationship of blood flow effects of adenosine during reperfusion to recovery of ventricular function after hypothermic ischemia in neonatal lambs. Circulation 96, II-227-II-232.

Norton, J. M., and Detar, R. (1972) Potassium and isolated coronary vascular smooth muscle. Am. J. Physiol. 222, 474-479.
Nunn, D. D., Belisle, C. A., Lee, W. H. Jr., and Parker, E. F. (1959). A comparative study of aortic occlusion alone and of potassium citrate arrest during cardiopulmonary bypass. Surgery $45,848-851$.

Olinger, G. N., Boerboom, L. E., Bonchek, L. I., Hutchinson, L. D., and Kissebah, A. H. (1983). Hyperkalemia in cardioplegic solutions causing increased cholesterol accumulation in vein grafts. J. Thorac. Cardiovasc. Surg. 85, 590-594.

Onorati, F., Santini, F., Dandale, R., Ucci, G., Pechlivanidis, K., Menon, T., et al. (2012). "Polarizing" microplegia improves cardiac cycle efficiency after CABG for unstable angina. Int. J. Cardiol. doi: 10.1016/j.ijcard.2012.06.099. [Epub ahead of print].

Opie, L. H., and Gersh, B. J. (2008). Drugs for the Heart, 7th Edn. London, New York NY: W.B. Saunders.

O'Rullian, J. J., Clayson, S. E., and Peragallo, R. (2008). Excellent outcomes in a case of complex re-do surgery requiring prolonged cardioplegia using a new cardioprotective approach: adenocaine. J. Extra Corpor. Technol. 40, 203-205.

Parolari, A., Rubini, P., Cannata, A., Bonati, L., Alamanni, F., Tremoli, E., et al. (2002). Endothelial damage during myocardial preservation and storage. Review. Ann. Thorac. Surg. 73, 682-690. doi: 10.1016/S00034975(01)03029-6

Parr, G. V., Blackstone, E. H., and Kirklin, J. W. (1975). Cardiac performance and mortality early after intracardiac surgery in infants and young children. Circulation 51, 867-874. doi: 10.1161/01.CIR.51.5.867

Paterson, D. J., Rogers, J., Powell, T., and Brown, H. F. (1993). Effect of catecholamines on the ventricular myocyte action potential in raised extracellular potassium. Acta Physiol. Scand. 148, 177-186. doi: 10.1111/j.17481716.1993.tb09547.x

Perrault, L. P., and Carrier, M. (2005). The central role of the endothelium in graft coronary vasculopathy and heart transplantation. Can. J. Cardiol. 21, 1077-1083.

Pfammatter, J. P., Wagner, B., Berdat, P., Bachmann, D. C., Pavlovic, M., Pfenninger, J., et al. (2002). Procedural factors associated with early postoperative arrhythmias after repair of congenital heart defects. J. Thorac. Cardiovasc. Surg. 123, 258-262. doi: $10.1067 / \mathrm{mtc} .2002 .11970$ 
Pinet, C., Le Grand, B., John, G. W., and Coulombe, A. (2002). Thrombin facilitation of voltage-gated sodium channel activation in human cardiomyocytes: implications for ischemic sodium loading. Circulation 106, 2098-2103. doi: 10.1161/01.CIR. 0000034510.64828 .96

Piper, H. M., Abdallah, Y., and Schäfer, C. (2004). The first minutes of reperfusion: a window of opportunity for cardioprotection. Cardiovasc. Res. 61 365-371. doi: 10.1016/j.cardiores. 2003.12.012

Piper, H. M., Meuter, K., and Schafer, C. (2003). Cellular mechanisms of ischemia-reperfusion injury. Ann. Thorac. Surg. 75, S644-S648. doi: 10.1016/S00034975(02)04686-6

Pitkanen, M., Feldman, H. S., Arthur, G. R., and Covino, B. G. (1992). Chronotropic and inotropic effects of ropivacaine, bupivacaine, and lidocaine in the spontaneously beating and electrically paced isolated, perfused rabbit heart. Reg. Anesth. 17, 183-192.

Przyklenk, K., Aoki, A., Bellows, S., Klinedinst, D., Zubiate, P., Hale, S. L., et al. (1994). Stunned myocardium following prolonged cardiopulmonary bypass: effect of warm versus cold cardioplegia in the canine model. J. Card. Surg. 9, 506-516.

Quignard, J. F., Feletou, M., Thollon, C., Vilaine, J. P., Duhault, J., and Vanhoutte, P. M. (1999). Potassium ions and endothelium-derived hyperpolarizing factor in guineapig carotid and porcine coronary arteries. Br. J. Pharmacol. 127, 27-34. doi: 10.1038/sj.bjp.0702493

Radovits, T., Lin, L. N., Zotkina, J., Koch, A., Rauen, U., Köhler, G., et al. (2008). Endothelial dysfunction after long-term cold storage in HTK organ preservation solutions: effects of iron chelators and N-alpha-acetyl-L-histidine. J. Heart Lung Transplant. 27, 208-216. doi: 10.1016/j.healun. 2007.11.002

Raivio, P., Lassila, R., and Petäjä, J. (2009). Thrombin in myocardial ischemia-reperfusion during cardiac surgery. Ann. Thorac. Surg. 88, 318-325. doi: 10.1016/j.athoracsur.2008.12.097

Raja, S. C. (2005). The response of the coagulation system to cardiac surgery is not similar with or without cardiopulmonary bypass. J. Cardiothorac. Vasc. Anesth. 19, 700-704. doi: 10.1053/j.jvca.2005.02.014
Rapoport, J., Teres, D., Zhao, Y., and Lemeshow, S. (2003). Length of stay data as a guide to hospital economic performance for ICU patients. Med. Care 41, 386-397. doi: 10.1097/ 01.MLR.0000053021.93198.96

Ravishankar, C., Tabbutt, S., and Wernovsky, G. (2003). Critical care in cardiovascular medicine. Curr. Opin. Pediatr. 15, 443-453. doi: 10.1097/00008480-20031000000001

Reidemeister, J. C., Heberer, G., and Bretschneider, H. J. (1967). Induced cardiac arrest by sodium and calciium depletion and application of procaine. Int. Surg. 45, 535.

Ringer, S. (1883). A further contribution regarding the influence of the different constituents of the blood on the contraction of the heart. J. Physiol. 4, 29-42.

Robb-Nicholson, C., Currie, W. D., and Wechsler, A. S. (1978). Effects of verapamil on myocardial tolerance to ischemic arrest: comparison to potassium arrest. Circulation 58, I119-I124.

Rosner, M. H., and Okusa, M. D. (2006). Acute kidney injury associated with cardiac surgery. Clin. J. Am. Soc. Nephrol. 1, 19-32. doi: 10.2215/CJN.00240605

Rudd, D. M., and Dobson, G. P. (2009). Towards a new cold and warm non-depolarising, normokalemic arrest paradigm for orthotopic heart transplantation. J. Thorac. Cardiovasc. Surg. 137, 198-207. doi: 10.1016/j.jtcvs.2008.06.031

Rudd, D. M., and Dobson, G. P. (2011a). Early reperfusion with warm, polarizing adenosinelidocaine cardioplegia improves functional recovery following 6 hours of cold static storage. J. Thorac. Cardiovasc. Surg. 141, 1044-1055.

Rudd, D. M., and Dobson, G. P. (2011b). Eight hours of cold static storage with adenosine and lidocaine (Adenocaine) heart preservation solutions: toward therapeutic suspended animation. J. Thorac. Cardiovasc. Surg. 142, 1552-1561. doi: 10.1016/j.jtcvs. 2011.05.023

Rudolph, J. L., Jones, R. N., Levkoff, S. E., Rockett, C., Inouye, S. K., Sellke, F. W., et al. (2009). Derivation and validation of a preoperative prediction rule for delirium after cardiac surgery. Circulation 119, 229-236. doi: 10.1161/ CIRCULATIONAHA.108.795260

Ruel, M., Khan, T. A., Voisine, P., Bianchi, C., and Sellke, F. W. (2004). Vasomotor dysfunction after cardiac surgery. Eur. J.
Cardiothorac. Surg. 26, 1002-1014 doi: 10.1016/j.ejcts.2004.07.040

Sands, W. A., and Palmer, T. M. (2005). Adenosine receptors and the control of endothelial cell function in inflammatory disease. Immunol. Lett. 101, 1-11. doi: 10.1016/j.imlet.2005.04.005

Sasagawa, S. (1991). Inhibitory effects of local anesthetics on migration, extracellular release of lysosomal enzyme, and superoxide anion production in human polymorphonuclear leukocytes. Immunopharmacol. Immunotoxicol. 13, 607-622. doi: 10.3109/08923979109019726

Schaff, H. V., Dombroff, R., Flaherty, J. T., Bulkley, B. H., Hutchins, G. M., Goldman, R. A., et al. (1978). Effect of potassium cardioplegia on myocardial ischemia and post arrest ventricular function. Circulation 58, 240-249. doi: 10.1161/01.CIR.58.2.240

Scherr, K., Jensen, L., Smith, H., and Kozak, C. L. (2006). Atrial fibrillation following cardiac surgery: a retrospective cohort series. Prog. Cardiovasc. Nurs. 21, 7-13. doi: 10.1111/j.0197-3118.2006.04603.x

Schrader, J. (1990). Adenosine: a homeostatic metabolite in cardiac energy metabolism. Circulation 81, 389-391. doi: 10.1161/01.CIR.81.1.389

Schubert, R., Vetter, H., Owen, P., Reichart, B., and Opie, L. H. (1989). Adenosine cardioplegia: adenosine versus potassium cardioplegia. J. Thorac. Cardiovasc. Surg. 98 1057-1065.

Sealy, W. C. (1989). Hypothermia: its possible role in cardiac surgery. Ann. Thorac. Surg. 47, 788-791. doi: 10.1016/0003-4975(89)90151-3

Seiden, J. E., Platoshyn, O., Bakst, A. E., McDaniel, S. S., and Yuan, J. X. (2000). High $\mathrm{K}+$ induced membrane depolarization attenuates endothelium-dependent pulmonary vasodilation. Am. J. Physiol. Lung Cell. Mol. Physiol. 278, L261-L267.

Seifert, H. A., Howard, D. L., Silber, J. H., and Jobes, D. R. (2007) Female gender increases the risk of death during hospitalization for pediatric cardiac surgery. J. Thorac. Cardiovasc. Surg. 133, 668-675. doi: 10.1016/j.jtcvs.2006. 11.014

Sellke, F. W., Boyle, E. M., and Verrier, E. D. (1996). Endothelial cell injury in cardiovascular surgery: the pathophysiology of vasomotor dysfunction. Ann. Thorac. Surg. 62, 1222-1228. doi: 10.1016/0003-4975(96)00538-3
Sellke, F. W., Shafique, T., Ely, D. L., and Weintraub, R. M. (1993). Coronary endothelial injury after cardiopulmonary bypass and ischemic cardioplegia is mediated by oxygenderived free radicals. Circulation 88(5 Pt 2), 395-400.

Shander, A., Hofmann, A., Ozawa, S., Theusinger, O. M., Gombotz, H., and Spahn, D. R. (2010). Activity-based costs of blood transfusions in surgical patients at four hospitals. Transfusion 50, 753-765. doi: 10.1111/j.1537-2995. 2009.02518.x

Shaw, A. (2012). Update on acute kidney injury after cardiac surgery. J. Thorac. Cardiovasc. Surg. 143, 676-681. doi: 10.1016/j.jtcvs.2011.08.054

Shaw, R. M., and Rudy, Y. (1997). Electrophysiologic effects of acute myocardial ischemia: a theoretical study of altered cell excitability and action potential duration. Cardiovasc. Res. 35, 256-272. doi: 10.1016/S0008-6363 (97)00093-X

Sheu, S. S., Korth, M., Lathrop, D. A., and Fozzard, H. A. (1980). Intra- and extracellular $\mathrm{K}+$ and $\mathrm{Na}+$ activities and resting membrane potential in sheep cardiac purkinje strands. Circ. Res. 47, 692-700. doi: 10.1161/01.RES.47. 5.692

Shi, W., Jiang, R., Dobson, G. P., Granfeldt, A., and Vinten-Johansen, J. (2012). The non-depolarizing, normokalemic cardioplegia formulation adenosine-lidocaine (Adenocaine) exerts anti-neutrophil effects by synergistic actions of its components. J. Thorac. Cardiovasc. Surg. 143, 1167-1175. doi: 10.1016/ j.jtcvs.2011.06.045

Shiroishi, M. S. (1999). Myocardial protection: the rebirth of potassiumbased cardioplegia. Tex. Heart Inst. J. 26, 71-86.

Shumway, N. E., Lower, R. R., and Stofer, R. C. (1959). Selective hypothermia of the heart in anoxic cardiac arrest. Surg. Gynecol. Obstet. 104, 750-756.

Siess, W. (1989). Molecular mechanisms of platelet activation. Physiol. Rev. 69, 58-178.

Sjöquist, P. O., Duker, G., and Johansson, B. W. (1986). Effects of induced hypothermia on organ blood flow in a hibernator and a nonhibernator. Cryobiology 23, 440-446. doi: 10.1016/0011-2240 (86)90029-5

Sloots, K., and Dobson, G. P. (2010). Normokalemic adenosine-lidocaine cardioplegia: importance of maintaining a polarized myocardium 
for optimal arrest and reanimation. J. Thorac. Cardiovasc. Surg. 139, 1576-1586. doi: 10.1016/j.jtcvs.2009.10.013

Sloots, K., Vinten-Johansen, J., and Dobson, G. P. (2007). Warm nondepolarising adenosine-lidocaine cardioplegia: continuous versus intermittent delivery. J. Thorac. Cardiovasc. Surg. 133, 1171-1178. doi: 10.1016/j.jtcvs.2006.12.058

Smith, I. C. P. (1989). Magnetic resonance spectroscopy in biology and medicine. Clin. Biochem. 22, 69-76. doi: 10.1016/S0009-9120 (89)80070-0

Snabaitis, A. K., Shattock, M. J., and Chambers, D. J. (1997). Comparison of polarized and depolarized arrest in the isolated rat heart for long-term preservation. Circulation 96, 3148-3156. doi: 10.1161/01.CIR.96.9.3148

Sohn, H. Y., Keller, M., Gloe, T., Morawietz, H., Rueckschloss, U., and Pohl, U. (2000). The small G-protein Rac mediates depolarisation-induced superoxide formation in human endothelial cells. J. Biol. Chem. 275, 18745-18750. doi: 10.1074/jbc. M000026200

Song, H. K., Grab, J. D., O’Brien, S. M., Welke, K. F., Edwards, F., and Ungerleider, R. M. (2008). Gender differences in mortality after mitral valve operation: evidence for higher mortality in perimenopausal women. Ann. Thorac. Surg. 85, 2040-2044. doi: 10.1016/j. athoracsur.2008.02.082

Speziale, G., Nasso, G., Barattoni, M. C., Bonifazi, R., Esposito, G., Coppola, R., et al. (2010). Operative and middle-term results of cardiac surgery in nonagenarians: a bridge toward routine practice. Circulation 121, 208-213. doi: 10.1161/CIRCULATIONAHA.108. 807065

Speziale, G., Nasso, G., Barattoni, M. C., Esposito, G., Popoff, G., Argano, V., et al. (2011). Shortterm and long-term results of cardiac surgery in elderly and very elderly patients. J. Thorac. Cardiovasc. Surg. 141, 725-731. doi: 10.1016/j.jtcvs.2010.05.010

Spinale, F. G. (1999). Cellular and molecular therapeutics targets for treatment of contractile dysfunction after cardioplegic arrest. Ann. Thorac. Surg. 68, 1934-1941. doi: 10.1016/S00034975(99)01034-6

Sprung, J., Laszlo, A., Turner, L. A., Kampine, J. P., and Bosnjak, Z. J. (1995). Effects of hypothermia, potassium, and verapamil on the action potential characteristics of canine cardiac Purkinje fibers. Anesthesiology 82, 713-722. doi: 10.1097/00000542-19950300000013

Steinberg, J. S. (2004). Postoperative atrial fibrillation: a billion-dollar problem. J. Am. Coll. Cardiol. 43, 1001-1003. doi: 10.1016/j.jacc.2003. 12.033

Stewart, G. J. (1993). Neurtophils and deep vein thrombosis. Haemostasis 32, 127-140.

Stowe, D. F., Varadarajan, S. G., An, J., and Smart, S. C. (2000). Reduced cytosolic Ca21 loading and improved cardiac function after cardioplegic cold storage of Guinea pig isolated hearts. Circulation 102, 1172-1177. doi: 10.1161/01.CIR.102.10.1172

Suleiman, M. S., Halestrap, A. P., and Griffiths, E. J. (2001). Mitochondria: a target for myocardial protection. Pharmacol. Ther. 89, 29-46. doi: 10.1016/S0163-7258 (00)00102-9

Suleiman, M. S., Zacharowski, K., and Angelini, G. D. (2008). Inflammatory response and cardioprotection during open-heart surgery: the importance of anaesthetics. Br. J. Pharmacol. 153, 21-33. doi: 10.1038/sj.bjp.0707526

Taggart, P., Sutton, P. M., Opthof, T., Coronel, R., Trimlett, R., Pugsley, W., et al. (2000). Inhomogeneous transmural conduction during early ischaemia in patients with coronary artery disease. J. Mol. Cell. Cardiol. 32, 621-630. doi: 10.1006/jmcc.2000. 1105

Takahashi, H. K., Iwagaki, H., Hamano, R., Wake, H., Kanke, T., Liu, K., et al. (2007). Effects of adenosine on adhesion molecule expression and cytokine production in human PBMC depend on the receptor subtype activated. $B r$. J. Pharmacol. 150, 816-822. doi: 10.1038/sj.bjp.0707126

Terzic, A., Jahangir, A., and Kurachi, Y. (1995). Cardiac ATP-sensitive K+ channels: regulation by intracellular nucleotides and $\mathrm{K}+$ channelopening drugs. Am. J. Physiol. 269, C525-C545.

Thom, T., Haase, N., Rosamond, W., Howard, V. J., Rumsfeld, J., Manolio, T., et al. (2006). Heart disease and stroke statistics2006 update a report from the American Heart Association Statistics Committee and Stroke Statistics Subcommittee. Circulation 113, e85-e151. doi: 10.1161/CIRCULATIONAHA.105. 171600
Tobias, M. D., Henry, C., and Augostides, Y. G. (1999). Lidocaine and bupivacaine exert differential effects on whole blood coagulation. J. Clin. Anesth. 11, 52-55. doi: 10.1016/S0952-8180 (98)00132-9

Tomoda, M. K., Tsuchiya, M., Ueda, W., Hirakawa, M., and Utsumi, K. (1990). Lidocaine inhibits stimulation-coupled responses of neutrophils and protein kinase $\mathrm{C}$ activity. Physiol. Chem. Phys. Med. NMR 22, 199-210.

Torchiana, D. F., Vine, A. J., Titus, J. S., Hahn, C., Shebani, K. O. Geffin, G. A., et al. (2000). The temperature dependence of cardioplegic distribution in the canine heart. Ann. Thorac. Surg. 70, 614-620. doi: 10.1016/S0003-4975 (00)01439-9

Torracca, L., Pasini, E., Curello, S., Ceconi, C., Coletti, G., Alfieri, O., et al. (1996). Continuous versus intermittent warm blood cardioplegia: functional and energetics changes. Ann. Thorac. Surg. 62 1172-1178. discussion: 1178-1179. doi: 10.1016/0003-4975(96) 00598-X

Tosaki, A., Balint, S., and Szekeres, L. (1988). Protective effect of lidocaine against ischemia and reperfusion-induced arrhythmias and shifts of myocardial sodium, potassium and calcium content. J. Cardiovasc. Pharmacol. 12, 621-628. doi: 10.1097/00005344198812000-00001

Tran, C. T., Schmidt, T. A., Christensen J. B., and Kjeldsen, K. (2009). Atrial $\mathrm{Na}, \mathrm{K}$-ATPase increase and potassium dysregulation accentuate the risk of postoperative atrial fibrillation. Cardiology 114, 1-7. doi: 10.1159/000209264

Travis, W., Belardinelli, L., and Kuo, L. (1999). Adenosine A2A receptors mediate coronary microvascular dilation to adenosine: role of nitric oxide and ATPsensitive potassium channels. J. Pharmacol. Exp. Ther. 291, 655-664.

Tsutsumi, T., Wyatt, R. F., and Abildskov, J. A. (1983). Effects of hyperkalemia on local changes of repolarization duration in canine left ventricle. J. Electrocardiol. 16, 1-6. doi: 10.1016/S0022-0736(83)80152-6

Tyers, G. F. (1997). Microvascular reactivity after cardioplegia. Ann. Thorac. Surg. 63, 598-599.

Tyers, G. F., Todd, G. J., Niebauer, I. M., Manley, N. J., and Waldhausen, J. A. (1975). The mechanism of myocardial damage following potassium citrate (Melrose) cardioplegia. Surgery 78, 45-53.

Urschel, H. C. J., Greenberg, J. J., and Hufnagel, C. A. (1959). Elective cardioplegia by local cardiac hypothermia. N. Engl. J. Med. 261, 1330-1332. doi: 10.1056/ NEJM195912242612607

Vaage, J., and Valen, G. (1993) Pathophysiology and mediators of ischemia-reperfusion injury with special reference to cardiac surgery. A review. Scand. J. Thorac. Cardiovasc. Surg. Suppl. 41, 1-18. doi: 10.3109/14017439309100154

Vaccarino, V., Abramson, J. L., Veledar, E., and Weintraub, W. S. (2002). Sex differences in hospital mortality after coronary artery bypass surgery. Evidence for a higher mortality in younger women. Circulation 105, 1176-1181. doi: 10.1161/hc1002. 105133

Valsangiacomo, E., Schmid, E. R., Schupbach, R. W., Schmidlin, D., Molinari, L., Waldvogel, K., et al. (2002). Early postoperative arrhythmias after cardiac operation in children. Ann. Thorac. Surg. 74, 792-796. doi: 10.1016/S0003-4975 (02)03786-4

van Breemen, C., Skarsgard, P., Laher, I., McManus, B., and Wang, X. (1997). Endothelium-smooth muscle interactions in blood vessels. Clin. Exp. Pharmacol. Physiol. 24, 989-992. doi: 10.1111/j.14401681.1997.tb02737.x

Vatner, D. E., and Vatner, S. F. (1998). Physiological and biochemical adrenergic regulation of the stunned myocardium. Mol Cell. Biochem. 186, 131-137. doi: 10.1007/978-1-4615-4979-6_16

Veech, R. L., Kashiwaya, Y., and King, M. T. (1995). The resting membrane potential of cells are measures of electrical work, not of ionic currents. Integr. Physiol. Behav. Sci. 30, 283-307. doi: 10.1007/ BF02691602

Verma, S., and Anderson, T. J. (2002). Fundamentals of endothelial function for the clinical cardiologist. Circulation 105, 546-549. doi: 10.1161/hc0502.104540

Vicchio, M., Feo, M. D., Giordano, S., Provenzano, R., Cotrufo, M., and Nappi, G. (2012). Coronary artery bypass grafting associated to aortic valve replacement in the elderly: survival and quality of life. J. Cardiothorac. Surg. 7:13. doi: 10.1186/1749-8090-7-13

Vinten-Johansen, J., and Dobson, G. P. (2013). Adenosine-procaine cardioplegia and adenosinelidocaine cardioplegia: two sides of the same coin? J. Thorac. 
Cardiovasc. Surg. 145, 1684-1685. doi: 10.1016/j.jtcvs.2013.01.049

Vinten-Johansen, J., Jiang, R., Reeves, J. G., Mykytenko, J., Deneve, J., and Jobe, L. J. (2007a). Inflammation, proinflammatory mediators and myocardial ischemia-reperfusion injury. Hematol. Oncol. Clin. North Am. 21, 123-145. doi: 10.1016/j.hoc.2006.11.010

Vinten-Johansen, J., Zhao, Z. Q., Jiang, R., Zatta, A. J., and Dobson, G. P. (2007b). Preconditioning and postconditioning: innate cardioprotection from ischemiareperfusion injury. J. Appl. Physiol. 103, 1441-1448. doi: 10.1152/japplphysiol.00642.2007

Vinten-Johansen, J., and Nakanishi, K. (1993). Postcardioplegia acute cardiac dysfunction and reperfusion injury. J. Cardiothorac. Vasc. Anesth. 7, 6-18. doi: 10.1016/10530770(93)90092-Y

Vinten-Johansen, J., Ronson, R. S., Thourani, V. H., and Wechsler, A. S. (2000). "Surgical myocardial protection," in Cardiopulmonary Bypass: Principles and Practice, eds G. P. Gravlee, R. F. Davis, and J. R. Utley (Baltimore, MD, Philadelphia, PA: Lippincott, Williams and Wilkins), 214-264.

Vinten-Johansen, J., Thourani, V. H., Ronson, R. S., Jordan, J. E., Zhao, Z. Q., Nakamura, M., et al. (1999). Broad-spectrum cardioprotection with adenosine. Ann. Thorac. Surg. 68, 1942-1948. doi: 10.1016/S0003-4975(99)01018-8

Vinten-Johansen, J., Zhao, Z. Q., Corvera, J. S., Morris, C. D., Budde, J. M., Thourani, V. H., et al. (2003). Adenosine in myocardial protection in on-pump and off-pump cardiac surgery. Ann. Thorac. Surg. 75, S691-S699. doi: 10.1016/S0003-4975(02)04694-5

Vinten-Johansen, J., Zhao, Z. Q., Zatta, A. J., Kin, H., Halkos, M. E., and Kerendi, F. (2005). Postconditioning a new link in nature's armor against myocardial ischemia-reperfusion injury. Basic Res. Cardiol. 100, 295-310. doi: 10.1007/s00395-005-0523-x

Vitola, J. V., Forman, M. B., Holsinger, J. P., Atkinson, J. B., and Murray, J. J. (1997). Reduction of myocardial infarct size in rabbits and inhibition of activation of rabbit and human neutrophils by lidocaine. Am. Heart J. 133, 315-322. doi: 10.1016/S00028703(97)70226-6

Vittone, L., Said, M., and Mattiazzi, A. (2006). beta(2)-Adrenergic stimulation is involved in the contractile dysfunction of the stunned heart. Naunyn Schmiedebergs
Arch. Pharmacol. 373, 60-70. doi: 10.1007/s00210-006-0045-6

Wagner, D. R., Combes, A., McTiernan, C., Sanders, V. J., Lemster, B., and Feldman, A. M. (1998). Adenosine inhibits lipopolysaccharide-induced cardiac expression of tumor necrosis factor-alpha. Circ. Res. 82, 47-56. doi: 10.1161/01.RES.82.1.47

Wan, X., Bryant, S. M., and Hart, G. (2000). The effects of $[\mathrm{K}+]_{\mathrm{o}}$ on regional differences in electrical characteristics of ventricular myocytes in guinea-pig. Exp. Physiol. 85, 769-774. doi: 10.1111/j. 1469-445X.2000.02048.x

Wang, S., Radhakrishnan, J., Ayoub, I. M., Kolarova, J. D., Taglieri, D. M., and Gazmuri, R. J. (2007). Limiting sarcolemmal $\mathrm{Na}+$ entry during resuscitation from ventricular fibrillation prevents excess mitochondrial $\mathrm{Ca} 2+$ accumulation and attenuates myocardial injury. J. Appl. Physiol. 103, 55-65. doi: 10.1152/japplphysiol.01167.2006

Wang, S. Q., Lakatta, E. G., Cheng, H., and Zhou, Z. Q. (2002). Adaptive mechanisms of intracellular calcium homeostasis in mammalian hibernators. J. Exp. Biol. 205(Pt 19), 2957-2962.

Wang, S. Q., and Zhou, Z. Q. (1999). Medical significance of cardiovascular function in hibernating mammals. Clin. Exp. Pharmcol. Physiol. 26, 837-839. doi: 10.1046/j.14401681.1999.03141.x

Ward, C. A., Bazzazi, H., Clark, R. B., Nygren, A., and Giles, W. R. (2006). Actions of emigrated neutrophils on $\mathrm{Na}+$ and $\mathrm{K}+$ currents in rat ventricular myocytes. Prog. Biophys. Mol. Biol. 90, 249-269. doi: 10.1016/j. pbiomolbio.2005.07.003

Warters, R. D., Allen, S. J., Davis, K. L., Geissler, H. J., Bischoff, I., Mutschler, E., et al. (1998). Betablockade as an alternative to cardioplegic arrest during cardiopulmonary bypass. Ann. Thorac. Surg. 65, 961-966. doi: 10.1016/S00034975(97)01420-3

Wasserman, F., Wolcott, M. W., Wherrry, C. G., and Brodsky, L. (1959). Comparative effect of 5 per cent potassium chloride and 30 per cent potassium citrate in resuscitation from ventricular fibrillation following acute myocardial infarction; an experimental study. J. Thorac. Cardiovasc. Surg. 38, 30-39.

Weidmann, S. (1956). Shortening of the cardiac action potential due to a bried injection of $\mathrm{KCl}$ following onset of activity. J. Physiol. 132, 157-163.
Weirich, W. L. (1962). The effects of elective cardiac arrest on ventricular function. Prog. Cardiovasc. Dis. 4 526-536. doi: 10.1016/S0033-0620 (62)80024-3

Weisel, R. D. (1993). Myocardial stunning after coronary bypass surgery. J. Card. Surg. 8, 242-244.

Welke, K. F., Shen, I., and Ungerleider, R. M. (2006). Current assessment of mortality rates in congenital cardiac surgery. Ann Thorac. Surg. 82, 164-170. doi: 10.1016/j.athoracsur.2006.03.004

Weman, S. M., Karhunen, P. J., Penttila, A., Jarvinen, A. A., and Salminen, U. S. (2000). Reperfusion injury associated with one-fourth of deaths after coronary artery bypass grafting. Ann. Thorac. Surg. 70, 807-812. doi: 10.1016/S0003-4975 (00)01638-6

Wernovsky, G., Wypij, D., Jonas, R. A., Mayer, J. E. J., Hanley, F. L., Hickey, P. R., et al. (1995) Postoperative course and hemodynamic profile after the arterial switch operation in neonates and infants. A comparison of lowflow cardiopulmonary bypass and circulatory arrest. Circulation 92, 2226-2235. doi: 10.1161/01.CIR.92. 8.2226

Wessel, D. L. (2001). Managing low cardiac output syndrome after congenital heart surgery. Crit. Care Med. 29, S220-S230 doi: 10.1097/00003246-20011000100004

West, T. C., Frederickson, E. L., and Amory, D. W. (1959). Single fiber recording of the ventricular response to induced hypothermia in the anesthetized dog: correlation with multicellular parameters. Circ. Res. 7, 880-888. doi: 10.1161/01.RES.7.6.880

Wiggers, C. J. (1950). The Physiology of Shock. Cambridge, MA: Harvard University Press.

Wilde, A. A. M., and Aksnes, G. (1995). Myocardial potassium loss and cell depolarisation in ischemia and hypoxia. Cardiovasc. Res. 29, 1-15.

Willis, J. S., Goldman, S. S., and Foster, R. F. (1971). Tissue K concentration in relation to the role of the kidney in hibernation and the cause of periodic arousal. Comp. Biochem. Physiol. A Comp. Physiol. 39, 437-445. doi: 10.1016/03009629(71)90307-0

Willman, V. L., Cooper, T., Zafiracopoulos, P., and Hanlon, C. R. (1959). Depression of ventricular function following elective cardiac arrest with potassium citrate. Surgery 46, 792-796.
Wilson, R. A., Soei, L. K., Bezstarosti, K., Lamers, J. M., and Verdouw, P. D. (1993). Negative iontropy of lidocaine: possible biochemical mechanisms. Eur. Heart J. 14, 284-289. doi: 10.1093/eurheartj/14.2.284

Woodbury, L. A., Woodbury, J. W., and Hecht, H. H. (1950). Membrane resting and action potentials of single cardiac muscle fibers. Circulation 1, 264-266. doi: 10.1161/01.CIR.1.2.264

Wu, M., Dong, Y. Y., Yang, Q., Yim, A. P., and He, G. W. (2005) Cellular electrophysiological and mechanical effects of celsior solution on endothelial function in resistance coronary arteries. Transplantation 80, 1765-1772. doi: 10.1097/01.tp.0000183961.17370.71

Wyman, M. G., Wyman, R. M., Cannom, D. S., and Criley, J. M. (2004). Prevention of primary ventricular fibrillation in acute myocardial infarction with prophylactic lidocaine. Am. J. Cardiol. 94, 545-551. doi: 10.1016/j.amjcard.2004.05.014

Yamaguchi, S., Watanabe, G., Tomita, S., and Tabata, S. (2007). Lidocainemagnesium blood cardioplegia was equivalent to potassium blood cardioplegia in left ventricular function of canine heart. Interact. Cardiovasc. Thorac. Surg. 6, 172-176. doi: 10.1510/icvts.2006.137240

Yang, Q., and He, G. W. (2005). Effect of cardioplegic and organ preservation solutions and their components on coronary endotheliumderived relaxing factors. Ann. Thorac. Surg. 82, 757-767. doi: 10.1016/j.athoracsur.2004.10.003

Yau, T. M., Ikonomidis, J. S., Weisel, R. D., Mickle, D. A., Ivanov, J., Mohabeer, M. K., et al. (1993). Ventricular function after normothermic versus hypothermic cardioplegia. J. Thorac. Cardiovasc. Surg. $105,833-843$.

Yavari, M., and Becker, R. C. (2009). Coagulation and fibrinolytic protein kinetics in cardiopulmonary bypass. J. Thromb. Thrombolysis 27, 95-104. doi: 10.1007/s11239-0070187-5

Zamponi, G. W., Doyle, D. D., and French, R. J. (1993). Fast Lidocaine block of cardiac and skeletal muscle sodium channels: one site with two routes of access. Biophys. J. 65, 80-90. doi: 10.1016/S0006-3495(93)81042-7

Zaroff, J., Aronson, S., Lee, B. K., Feinstein, S. B., Walker, R., and Wiencek, J. G. (1994). The relationship between immediate outcome after cardiac surgery, homogeneous cardioplegia delivery, and 
ejection fraction. Chest 106, 38-45. doi: 10.1378/chest.106.1.38

Zweier, J. L., and Talukder, M. A. (2006). The role of oxidants and free radicals in reperfusion injury. Cardiovasc. Res. 70, 167-169. doi: 10.1016/j.cardiores.2006.02.025

Conflict of Interest Statement: Geoffrey P. Dobson is the inventor of AL and ALM platform, and ALM has been trademarked. The other authors declare that the research was conducted in the absence of any commercial or financial relationships that could be construed as a potential conflict of interest.

Received: 15 April 2013; paper pending published: 09 June 2013; accepted: 05 August 2013; published online: 28 August 2013.
Citation: Dobson GP, Faggian G, Onorati F and Vinten-Johansen J (2013) Hyperkalemic cardioplegia for adult and pediatric surgery: end of an era? Front. Physiol. 4:228. doi: 10.3389/fphys. 2013.00228

This article was submitted to Clinical and Translational Physiology, a section of the journal Frontiers in Physiology.

Copyright (C) 2013 Dobson, Faggian, Onorati and Vinten-Johansen. This is an open-access article distributed under the terms of the Creative Commons Attribution License (CC BY). The use, distribution or reproduction in other forums is permitted, provided the original author(s) or licensor are credited and that the original publication in this journal is cited, in accordance with accepted academic practice. No use, distribution or reproduction is permitted which does not comply with these terms. 